\title{
WestVirginiaUniversity
}

THE RESEARCH REPOSITORY @ WVU

Graduate Theses, Dissertations, and Problem Reports

2021

\section{Learning and Workers in Transition (WIT)}

Jeffrey Burgazzoli Jr

West Virginia University, jburgazz@mix.wvu.edu

Follow this and additional works at: https://researchrepository.wvu.edu/etd

Part of the Adult and Continuing Education Commons, and the Instructional Media Design Commons

\section{Recommended Citation}

Burgazzoli, Jeffrey Jr, "Learning and Workers in Transition (WIT)" (2021). Graduate Theses, Dissertations, and Problem Reports. 8255.

https://researchrepository.wvu.edu/etd/8255

This Dissertation is protected by copyright and/or related rights. It has been brought to you by the The Research Repository @ WVU with permission from the rights-holder(s). You are free to use this Dissertation in any way that is permitted by the copyright and related rights legislation that applies to your use. For other uses you must obtain permission from the rights-holder(s) directly, unless additional rights are indicated by a Creative Commons license in the record and/ or on the work itself. This Dissertation has been accepted for inclusion in WVU Graduate Theses, Dissertations, and Problem Reports collection by an authorized administrator of The Research Repository @ WVU.

For more information, please contact researchrepository@mail.wvu.edu. 
Learning and Workers in Transition (WIT)

Jeffrey Burgazzoli Jr.

Dissertation submitted to the College of Education and Human Services at West Virginia University in partial fulfillment of the requirements for the degree of Doctor of Philosophy in

Education with emphasis in Learning, Instructional Design and Technology

\author{
Malayna Bernstein, Ph.D., Chair \\ John Oughton, Ed.D. \\ Jiangmei Yuan, Ph.D. \\ M Cecil Smith, Ph.D.
}

Department of Counseling and Learning Sciences

\author{
Morgantown, West Virginia
}

2021

Keywords: Professional Learning, Instructional Design, Workplace Transitions Copyright 2021 Jeffrey Burgazzoli Jr. 


\section{ABSTRACT \\ Learning and Workers in Transition (WIT) \\ Jeffrey Burgazzoli Jr.}

This study utilized autoethnography to generate new understandings about learning and workplace transitions. I journaled the first 90 days in a new job, writing about the notable learning events that occurred and collecting work artifacts to create a rich storyboard of the transition scene. Qualitative analysis of the storyboard revealed four broader dimensions of learning that must be considered: 1) knowledge growth and development, 2) cognition, 3) situational context, and 4) emotion. The results of the study illuminated key inflection points that happened during the transition process, conceptualized how my learning changed over time, and showed how I processed and refined specific knowledge in route towards constructing novel thoughts and ideas. The study makes theoretical contributions by describing the cognitive, situational, and emotional characteristics of "workers in transition" (WIT) learning. The study makes practical contributions by extending findings into design considerations for WIT learning spaces, through demonstrating the affordances of reflective writing, and by offering a unique combination of methodological instruments. 
Dedication

In memory of Dr. Terence C. Ahern. 


\section{Acknowledgements}

I owe tremendous gratitude to the many people who supported me during the construction of this piece. Without your support this would truly not be possible, and I take a moment to acknowledge a few notable names who served as beacons of motivation and inspiration throughout this rugged journey.

Dr. Ahern, your creative thinking, energy, and passion for instructional design will always fuel me as a scholar. I relish in the fact that this piece builds on your prior accomplishments and furthers your research legacy. This piece is dedicated to you. Rest in peace.

Dr. Bernstein, my chair and steward. Your unwavering support pushed me to the finish line. Our conversations fueled the direction of this piece and matured me as a scholar. I am forever grateful that you took on the duties of chair and for how you embraced my ideas as I fought my way forward. Thank you.

To the members of my committee, Dr. Oughton, Dr. Yuan, and Dr. Smith. Your encouragement and support were instrumental. The scaffolding and feedback you provided molded this dissertation into a worthy product. Thank you.

Dr. Goeres, you lifted me on your shoulders as a young and ambiguous graduate student. Without you, this opportunity would not be possible. I will forever cherish the opportunity to shadow and learn from you. Know that I aim to be half the man you are.

Dr. Lefebvre, Dr. Feirstein, Dr. Jones, Dr. Chapman, Dr. Sorber, Dr. Stallings, and Dr. Stack. Each of you is a part of my journey as a graduate student, and although we may be more distant at present, your words and advice will always echo in my mind. Thank you for continuing to root for me from the sidelines. 
To my wonderful colleagues at Columbia who were an intricate part of the study. I appreciate the support you've given me. And, to my mentor John especially, our friendship will always persist, and I am grateful that we found each other during this unique stage of my life.

To my parents, Susan and Jeffrey Sr. The success I find is because of you. I hope this dissertation makes you as proud as I am to call you my parents.

Finally, to my wonderful wife, Gabriella. You raised my spirits and lifted me on the darkest days when uncertainty and doubt crept in. To say you supported me is an understatement. You are my guiding light and it's a blessing to have you in my life. 


\section{Table of Contents}

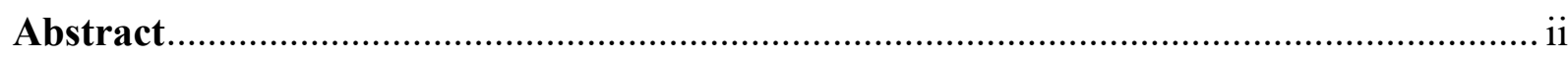

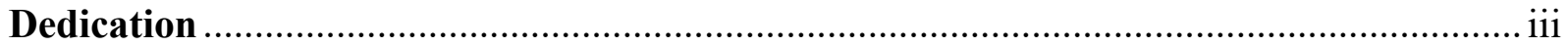

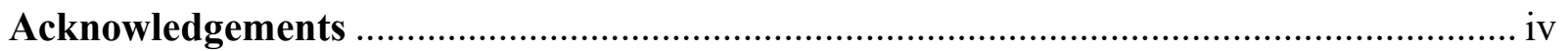

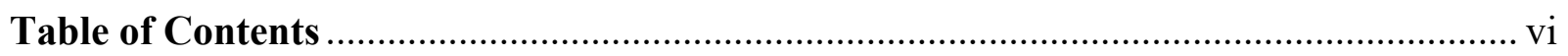

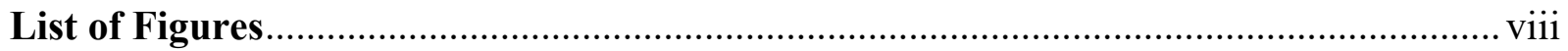

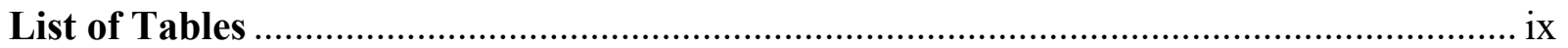

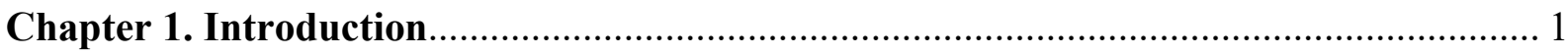

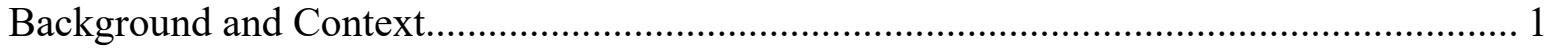

Statement of the Problem.............................................................................................. 3

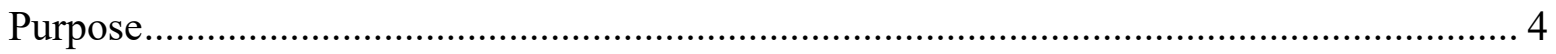

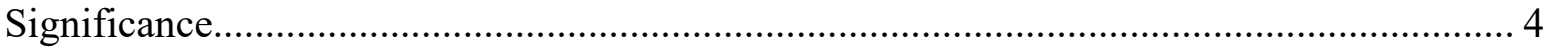

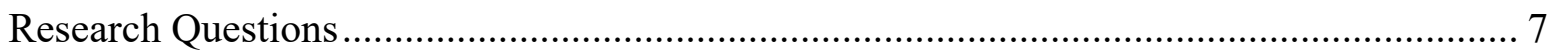

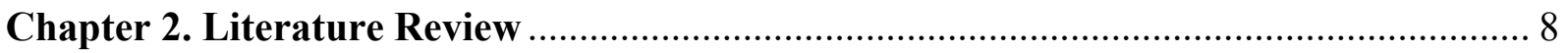

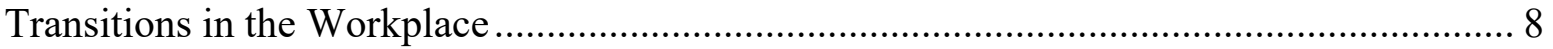

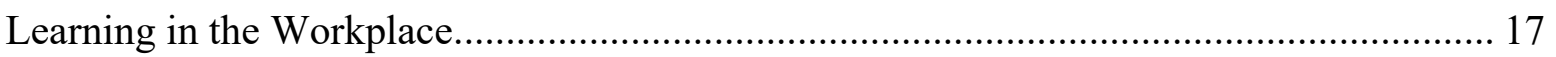

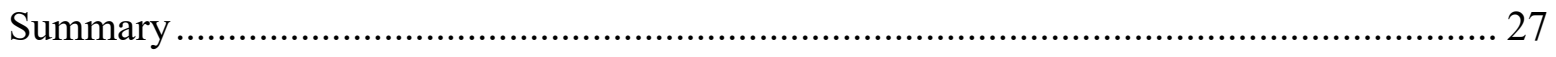

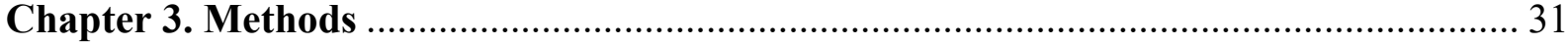

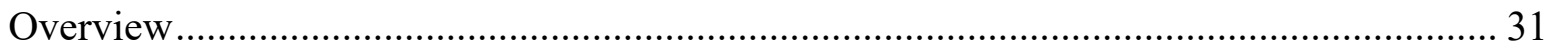

Alignment with Research Questions ....................................................................... 33

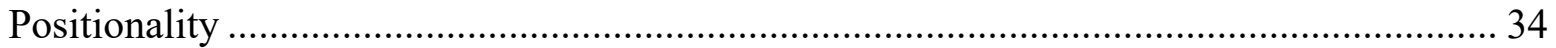

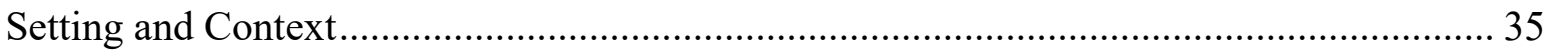

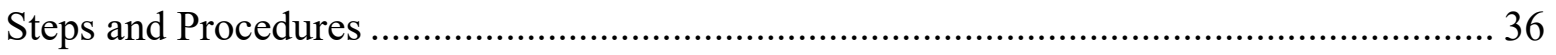

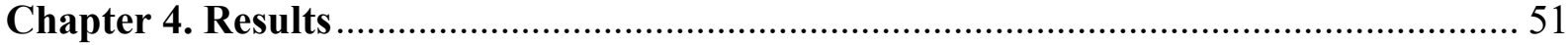

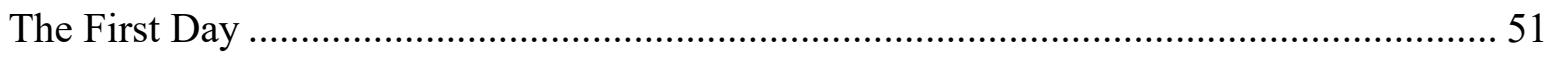

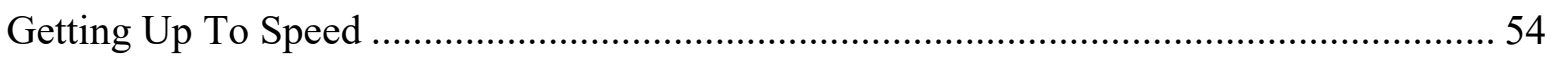

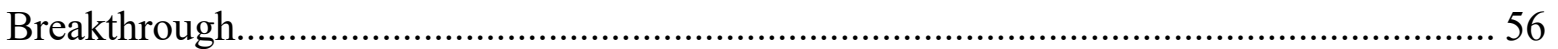

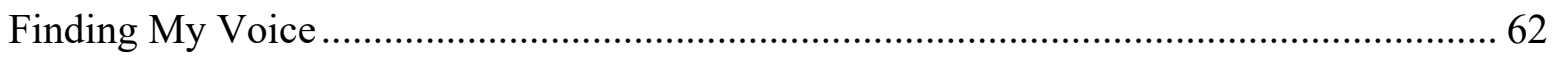

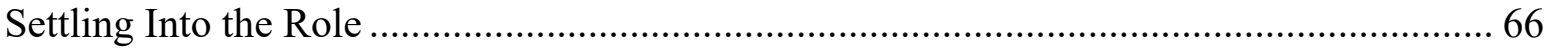




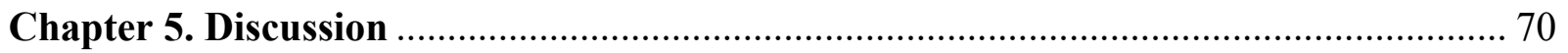

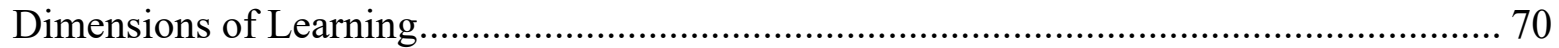

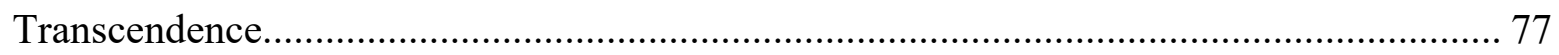

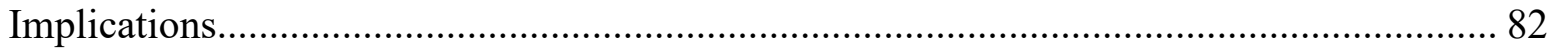

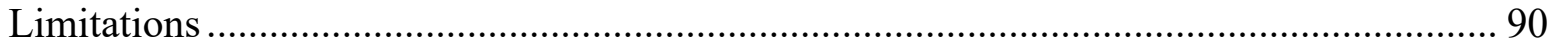

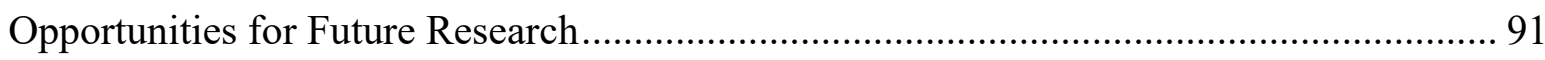

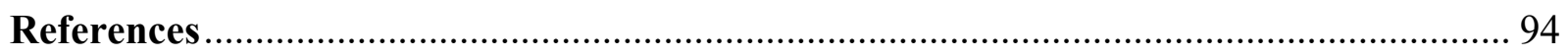

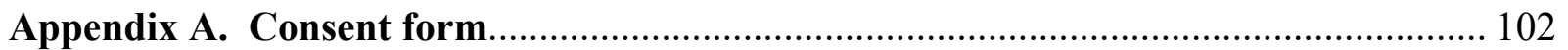

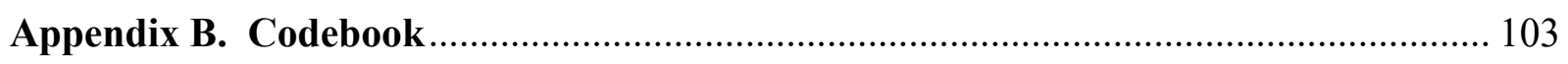

Appendix C. Storyboard Document (Google Document)............................................... 110

Appendix D. Storyboard Script (Google Script) .......................................................... 121

Appendix E. Storyboard Export (Google Sheets) ………………………………........ 123

Appendix F. Transcendent Episodes T1 to T7 .......................................................... 124

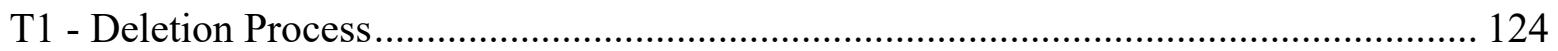

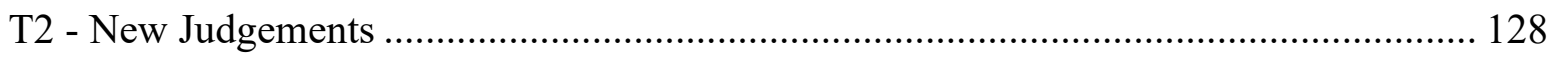

T3 - Dashboard …………………………………............................................... 132

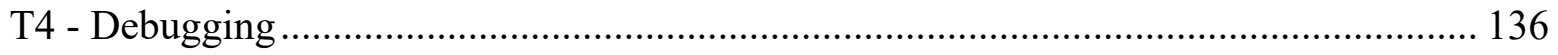

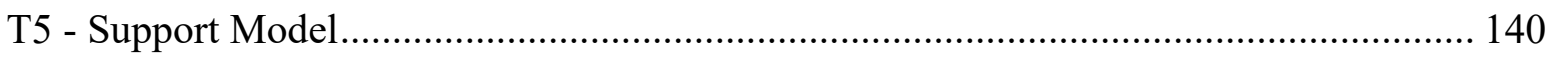

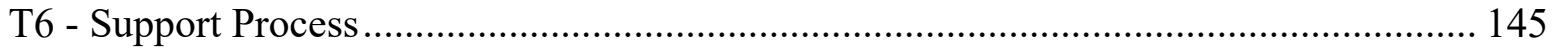

T7 - Blank Spreadsheet .......................................................................................... 148 


\section{List of Figures}

Figure 1. Google Trends Topic Search: "Onboarding” $2004-2020 \ldots \ldots \ldots \ldots \ldots \ldots \ldots \ldots \ldots \ldots . \ldots$

Figure 2. Eraut's Typology of Informal Learning............................................... 18

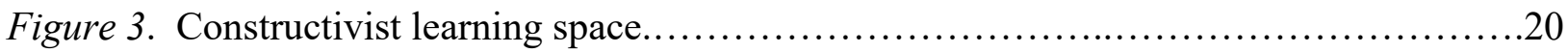

Figure 4. Summary of study design, steps and procedures................................. 31

Figure 5. Trajectory of my epistemological, theoretical, methodological assumptions............34

Figure 6. Template for data fields collected for each experience............................ 37

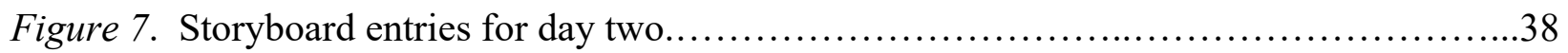

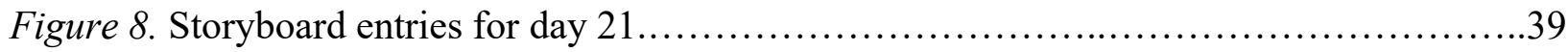

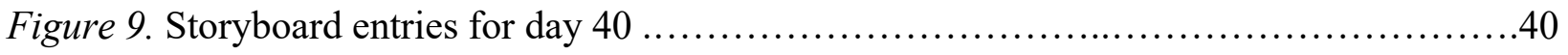

Figure 10. Table of contents and headers for storyboard instrument...........................41

Figure 11. Storyboard with descriptive codes.............................................. 45

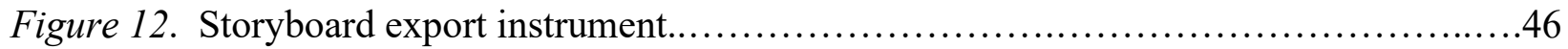

Figure 13. Conceptual map of cognitive, knowledge-building and situated dimensions..........47

Figure 14. Google Spreadsheet Functions............................................ 48

Figure 15. Storyboard export with codes, functions and graphs.............................49

Figure 16. Knowledge building during the consumer state, day one to $14 \ldots \ldots \ldots \ldots \ldots \ldots \ldots . \ldots 5$

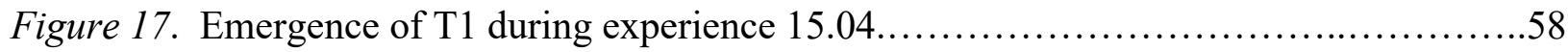

Figure 18. Cognitive dimension and trajectory of experiences leading up to T1..............58

Figure 19. Knowledge-building dimension and trajectory of experiences leading up to T1......59

Figure 20. Situated dimension and trajectory of experiences leading up to T1 .................60

Figure 21. Knowledge building during the producer state, day 15 to $33 \ldots \ldots \ldots \ldots \ldots \ldots \ldots \ldots \ldots . .65$

Figure 22. Knowledge building during the contributor state, day 34 to $58 \ldots \ldots \ldots \ldots \ldots \ldots \ldots . . .68$

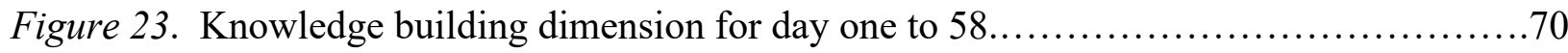

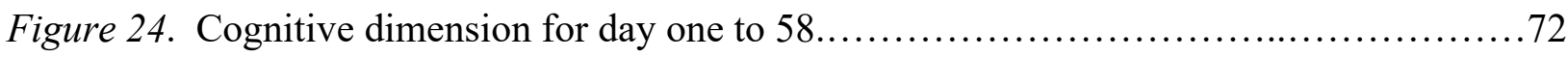

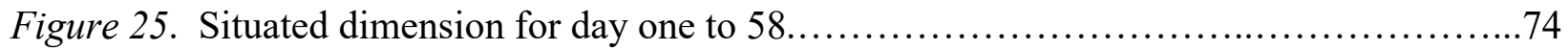

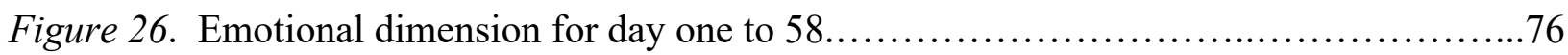




\section{List of Tables}

Table 1. Factors considered for average tenure summary by the Bureau of Labor Statistics.....10

Table 2. Median years of tenure for employed wage and salary workers.......................12

Table 3. Profile of participant based on U.S Bureau of Labor Statistic definitions.................35

Table 4. Descriptive, process and in vivo codes generated from first pass....................43

Table 5. Summary of trajectory of experiences for T1 - Deletion Process ....................57

Table 6. Code and description of Transcendence, a part of the Cognitive dimension.............77

Table 7. Summary of WIT Learning Space and Knowledge Building..........................80 


\section{Chapter 1. Introduction}

\section{Background and Context}

The recruiter called a few days after I interviewed for the role of Associate Director of Student Systems at Columbia University. To my surprise, I was being offered a newly created position in the office of Columbia University Information Technology (CUIT). We exchanged pleasantries and discussed the conditions of the offer, for which I accepted.

The transition had begun. Ecstatic to join a prestigious institution such as Columbia, I phoned my wife to celebrate and thought how I would break the news to my current boss. It was certainly a bittersweet moment as I loved my job, the opportunities it offered me over the past five years, and the overwhelming development and growth I endured here. I was leaving a prominent educational technology company in Ellucian, a major provider of student information systems at institutions spanning the world. I was happy in my role, and yet, it was because of these experiences at Ellucian that I felt well equipped to take the plunge back into academia and serve as a director of student systems.

In my consulting role, I often wondered what it would be like to walk in the client's shoes, to support and maintain the systems I consulted with; and to be as the clients would put it: "on the frontlines." I was re-entering higher education for the first time in nearly five years, moving into a highly visible leadership position tasked with supporting the day-to-day operations of Columbia's newly developed, home grown student information system. The assignment seemed unprecedented as few institutions were developing their own system. I also knew the adjustment would be dramatic as I never served as a student systems director, nor in an information technology capacity. My prior experiences were far narrower to this end and this 
role would challenge me to delve into areas that escaped the boundaries of my existing knowledge. Of course, there was some overlap with my time at Ellucian. I was familiar with concepts such as web design, configuration, managing access, and troubleshooting issues, key skills needed to oversee and manage a system of this kind. However, this role's requirements extended into other less familiar areas that would have me design backend features, solution new functionality, assign work to developers, support end users, and facilitate strategic planning. In essence, I had far less direct experience with these matters, and especially with respect to designing key aspects of the system, creating development tasks, engaging with operational planning, and managing developers.

Coincidentally, this dramatic change aligned with my scholarly aspirations. Amid joining Columbia, I thought about how my transition experiences, and in particular, this dramatic adjustment into becoming a student systems director, could be leveraged to expand what educational researchers understand about learning and transitions. Intrigued by the rigorous learning process that awaited me, I began surveying research on workplace and work-role transitions. I focused on sources that spoke to the relationship between learning and transitions (Nicholson, 1984), surveying works that summarized how transitions had been studied using approaches in developmental psychology, life course studies, and within the context of career passages (Fenwick, 2013). Considering these sources, the diverse perspectives used to study transitions, and thinking about how I would be so close to the transition scene, I decided to narrow on studies that took a developmental approach. Consequently, I searched for sources that focused on the direct, authentic, and real learning experiences of workers in transition (WIT). I figured that such perspectives could tell me more about unique aspects of workers' learning 
process. Expecting to find rich accounts and descriptions from cases of transition in medicine, business, and education, instead, I was met with a surprising gap.

\section{Statement of the Problem}

Although more workers are moving between jobs at present (Bureau of Labor Statistics, 2020), cases and accounts of transitions are sparse. In fact, most research on workplace transitions has focused on evaluating transitional outcomes between postsecondary institutions and the workforce (i.e., school-to-work transitions), studying barriers of entry and the efficacy of preparation programs. Far fewer studies have been examining transitions as sites of learning, delving deeper into the details of workers' knowledge building, metacognition, and situational context surrounding these experiences. Further, the perceptions and attitudes of workers are noticeably absent in studies executed outside of the domain of medicine.

Given that transitions are "fundamentally about learning (Fenwick, 2013, p. 357)", the lack of personal and descriptive research is problematic. In my review, I expected to find rich and contextual sources spanning a range of contexts. However, the learning processes of workers (i.e., practices, arrangements, and knowledge structures) have been largely undocumented in workplace and adult learning literature. Fewer personal and first-hand accounts have been disseminated, which is surprising considering how so many young workers are broadcasting their livelihoods to a greater extent than ever. Aside from a principal over a decade ago (Dethloff, 2007), and broad surveys of engineers and educational administrators' experiences respectively (Lutz, 2017; Olson, 2015), such personalized and detailed accounts simply do not exist. The lack of descriptive and personalized research focusing on transitions is problematic given how most workplace learning is informally situated (Eraut, 2004). It is also problematic given how transitional scenarios are becoming increasingly widespread and 
consequential (Evetts, 2009), because of increasing organizational interest with the onboarding process (Gallup, 2017), and due to how workers' early learning experiences are connected with success and retention (Marsick, Watkins, \& O’Conor, 2011).

\section{Purpose}

In summarizing literature on workplace transitions, Fenwick (2013, p. 363) suggested that we "look more closely at accounts of transition", including the "learning practices that restrict or enhance mobility (p. 359)." Given the dearth of personalized research on workplace transitions, I wrote about my experiences during the first 90 calendar days (58 working days), creating a narrative of my transition. I captured perceptions, exchanges, and anecdotes from my work, while concurrently gathering tools, resources, and artifacts from the field, some of which were directly referenced in my writing. Consequently, I used these sources to generate a more personalized and detailed account of a workplace transition. The purpose of this piece was to unearth new understandings about learning and transitions from the perspective of my own experiences, uninfluenced by prior agendas or frameworks.

\section{Significance}

I executed this qualitative study to better understand how people learn while transitioning in the workplace. It is important to understand this dynamic given how workers' learning experiences have become more important in the contemporary landscape of work. Organizations are laboring to retain skilled knowledge workers while also reconfiguring their workspaces. It is imperative that we better understand how people learn in this shifting landscape of work. The significance of the study is that it both explains what I learned during the first 90 days and how my learning unfolded as I became more comfortable in the new role. My analysis took into 
consideration the cognitive, situated, and emotional aspects of my learning. This constructivist approach pays respect to how transitions are situated in the ordinary work people do (Lave \& Wenger, 1991) and the experiences they engage with (Kolb, 1984; Eraut, 2004).

The study fills gaps in existing literature by projecting the cognitive, situational, and emotional aspects of WIT learning. There was an urgent need to better understand how WIT learn given the current economic and social climate, which I discuss further in Chapter 2. In Chapter 3, I present an overview of my methods, including the processes used to collect, organize, and summarize data, as well as an original coding scheme generated from my analysis (Appendix B).

In Chapter 4, I describe my experiences from the first day, through getting up to speed over the first several weeks, early major contributions, struggles to find my voice, and eventually settling into my role. I used a knowledge building (schema development), cognitive, situational, and emotional lens to analyze the different dimensions of my learning, and in Chapter 5, I explain how these aspects intersected with one another and led me towards generating a new theoretical construct called "transcendence."

The study makes theoretical contributions by characterizing the social, cognitive, and emotional aspects of WIT learning. It makes practical contributions by extending findings into design considerations for WIT learning spaces. I conclude by offering suggestions for how transition programs can be redesigned to support more collaborative and reflective learning during the first 90 days. Finally, I present an original combination of methodological instruments that include a "storyboard instrument" (Appendix C), a script (Appendix D), and "storyboard export" (Appendix D). I am disseminating these items to demonstrate the rigor of this work, but also to support the assessment and evaluation efforts of educational researchers, 
instructional designers, and human resource professionals moving forward. 


\section{Research Questions}

I used my own transition experience to help instructional designers, program developers, human resource professionals, and employee mentors better understand how people learn during workplace transitions, and to unearth new ways to support such learning. I used a schema development lens to analyze different dimensions of my learning and describe how it changed throughout the transition process. The following research questions guided the study:

RQ1: What knowledge is constructed?

RQ2: How is it constructed? In other words, which experiences support such learning?

RQ3: How does this change throughout the transition? 


\section{Chapter 2. Literature Review}

To establish the need for the study, I examined the broader social and economic context surrounding workplace transitions. I reviewed literature that illuminated the shifting landscape of work, studies that explained how and why workers' transition, and research that delved into how people learn during transitional moments. These sources informed me about the learning processes that workers engage with as well as how people more generally construct and refine knowledge within different contexts, such as when changing one's role or migrating to a new work site.

\section{Transitions in the Workplace}

\section{Who are WIT? Characterizing "workers" and "transitions"}

"Workers" provide service or labor "following a period of education and/or vocational training” (Evetts, 2011, p. 5). "Transitions" are "major change in job content including all instances of 'status passages' (Glaser \& Strauss, 1971), forms of intra- and interorganizational mobility (Louis, 1980) and changes in employment status (e.g., unemployment, retirement, reemployment)" (Fenwick, 2013, p. 173). These scenarios include movement between work roles, responsibilities, and/or sites more generally. Therefore, WIT have at least some professional experience and endure the process of moving into a new role or site.

\section{Shifting landscape of work}

Economists define transitional scenarios as "job churn” or literal movement between occupations and sites. Workers have historically transitioned due to "restructured work arrangements, new technologies and shifting public demands" (Fenwick, 2013, p. 352). Fenwick 
(2013) explained that notable catalysts are quests for upward mobility, insecurity, tensions in the workplace, conflicts between work-life balance, and issues related to health and wellness.

More recently, greater attention has been placed on the onboarding process. Figure 1 shows how organizations have grown more interested in the process that helps workers become oriented.

\section{Figure 1}

Google Trends Topic Search: “Onboarding” 2004 - 2020

\section{Google Trends Explore}

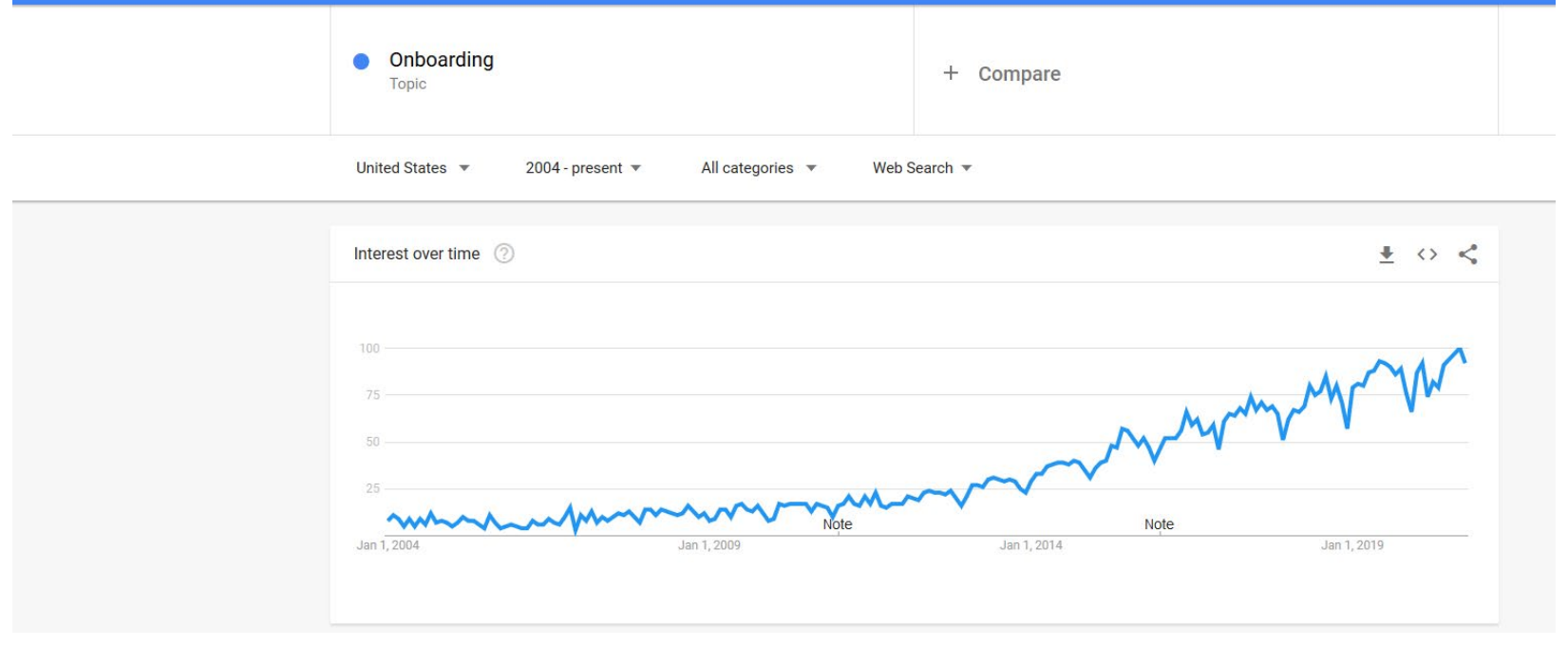

Note. Adapted from Google Trends (2020) for the topic on onboarding. Google provides search insights for topics since 2004.

Why are organizations so interested in the onboarding process? Program developers and instructional designers are examining workers' learning experiences to understand how organizations can better promote more meaningful opportunities for professional learning. Organizations are recognizing that such opportunities are critical for orienting new workers, developing skills, and improving retention outcomes (Gallup, 2017). 
Concurrently, broader social and economic factors are accelerating workplace transitions. Average tenure has been declining over the past eight years (Bureau of Labor Statistics, 2020a) and a recent survey found that workers are holding more jobs by the age of 32 (Bureau of Labor Statistics, 2020b). The service-oriented economy is changing how people work (Sweet \& Meiksins, 2013) and perhaps accelerating voluntary movement in the workplace (Gallup, 2017). Workers are more frequently shifting into new lines of work, reconfiguring their portfolios and toolkits, and applying knowledge in novel work contexts (Gee, 2005). According to Gee (2005), workers' do so by reshaping their professional portfolios and identities, describing this phenomenon as "shape-shifting" in nature. Of course, transitional scenarios are guided by a range of factors, including the type of work one engages with (e.g., service-based) as well as age, class, and race (Elder, 2003; Moen, 2011). The Bureau of Labor Statistics (2020a) considers a variety of occupational, demographic, and industry-specific factors in the annual report for average worker tenure. These are summarized in Table 1. 


\section{Table 1}

Factors considered for average tenure summary by the Bureau of Labor Statistics

\begin{tabular}{ll}
\hline Category & Factors Considered \\
Demographics & Gender \\
& Age \\
& Race \\
& Compensation Type \\
& Educational attainment \\
& Public \\
Industry & Private \\
Occupation & Management, professional and related occupations \\
& Sales and office occupations \\
& Natural resources, construction and maintenance occupations \\
& Production, transportation and material moving occupations \\
\hline
\end{tabular}

Note. Adapted and summarized from the most recent Average Worker Tenure Summary (Bureau of Labor Statistics, 2020b, p.5 - 11)

Socioeconomic status and occupation are some of the most important considerations here. American workers are increasingly renting homes, and thus, have more flexibility and autonomy to navigate different lines of work (Sweet $\&$ Meiksins, 2013). Such autonomy has afforded more opportunities to change jobs, and according to Sweet and Meiksins (2013), have caused transitions to become more commonplace alongside the shifting contours of our new economy. The workplace has become more service-based and knowledge-driven, paving way for more voluntary transitions due to the nature of how we work.

The Bureau of Labor Statistics has been keeping tabs on average work tenure for some time. A survey found that baby boomers (i.e., workers born between 1957 and 1964) held an average of 10-12 jobs by the age of 55 (Bureau of Labor Statistics, 2019). More recently, the 
Bureau of Labor Statistics (2020b) claimed that millennial workers, born in the early 1980's, are holding more jobs through the ages of 32 than prior generations. Concurrently, the average tenure across all occupations declined from 4.4. to 4.1 (Bureau of Labor Statistics, 2020), although some occupations were impacted more than others. Table 2 projects the average tenure across management, professional, and service occupations, respectively. 
Table 2

Median years of tenure with current employer for employed wage and salary workers

\begin{tabular}{|c|c|c|c|c|c|c|}
\hline Occupation & $\begin{array}{c}\text { Jan } \\
2010\end{array}$ & $\begin{array}{c}\text { Jan } \\
2012\end{array}$ & $\begin{array}{c}\text { Jan } \\
2014\end{array}$ & $\begin{array}{c}\text { Jan } \\
2016\end{array}$ & $\begin{array}{c}\text { Jan } \\
2018\end{array}$ & $\begin{array}{c}\text { Jan } \\
2020\end{array}$ \\
\hline All occupations, Total, 16 years and over & 4.4 & 4.6 & 4.6 & 4.2 & 4.2 & 4.1 \\
\hline Management, professional and related occupations & 5.2 & 5.5 & 5.7 & 5.1 & 5.0 & 4.9 \\
\hline Professional and related occupations & 5.0 & 5.4 & 5.3 & 4.9 & 4.7 & 4.6 \\
\hline Computer and mathematical occupations & 4.8 & 4.8 & 5.0 & 4.4 & 4.3 & 3.9 \\
\hline Architecture and engineering occupations & 5.7 & 7.0 & 6.4 & 5.5 & 5.7 & 5.1 \\
\hline Life, physical, and social science occupations & 4.6 & 5.3 & 5.0 & 4.9 & 4.8 & 4.1 \\
\hline Community and social science occupations & 4.6 & 5.0 & 5.1 & 4.3 & 4.6 & 4.6 \\
\hline Legal occupations & 4.6 & 5.4 & 5.4 & 5.5 & 5.1 & 5.8 \\
\hline Education, training, and library occupations & 5.6 & 5.9 & 6.2 & 5.3 & 5.1 & 5.0 \\
\hline Arts, design, entertainment, sports and media occupations & 3.9 & 4.2 & 3.4 & 3.8 & 3.9 & 3.4 \\
\hline Healthcare practitioners and technical occupations & 4.8 & 5.2 & 5.2 & 4.8 & 4.3 & 4.7 \\
\hline Service occupations & 3.1 & 3.2 & 3.3 & 2.9 & 2.9 & 2.9 \\
\hline Healthcare support occupations & 3.3 & 3.3 & 3.5 & 3.1 & 3.0 & 2.8 \\
\hline Protective service occupations & 5.0 & 6.4 & 6.5 & 6.2 & 5.0 & 5.3 \\
\hline Food preparation and serving related occupations & 2.3 & 2.3 & 2.2 & 1.9 & 1.9 & 1.9 \\
\hline Building and grounds cleaning and maintenance occupations & 4.1 & 4.0 & 4.3 & 3.8 & 4.1 & 4.0 \\
\hline Personal care and service occupations & 2.9 & 3.0 & 2.9 & 2.9 & 3.0 & 3.1 \\
\hline
\end{tabular}

Note. Median tenure has shown by organized by occupation, selected years, 2010-2020 (Bureau

of Labor and Statistics, 2020a)

Healthcare support occupations (3.3 to 2.8), computer and mathematical occupations (2.8

to 3.9 years), and food services occupations (2.9 to 1.9 years) saw a significant decline (Bureau

of Labor Statistics, 2020a). These occupations already had the lowest tenure across all fields and 
the upcoming tenure summary will be interesting to follow in the aftermath of the Covid-19 pandemic.

Prior to the pandemic, Gallup's (2017) summary found “the number of Americans voluntarily leaving jobs reached a post-recession high of nearly 3.1 million workers" (p. 16). The emergence of Covid-19 is now causing an unprecedented number of workers to migrate to new work sites. These same workers are refactoring portfolios (Gee, 2005) and moving into entirely different lines of work (Schwarts, 2020). Over eight million people separated from jobs in March 2020 alone (Bureau of Labor Statistics, 2000c). The pandemic has reshaped the ordinary processes and rituals in some occupations. For example, adult educators are adapting to different modes of teaching causing more interest in the impact of the global Covid-19 on some professions (Smith, Bohonos, \& Patterson, 2020). Some medical practitioners are even absorbing new roles and responsibilities because of the pandemic (Tachibana, 2020). Some of these same professionals are transitioning into new settings. Nurses in primary care settings and acute care facilities are changing workplaces due to shifting "demand associated with the aging population and rise of chronic diseases" (Ashley, Brown, Halcomb \& Peters, 2017, p. 662).

Finally, opportunities for remote work have also changed the landscape of work. As new technological innovations become more widely adopted (e.g., web conference, collaboration tools such as Slack), organizations are being encouraged to remotely onboard new workers recruit and retain the most skilled and coveted professionals. Increasing opportunities for remote-based work, especially in the information technology, computer, and mathematical occupations, is fostering greater competition and driving more organizations to consider remotebased work. Younger workers are entering the workplace for the first time by way of their childhood homes (Pietsch, 2020), which is notable given how younger generations have been 
labeled as the "job-hoppers" (Rivers, 2018). The emergence of more remote-based work may impact retention outcomes for this generation of workers.

All these factors have combined to increase the frequency and magnitude of transitions. The changing contours of work coupled with the Covid-19 pandemic, accelerating voluntary transitions, and emerging remote-based opportunities have increased transitional scenarios among highly educated and skilled knowledge workers. These trends have also caused instability for certain occupations and have more generally increased the frequency and prevalence of transitional scenarios.

\section{The connection between transitions and learning}

Transitions are "fundamentally about learning" (Fenwick, 2013, p. 357). In order to change roles or jobs, one must construct, transfer, and apply a great deal of knowledge into the new context. Workers use their prior experience to become comfortable and navigate novel scenarios and contexts. Novice workers have far less experience to call upon and, therefore, must transfer knowledge from university, college, or other postsecondary setting into the real world. Experienced workers have an undeniable advantage here as they are afforded more opportunities to form connections between past and current work experiences. Ultimately, transitional moments require all workers to command "new levels of responsibility, implement new protocols for practice and migrate to new work sites and cultures" (Fenwick, 2013, p. 352). Therefore, workers must learn and adapt during transitional scenarios, and certain conditions allow for and support this process.

Motivation. Workers must be motivated to learn. Sofer's (1970) work demonstrated how achievement and motivation relate to transitional outcomes. Lack of motivation has adverse consequences towards workers' learning and being motivated allows one to engage with a 
constructivist learning process that serves as a "strong predictor of overall success or failure" (Marsick, Watkins, \& O'Conor, 2011, p. 1). Hence, workers are more likely to remain with a given organization if they are motivated and afforded opportunities to learn. Further, such learning is critical towards productivity and retention outcomes (Govaerts et al., 2011; Trede \& McEwen, 2015; Gallup, 2017). Therefore, learning is more generally intertwined with organizational health as well as worker success and retention.

Job Satisfaction. In some domains the cost of replacing workers is greater than investing into professional learning (Hillman \& Foster, 2011). Further, increasing turnover may also lead towards poor morale and job satisfaction (Hillman \& Foster, 2011), which is why some organizations are becoming more interested in workers' experiences. The following cases in the domains of medicine and business summarize the connection between learning and transitional outcomes.

Bowles \& Candela (2005) and Winfield et al. (2009) studies found that $30 \%-50 \%$ of new nurses were voluntarily leaving within the first year of employment. By examining the experiences of new nurses, Hillman and Foster (2011) noted gaps in procedural knowledge, for example, understanding of procedures outside of direct responsibilities. Hillman and Foster (2011) suspected that mentoring assignments could help bridge these gaps and support new nurses as they entered the organization. They found that retention increased from $50 \%$ to $72.5 \%$ by introducing formal mentoring assignments, and that incumbent nurses were more satisfied with their jobs as these opportunities promoted greater collaboration and reduced turnover (Hillman \& Foster, 2011). This case demonstrates a few things. First, the importance of examining workers' learning experiences. Second, how transition experiences are not only connected with learning outcomes, but also aligned with satisfaction and retention more 
generally.

Companies such as Apple have been leveraging "exchange journals" to promote more reflection during the onboarding process. Writing samples are disseminated upward so that supervisors and leadership can better understand workers' experiences. Such efforts help stakeholders gauge success, engagement, and empowerment across the organization (Guzman Vergara, 2014).

These cases demonstrate how our learning experiences relate to organizational health and wellbeing. Ultimately, more opportunities to learn during the onboarding process are beneficial to both workers and the organization. Organizations have become aware that workers value such moments and have ramped up efforts to monitor and facilitate opportunities that develop worker skills and knowledge (Galanek, Gierdowski, \& Brooks, 2019).

\section{Learning in the Workplace}

\section{The situational nature of workplace learning}

There are overarching constructs that guide workplace learning theory. Learning is situated in the work that people do (Lave \& Wenger, 1991) and the experiences in which workers engage with (Kolb, 1984). Eraut (2004) categorized these opportunities as both formal and informal moments, drawing contrast between well-structured events that are facilitated by the organization and the ones that are a consequence of engaging with ordinary tasks and routines. This is not to discount the formalized opportunities that organizations may or may not facilitate. But, rather, to call special attention to the range of informal opportunities that are supporting workers.

There are some notable differences between these two categories, respectively. Formal 
opportunities allow designers and program developers to define learning outcomes, prepare agendas, and collect formative and summative feedback. Workers engage with training, demonstration, and formal shadowing assignments to get up to speed, and designers closely monitor these experiences to capture feedback. Yet, the nature of work and the learning process has changed. Learning is more on the fly, in the trenches, and may even occur with limited support from others. Hager (p. 10, 2010) found that many learning opportunities "arise naturally from the demands and challenges of work such as when solving problems, improving quality and/or productivity or coping with change." Therefore, this notion of informal learning strongly aligns with workers' ordinary experiences and views the learning process as situated in the work that people do. Figure 2 summarizes the processes considered in Eraut's (2004) construct of informal learning. 


\section{Figure 2}

Eraut's Typology of Informal Learning

\begin{tabular}{|c|c|c|c|}
\hline Time of Focus & Implicit learning & Reactive learning & Deliberative learning \\
\hline Past episode(s) & $\begin{array}{l}\text { Implicit linkage of } \\
\text { memories with } \\
\text { current experience }\end{array}$ & $\begin{array}{l}\text { Brief near- } \\
\text { spontaneous } \\
\text { reflection of past } \\
\text { episodes, events, } \\
\text { incidents, experiences }\end{array}$ & $\begin{array}{l}\text { Discussion and } \\
\text { review of past } \\
\text { actions, } \\
\text { communications, } \\
\text { events, experiences }\end{array}$ \\
\hline Current experience & $\begin{array}{l}\text { A selection from } \\
\text { experience enters } \\
\text { episodic memory }\end{array}$ & $\begin{array}{l}\text { Noting facts, ideas, } \\
\text { opinions, impression; } \\
\text { asking questions; } \\
\text { observing effects of } \\
\text { actions }\end{array}$ & $\begin{array}{l}\text { Engagement in } \\
\text { decision making, } \\
\text { problem solving, } \\
\text { planned informal } \\
\text { learning }\end{array}$ \\
\hline Future behavior & $\begin{array}{l}\text { Unconscious } \\
\text { expectations }\end{array}$ & $\begin{array}{l}\text { Recognition of } \\
\text { possible future } \\
\text { learning, } \\
\text { opportunities }\end{array}$ & $\begin{array}{l}\text { Planning learning } \\
\text { opportunities; } \\
\text { rehearsing for future } \\
\text { events }\end{array}$ \\
\hline
\end{tabular}

Note. Adapted from the Informal Learning construct by Eraut (2004, p. 250)

From this perspective, learning emerges from “opportunistic and unstructured” (Eraut, 2004, p. 250) assignments that allow workers to make sense of experience, process these moments in new situations and contexts, and refine understanding about ideas and subjects. This ultimately leads towards improved decision making and problem solving. This constructivist process encompasses a range of experiences over the lifespan, and therefore it is workers' combined experiences that are refined and applied within different contexts, such as when taking on a new work project or entering a new role. These experiences also differ with respect to time, place, and setting. Collaborative, reflective, and self-directed opportunities emerge as workers read and reflect about their own experiences as well as the experiences of others. Workers are reviewing cases and narratives in their work to identify control strategies and solve problems 
(Clark \& Rossiter, 2008; Shulman, 1992). This enables them to "understand why the people they work with behave the way they do" (Polkinghorne, 1988, p. 4) and it is by revisiting and reprocessing this totality of experiences that affords knowledge construction.

Reflective journal writing is a viable method for promoting learning (Progoff, 1975). In the field of medicine, illness narratives are supporting medical professionals' learning about disease and illness. Medical practitioners capture their experiences with different patients and revisit these in different contexts. In the domain of education, "case methods" are used to examine and process different experiences from the classroom. Such opportunities allow teachers to form connections, opinions, and judgements about modes of teaching (Merseth, 2003) and allow for teachers to notice the strategies and practices of other teachers (Sherin \&Van Es, 2002). These types of experiences help form connections between one's own experiences and the experiences of others. They allow workers to develop understanding and apply it in new contexts. This process has become increasingly guided by instruments, tools, and other mediums that are driving new possibilities for learning. Knowledge management tools (Seng, Zannes \& Pace, 2002) have been supporting workers for decades, and now, new generations of these tools such as Salesforce and ServiceNow are allowing workers to consume more volume and discourse than ever before. Thus, the contemporary worker is no longer guided by merely their own internal structures, but also by the experiences and narratives that such instruments collect and curate.

Fenwick (2013) identified this "shift from learning as knowledge/skill acquisition to constructivist notions of workplace learning as sense making with emphasis on reflective practice, self-directed learning, transformative learning and learning style" (pp. 19-20). The learning process begins with direct engagement with one's own experiences and extends into 
observing, reflecting, and refining knowledge via the experiences of others. Learning is "nested within systems that are in turn, part of larger systems, all of which interact and lead toward 'emergence' of new knowledge and ways of being and working” (Fenwick, 2008). Figure 3 conveys this notion of nested layers within a given learning space, using Ahern's (2002) model.

\section{Figure 3}

Constructivist learning space

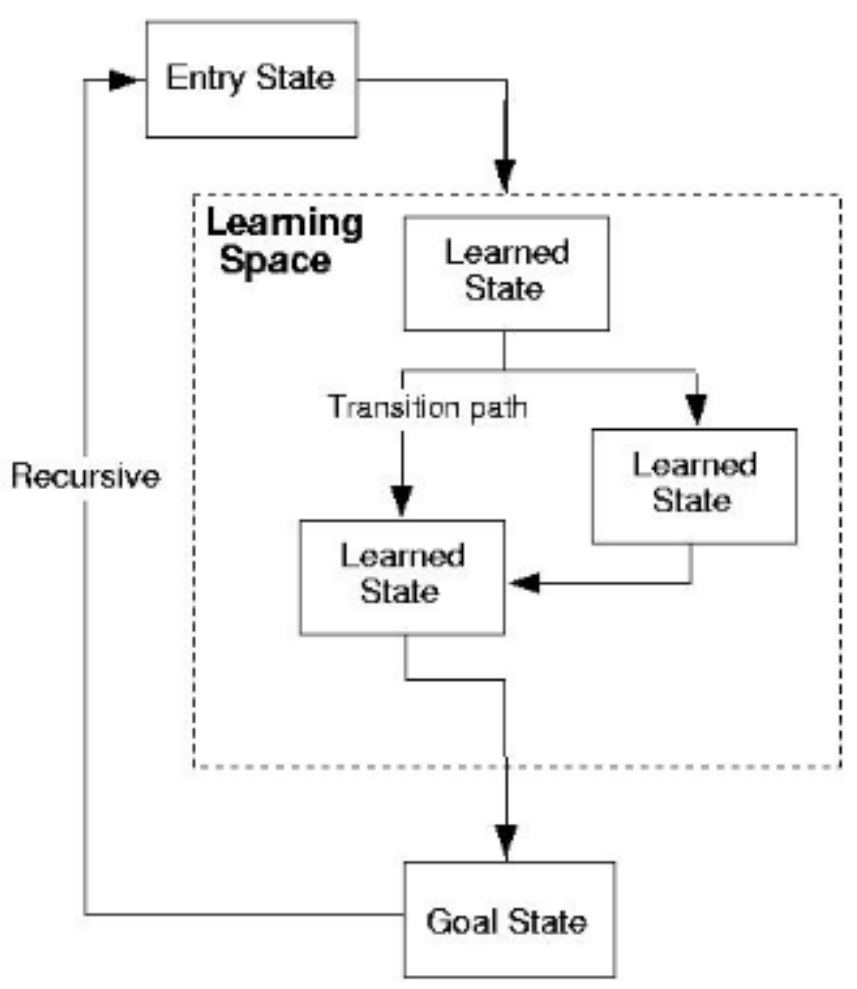

Note. Adapted from Ahern, T.C. (2002, p. 3)

Learners navigate the learning space by "making sense" of experience and traversing distinct "learned states" (Ahern, 2002, p. 2). These transition paths achieve a desired goal [state], 
and this perspective can be applied to the workplace. Workers [learners] engage with an iterative and recursive process to construct work knowledge.

\section{Constructing work knowledge}

A schema development lens helps conceptualize the learning process. If we accept that knowledge is constructed and stored in workers' memories, Rumelhart and Ortony's (1977) representation of knowledge in memory helps us examine the learning process. Knowledge encoded for ideas, concepts, and subjects is how workers consume, store, and transfer knowledge. This process is representative of the learning process and it is important to recognize the cognitive dimension at play here. The human memory system of an adult worker contains a wide range of information that spans numerous roles and sites. To store this effectively, workers create what is comparable to a library of schemas or "schemata", chunked information that spans different knowledge categories (Rumelhart \& Ortony, 1977). These schemata not only contain explicit details about one's own experiences, but also carry more generalizable concepts and constructs that create "records of experiences" (Rumelhart \& Ortony, 1977, p. 111). These may be abstract or detached from particular events or episodes. For example, when facing a problem one may invoke an abstract "PROBLEM SOLVING" schema to assess which strategies are appropriate to proceed. Information is consumed, processed, and refined alongside existing schemas and, in turn, new knowledge is constructed. This process of storing and refining existing knowledge is a key component of Eraut's (2004) informal learning construct. Eraut (2004) conceptualizes the learning process as one in which workers learn by constructing and transferring conceptual and episodic knowledge within new contexts. The "generation, modification and instantiation of a schema seems to characterize both informal learning and formal schooling” (Rumelhart \& Ortony, 1977, p. 132). In other words, this process of 
recognizing, refining, and applying knowledge in different contexts is representative of learning.

\section{Learning and transitions}

Learning scientists have long been interested in the transition process. Schlossberg's (1981) model explained how people adapt during transitions by using situational context, support mechanisms, and coping strategies. Nicholson (1984) built on his prior work to introduce three further contexts that we must consider.

The first is the occupational and motivational context, which impacts the degree to which one is able to learn and adjust (Sofer, 1970). The next is the social context, which is the social process that explains how people assimilate to the rules, customs and norms of a given site (Feldman, 1976, Van Maanen \& Schein, 1979). "Socialization" is the process that explains how workers more generally "learn the ropes" (Van Maanen \& Schein, 1979, p. 21) and builds a social and cultural awareness that leads to narrower role-based learning (Nicholson, 1984). This awareness is "influenced both by the semi-conscious socialization, and by their conscious learning from others, and with others, as they engage in cooperative work" (Eraut, 2004, p. 254). In other words, workers build awareness from social experiences whether they realize it or not. Experienced workers may form connections to their past work sites and therefore have far more prior experience to call upon (Haueter, 2003).

The third context in Nicholson's (1984) theory is how workers' construct an understanding about the role. Exploratory and descriptive studies have been particularly useful in shedding light on narrower experiences that support workers. For novices, the initial transition is a "major phase of development in terms of the extent of their employability within the first few months" (Wood, Psaros, French \& Lai, 2015, p. 2). Wood et al. (2015) summarized the types of experiences that support workers including instances of demonstration, trial and 
error, discussion, coaching, shadowing, observation, and self-study. Wood et al. (2015) noted differences with how experienced workers and novices perceived these experiences, respectively. Novices perceived "case studies, group work, and oral presentations, and rate lectures and guest lectures from practitioners as the least important in their transition to work" (Wood, Psaros, French \& Lai, 2015, p. 2). Conversely, experienced workers valued "real-life situations" and exercises that mimic "situations and tasks that they are likely to encounter (Wood, Psaros, French, \& Lai, 2015, p. 2).

So, then, which experiences are supporting workers? Milligan, Margaryan and Littlejohn (2013) found a similar range, also noting differences between how novices and seasoned workers perceive these experiences. Novices perceived mentoring and apprenticeship opportunities as the most valuable, while experienced workers perceived informal, independent, and self-directed opportunities as more valuable (Milligan et al., 2013). Further, the availability of prior experience influenced the strategies used to learn (Milligan et al., 2013).

How then is prior experience helping workers? Brown, Halcomb and Peters (2018) found that nurses transitioning between acute care and primary healthcare settings had “differences in orientation depending on the level of experience." (p. 664). Brown et al. (2018) noted two broader categories of learning that included role-based learning, the narrower processes that workers use to learn about their roles, and role socialization, the social awareness they generate about peers and the organization. These two dimensions extend from the constructs raised by Nicholson (1984).

What else is unique about the learning process? Olson (2015) examined the transition experiences of administrators at a small private higher education institution, finding that participants organized around informal opportunities that centered around developing an 
understanding about roles and responsibilities. Workers also expressed feelings of frustration and distress struggling to situate the requirements of the role due to ambiguous job descriptions and lack of guidance from the organization (Olson, 2015). This suggests that transitions can be an emotional experience. And, according to Olson (2015), the more opportunities workers had to reaffirm requirements of a given role, the more at ease they felt. Olson (2015) also found that tools and artifacts supported the learning process, and although intrigued by these, she expressed challenges with acquiring such objects. This raises some interesting questions about how tools and artifacts are being utilized. Olson (2015) suggested that we know less about such tools given how they are commanded within ordinary processes of work.

What else do we know about learning and transition experiences? Ten Hoeve, Kunnen, Brouwer, and Roodbol (2018) study of new nurses showcased 1,321 distinct events that spanned themes of relatedness, competence, development, organizational content, existential events, goals, autonomy and fit. Findings from the study suggested that workers had both positive and negative learning experiences. However, positive ones were more likely to be shared with peers and supervisors. Workers described the most meaningful experiences as on-the-job, informal exchanges that occurred with patients, peers and supervisors. Ten Hoeve, Kunnen, Brouwer, and Roodbol (2018) also described learners' engagement with problem-based scenarios, such as issues with patients, and cited these as notable moments that supported their learning (Ten Hoeve et al., 2018). This raises some interesting questions about the types of failures and problems that support the learning process.

What else do we know about such informal and in-situ work experiences? Lutz (2017) summarized the totality of informal experiences, recounting the transition experiences of recent engineering graduates who generated 129 weekly journal entries. These entries illuminated the 
on-the-job, off-the-job, structured, unstructured, passive and collaborative experiences used to learn (Lutz, 2017, p. 72). Nearly half (58 of 129) of these experiences were "on-the-job", "without planned learning (e.g., unstructured)" and "without direct involvement of others (passive) (Lutz, 2017, p. 60)." His findings suggested that technical workers, for example engineers, rely mostly on unstructured and informal scenarios. He also found that these occurred both within and away from the workplace, including passive, off-the-job moments, and without facilitators present. This is notable given that other studies have failed to raise narrower details about the situational context of WIT learning. Lutz (2017) lobbied for the use of reflective writing instruments in future inquiries to unearth more personal and contextual details about the learning process.

Some other studies have positioned reflective writing to study learning and transitions. Abu-Arja (2018) reviewed the experiences of five educators who were in the midst of being promoted. Educators gravitated towards direct supervisors to build knowledge about the role. These were also through informal and collaborative experiences.

Dethloff (2007) is another descriptive study that made use of reflective writing. He journaled the process of moving into a new principalship, describing the context around his transition, the process of leaving his school and entering the new one, the process of socializing with peers and teachers, challenges and struggles faced, and other instances where customs, norms and other routines became illuminated in the new site. He recommended using reflective writing as a method to look deeper into the experiences of more educators, including central office staff. 


\section{Summary}

Shifting social and economic conditions are reshaping how people learn in their work, perhaps calling for more attention to be paid to workers' transition experiences. Covid-19 is disrupting the ordinary routines of the workplace and refactoring the learning spaces that support workers. The Bureau of Labor Statistics reported a steady decline in workplace tenure over the last eight years $(2012,2016,2020)$, and the latest annual tenure summary revealed more separations and exits among younger generations of workers, and across some occupations in particular (e.g., computer and mathematical occupations). Further, the Covid-19 pandemic has displaced millions of workers who are now reinventing their professional identities and shifting into new lines of work.

Workers are guided by a constructivist learning process that affords the construction and transfer of work knowledge. Such knowledge is processed in the cognitive structures and tools of workers and, in some cases, has become more valuable than the actual labor and service that workers provide. Stakeholders in the computer and mathematical occupations, for example, are increasingly valuing the thoughts, ideas, and narrower contributions of workers. Organizations are competing with one another to recruit and retain the most skilled and coveted knowledge workers. Organizations are also looking for more contribution during the earliest days in a new role. Because of this, the onboarding process is being carefully considered.

As expectations continue to increase in this regard, some workers, mainly skilled and educated knowledge workers, have more control and autonomy over their working lives than ever before. Skilled knowledge workers, in particular, are reshaping portfolios and toolkits to move into new lines of work (Gee, 2005). This accelerating shape-shifting phenomenon described by Gee (2005) has created an increasing demand for skilled workers, and perhaps 
caused more transitional scenarios as workers feel more emboldened and empowered to change jobs.

There is also an emerging perspective that we should be promoting more opportunities for professional learning, to both support the learning process while transitioning and to work towards retaining skilled workers. Opportunities for professional learning are no longer viewed as an optional luxury reserved for the most high-performing, prestigious institutions, but rather, as critical mechanisms for developing and retaining skilled workers. Workers value opportunities to learn, and thus, retention outcomes are connected with such learning and development (Gallup, 2017).

A knowledge development lens helps conceptualize the learning process. Workers' construct knowledge through a range of professional experiences, processing, refining and applying knowledge across these in different contexts. Therefore, learning is situated both within ordinary work tasks and as an unfolding narrative that is shaped by one's past, present and future work experiences.

More narrowly, the nature of workplace learning has changed. In examining transitions research across professional practice, Fenwick (2013) discussed a shift in workers' learning process. Workers are increasingly relying on reflective, self-directed, and impromptu episodes to learn, and studies over the past decades have suggested that workers' meaningful learning experiences are mostly informal (Eraut, 2004). Recent efforts by Lutz (2017), Ten Hoeve (2018), and Olson (2015) have shed more light on such informal moments in engineering, nursing and higher education.

In summary, informal and collaborative learning opportunities are common themes that emerge across transitions research. Cases in the domains of medicine, business and education 
are revealing more personalized and contextual details about the learning process. These same sources are also calling for more attention to be paid towards the narrower details of the learning process.

\section{Gaps in current research}

The review found notable gaps in existing literature. The first is the general lack of studies more narrowly examining what happens during the learning process. Few studies have taken a worker's perspective and even fewer have utilized exploratory and grounded frameworks. Lutz (2017) and Ten Hoeve et al. (2018) are some of the notable efforts that examined workers' direct experiences through real anecdotes and exchanges. Some other efforts have raised more personal and contextual details in select occupations such as the principalship (Dethloff, 2007). However, most failed to raise the explicit practices, arrangements, and knowledge structures that support workers. Further, perceptions and perspectives have escaped current research. In some cases, researchers are steering workers' towards particular directions using predetermined lines of questioning with specific directions in mind. More grounded inquiries are needed to illuminate the direct perspectives of workers, especially due to the highly personalized and contextual nature of workplace learning (Eraut, 2004). The lack of research shedding light on informal experiences is problematic, and except for Abu-Arja (2018), few descriptive studies are explicitly focusing on informal learning.

Despite the abundance of tools and technologies that are increasingly available in technology-centric work environments, researchers have struggled with obtaining real-world artifacts and tools (Olson, 2015). Surely there are many artifacts and instruments that support workers' learning and unearthing these will become more important as we continue to promote emerging tools and technologies. This will also matter as we continue to operate within more 
distant and remote spaces. Therefore, it is important that we better understand the range of tools and processes that support workers' learning process as they become more isolated, remote, and distributed. Given the lack of descriptive studies available at present, how workers engage with phenomena such as the knowledge management tools and devices from prior lines of work (e.g., cases and articles), may be escaping current research.

Finally, in many of the studies surveyed here, the authors claimed that transitional scenarios are understudied within their respective domains. Except for the medical domain, I found this to be the case. Even in select domains where transitions research may be less sparse, studies are focusing too deeply on notions of transfer and evaluation, either by examining the impact of preparation programs or investigating barriers of entry. Such works are juxtaposed to studies that more authentically examine experiences in the real world. Because of this gap, some studies have been calling for more personalized and detailed inquiries into the learning process (Fenwick, 2007; Lutz, 2017; Ten Hoeve et al., 2018). 


\section{Chapter 3. Methods}

\section{Overview}

Autoethnography was the methodological approach adopted for the study. This "genre of qualitative research brings the reader closer to the subculture studied through the experiences of the author (p. Dethloff, 2007, p. iii).” But, why autoethnography? How was it useful for studying my experiences? And why are qualitative methods appropriate for studying transitions?

It made sense to use a qualitative approach given how transitions are a product of the learning space. Qualitative methods bring readers closer to the details of the learning space, including the practices, arrangements, and knowledge cultures that emerge from it (Fenwick, 2013). Qualitative methods assume the researcher must come to understand what matters through the research process and, therefore, do not need to bring conceptual and theoretical assumptions into the empirical design. I recognized "learning and learning cultures in transitions are obvious aspects, even though they have been largely ignored (Kiliminster et al., 2010, p. 559)." I aimed to raise new understandings about the learning process without pre-determining my area of focus. Therefore, qualitative methods were suitable to delve deeper into the personal, situational, and contextual details of my learning space.

As Ellis \& Bochner (2000, p. 737) explained, autoethnography enables researchers to pay "attention to feelings, thoughts and emotions to understand the experiences we've lived through (Ellis \& Bochner, 2000, p. 737)." Therefore, by understanding my own experiences, I can better articulate the learning process that workers endure and make connections between my own experiences and the broader cultural phenomena of workplace transitions. Further, autoethnographic methods allowed me to document my experiences directly from the worker perspective. Autoethnography linked "desired outcomes" (Crotty, 2015, p. 11) with 
methodological decisions, and I used Ellis \& Bochner's (2000) method of reflexive writing to generate a worker-centric narrative. In turn, the design created a multidimensional representation of my learning space. Journal entries were the primary data source but were supplemented by secondary sources from the field. For example, calendars, notes, documents, pictures, and messages. These sources combined to create a rich storyboard of the entire transition process for working days one to 58 (90 calendar days), aligning with my decision to execute a more grounded and detailed inquiry. Figure 4 summarizes the overarching design of my methods.

\section{Figure 4}

Summary of study design, steps and procedures

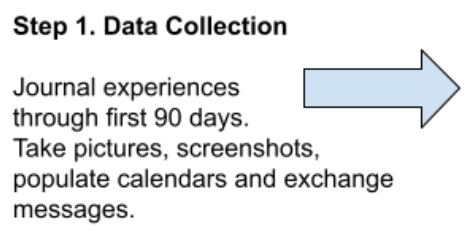

Step 2. Data Organization

Organize data sources. Add calendars, messages, pictures, screen captures alongside reflective writing

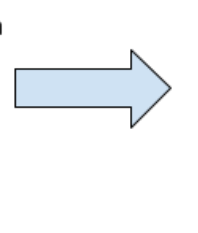

\author{
Step 3. Data Analysis \\ Apply descriptive, process and \\ in vivo codes to the data. \\ Generate themes and \\ conceptual figures. Summarize \\ results.
}

I captured experiences that both occurred on my own (autonomous) and with others (collaborative). These included reflective episodes on the train ride to the office, when I reviewed documentation on my own, and collaborative and social experiences when meeting with colleagues to solve problems. I wrote about each of these experiences to build a more comprehensive narrative of the transition process (Wall, 2008). The idea was to summarize the totality of my experiences and "expand scholarship about human experience" (Ellis, 2009, p. 16). Again, this was due to the lack of personalized transitions research, and how few studies have positioned autoethnographic writing to study the learning processes of workers (Dethloff, 2005; 
Lutz, 2017).

Human subjects research approval through the West Virginia University Institutional Review Board (IRB) was obtained to conduct this study. I distributed the consent form in Appendix A. Participant's identities were kept confidential and anonymous throughout data collection, analysis, and reporting. Each person referenced in reflective writing entries was given a pseudonym and any identifying information was omitted (e.g., my mentor "John").

\section{Alignment with Research Questions}

I executed a "grounded design" to examine my experiences outside the boundaries of existing frameworks. Grounded inquires refrain from applying existing models and frameworks to study phenomena of interest. The idea here was to answer my research questions without predetermining my area of focus. However, there were some notable ideas and constructs that guided my analysis and aligned with my research questions. Recall that my research questions were:

RQ1: What knowledge is constructed?

RQ2: How is it constructed? In other words, which experiences support such learning?

RQ3: How does this change throughout the transition?

Regarding RQ1, I viewed my data through a schema development lens and used schema theory as an approach to answer RQ1. Constructivism and Ahern's (2002) model made me think about the totality of my experiences and how they were connected. Constructivism as well as Ahern's (2002) framework aligned with RQ2 and RQ3, respectively, which made sense due to how Ahern's (2002) model was underpinned by Kolb's (1984) experiential learning construct, and therefore, was congruent with my epistemological considerations. 


\section{Positionality}

Constructionism [epistemology] and constructivism [the way I view the learning process] guided the broader design of this study. I believe that new knowledge emerges by complex engagements between subjects and objects in the real world (i.e., constructionism). I also hold certain assumptions about learning to make the "arguments and outcomes of this research convincing" (Crotty, 2015, p. 10). My primary assumption is that learning is constructivist in nature, driven by the experiences that we engage with (Kolb, 1984) and as situated in the work people do (Lave \& Wenger, 1991). Further, there are a range of moments that guide us towards developing new knowledge, including instances of collaborative, reflective, and self-directed learning. To build new understandings about these multifaceted learning experiences, we must position methodological approaches that best capture these. Autoethnography sheds light on learning within certain contexts. For example, how a tool was utilized to understand the history and details of a project while moving into a new job. Figure 5 represents the trajectory of my assumptions here. 


\section{Figure 5}

Trajectory of my epistemological, theoretical, methodological assumptions

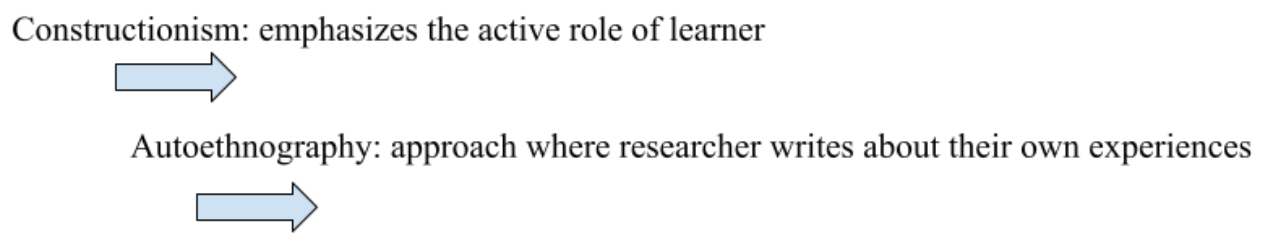

Reflexive Writing: writing that pays attention to feelings, thoughts and emotions

\section{Setting and Context}

My role in the study was two-pronged as both researcher and participant. At the time this study was executed, I was 31 years of age, entering an information technology professional role with approximately 6 years of prior experience in various consulting and technologist roles. I had never been a technology director but had delivered training and consulted on the subjects of web design, data analysis, and reporting. I had some relevant prior experience, but had no direct, prior experience as a technology director. Table 3 summarizes my demographics as characterized by the Employee Tenure Summary (Bureau of Labor Statistics, 2020a). 


\section{Table 3}

Profile of participant based on U.S Bureau of Labor Statistic definitions

\begin{tabular}{ll}
\hline Occupation & $\begin{array}{l}\text { Professional and related occupations - Computer and mathematical } \\
\text { occupations; Education, training and library occupations }\end{array}$ \\
Age & 31 \\
Gender & Male \\
Race & White-Caucasian \\
Compensation Type & Wage and salary worker \\
\hline
\end{tabular}

Note. Summarized using factors from the average worker tenure summary by the Bureau of Labor Statistics (2000a)

As it relates to the setting, I joined Columbia University Information Technology (CUIT). Columbia University is a large, private research university in New York, NY. CUIT is a narrower sub-unit that provides services and support for technology needs around the university.

\section{Steps and Procedures}

\section{Overview}

From data collection through analysis, I used a common suite of tools and instruments, including Google Keep, Google Documents, and Google Sheets. First, I journaled my experiences through the first 90 days while taking pictures, screenshots, and gathering documents, calendar entries, and other artifacts. Next, I organized all my data sources bringing each of these items into one "storyboard" document. Finally, I applied descriptive, process, in vivo, and emotional codes to my data. In the following sections, I describe each of these steps in greater detail. 


\section{Data Collection.}

The raw data captured included 58 working days of reflective writing, 105 pictures and screenshots, 353 calendar entries and 1,231 messages between colleagues. This equated to 474 distinct experiences across the first 90 calendar days. The collection and organization process mattered to me given how working with qualitative data can be overwhelming.

My primary source was daily journal entries (writing) from the field. Secondary sources included messages, emails, pictures, screenshots, notes and documentation, which allowed me to view the same [writing] experiences from multiple perspectives. Following suggestions by Muncey (2005), I used multiple sources to establish the scene, and compiled each of these into the storyboard day by day.

\section{Data Organization.}

Post data collection, I organized all these sources chronologically and created titles which served as boundaries between each experience, respectively. Each "experience" was given an event number and title in the format of XX.XX TITLE. For example, a distinct experience could be: 43.00 JEFF ATTENDS MEETING. This convention denoted when one experience ended, and another began. It allowed me to cite each experience respectively, or in other words, create distinct experiences. The minimum information needed for these was the date (e.g., Thursday, December 12, 2019), day of the transition period (Day 43), title of the experience (e.g., JEFF ATTENDS MEETING) and the reflective writing entry from the field (e.g., Entered the standup meeting with John, etc.).

Alongside this, I included calendar meeting information, such as the title, participant list, time and place, notes and documents, pictures, and screenshots if applicable/available. Figure 6 summarizes the information described here for each unique experience. Figure 7, 8 and 9 shows 
example entries during days two, 21, 40, respectively, and Figure 10 shows the generated table of contents for the entire storyboard. The complete entries for each of these can be viewed in Appendix C.

Figure 6

Template for data fields collected for each experience

Day X - Day of the week, Date

XX.XX TITLE OF EXPERIENCE

Calendar meeting information/title (if applicable)

Participant list (if applicable)

Time/place (if applicable)

Reflective writing entry

Notes from the field (if applicable)

Pictures/screenshots from the field (if applicable) 


\section{Figure 7}

Storyboard entries for Day Two

\section{Day 2 - Tuesday, November 19, 2019}

Decide to navigate to work using a different route. Looking at the bus station via apple maps, I find the * train (subway) connects via a pedestrian tunnel. I read online and it seems to be a better alternative to walking above ground to the *.

\subsection{JEFF REVIEWS DOCUMENTS}

I enter the office at approx. 8:40am. I glance at my goals document again. The office is noticeably quieter at this time compared to when I arrived yesterday. I login to ** for the first time. I browse the app and await my first meeting with John. I use developer tools and strategies from my past work to orient myself. I revisit the specs/summary documents shared by **. I exit my chair and approach John's desk.

\subsection{JEFF ATTENDS MEETING}

SIS overview

Tuesday, November 19, 2019 9:30 - 10:15am

John's desk

John forwards me more meeting invites for a $2 \mathrm{pm}$ (moved to 11am) and 4pm meeting. He explains these are weekly, recurring meetings. He proceeds to demonstrate how to use *. He lectures about the nature of the tool, it's history, the different features, how they are connected, and more. Many of these concepts are foreign to me. He demonstrates features and introduces several tools/technologies associated with the project. We exit his desk and attend standup.

\subsection{JEFF ATTENDS MEETING}

SIS Daily Stand-Up

Monday, November 19, $2019 \cdot 10: 30$ - 10:45am

Weekly on weekdays, until Aug 10, 2020

The developers sound off and voice work they accomplished since the day prior and work for the current day. Surprised, John calls upon me. I exclaim "reviewing documents and getting my work station setup." The rest of the team continues. Some issues are raised and John consults with the developers. The meeting ends. 


\section{Figure 8}

Storyboard entries for Day 21

\section{Day 21 - Wednesday, December 18, 2018}

\subsection{JEFF REFLECTS}

Thinking about my progress through the first month. How I was able to contribute in yesterdays meeting or my troubleshooting strategies used for steps towards resolution of problems faced.

Thinking about the evolution of my work - being mostly a casual observer in the first month to more of a voice/contributor in recent days

\subsection{JEFF REVIEWS TICKETS AND DOCUMENTATION}

Reviewing issues/tickets - looking to follow up on pressing issues. Pushing to prod today and ill lead the change call - submitted the change request for the first time yesterday w the assistance of Steves model. Reviewing notes from yesterdays meeting so I can connect w John and discuss next steps. Reviewing organization update/creation steps in confluence, understanding this notion of an org more now

Meetings all morning and discussion/demo about new catalog and degree audit

\subsection{JOHN MESSAGES JEFF}

John S.: 8:30 AM

I am remote today, but if you are available I'm adding to the backlog and would be happy to do a sreenshare

Jeff B 8:30 AM

yea, give me one moment and we'll connect

John S.: 8:31 AM

sure

Jeff B 8:39 AM 


\section{Figure 9}

Storyboard entries for day 40

\section{Day 40 - Tuesday, January 21, 2020}

\subsection{JEFF REVIEWS TICKETS}

I start the day off checking on tickets from Friday evening, some devs update late in the day. Prepping for questions for dev's. Thinking about when its best to approach them e.g. 10am and later.

New issues opened friday and tuesday by business. I dig into some of these - gathering details and thinking about troubleshooting strategies

\subsection{JEFF MESSAGES JOHN}

I chat with John about weekend. I show him some of the issues we discovered.

Agree to touch base w FE lead after stand up.

\subsection{JEFF ATTENDS MEETING}

John and I head to standup. Developers begin to sound off. I report what I am doing. Paying more attention to $* *$ updates, ticket 2239

\subsection{JEFF ATTENDS MEETING}

I connect $\mathrm{w} * *$ and $* *$ after standup. Brief discussion about 2239. I tell FE lead to join us after all. We review an issue via screenshare. Discussion ensues. Developers are clearer on the issue. I exit the standup.

John.: 10:46 AM

Call

Call Ended

Ended at 11:03 AM - Lasted 17 minutes

3 people joined 


\section{Figure 10}

Table of contents and headers for storyboard instrument

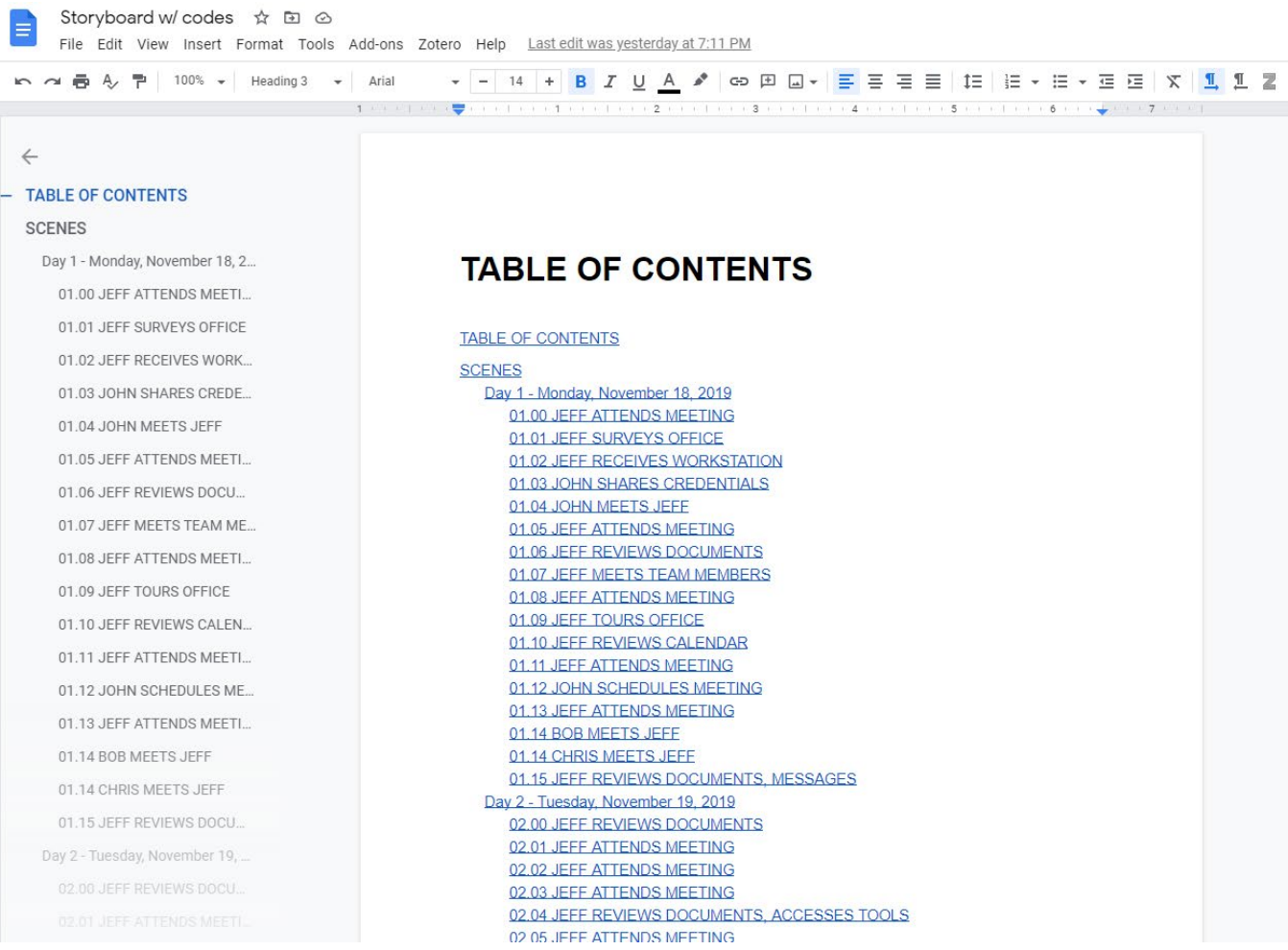

\section{Data Analysis.}

I created an index for all my materials, including data sources, memos and reflections, conceptual figures, and a summary of steps and procedures (Miles, Huberman, \& Saldana, 1994). I frequently returned to my research questions throughout the analysis:

RQ1: What knowledge is constructed?

RQ2: How is it constructed? In other words, which experiences support this?

RQ3: How does this change throughout the transition process?

I thought the answers to these would lead me towards answering a broader, action-oriented one, such as how can we better support WIT? 
I started by reviewing the storyboard to identify major themes. Using a schema development lens, I identified the "categories of knowledge" to trace these schemas back to different experiences (e.g., instances where I performed tasks on my own or collaborated with team members). This was an iterative process, and the goal was to create emergent themes from the data to situate when, where and how these schemas were constructed.

Descriptive, in-vivo, and process codes described what actually occurred each day. I used descriptive and in vivo codes because these provided "an inventory of topics for indexing and categorizing which can be especially helpful for ethnographies and studies with a wide variety of data forms (Saldana, 2015, p. 80)." In Vivo codes made use of "short phrases from the participants' own language" (Saldana, 2015, p. 110) and aligned with my goal of grounding the analysis from the worker perspective. Process codes derived from the actions in my writing conveyed the "observable and conceptual action in the data (Saldana, 2015, p. 105)." Finally, affective coding methods helped me "investigate subjective qualities" of my experiences (Saldana, 2017, p. 124)." I wanted to illuminate these qualities given how constructivism places emphasis on the perspective and qualities of the learner (subject). Therefore, I used emotional codes as "one can't separate emotion from action; they flow together one leading into other (Corbin \& Strauss, 2015, p. 23)

The first pass generated descriptive, process, and in vivo codes for day one to five. Table 4 represents examples of the overarching codes and themes that were captured. 


\section{Table 4}

Descriptive, process and in vivo codes generated from first pass

\section{RECOGNITION}

Tools and Artifacts

Communication

Documentation

Planning and Organization

Design and Development

Processes and Rituals

Requests

Meetings

Access

Project Planning

Training

Design and Development

Tools

Django Admin

Grouper

Steps and Procedures

Provisioning Access

Terms and Concepts

Oauth

Permissions

Roles and Responsibilities

Organization

My Role

Peers and Team Members

Identity Management

Developers

Supervisors

Business Analysts

Clients

History and Context

Project Details

Rules, Customs and Norms

Problems and Cases

\section{PRODUCTION}

Communication

Sending Messages

Reviewing Messages

Reviewing Documentation

Providing Updates

Providing Input or Advice

Proficiencies and Skills

Accessing Tickets

Searching Tickets

Reviewing Knowledge Pages

Designing and Developing

Using Browser Tools

Using API Tools

Installing Tools

Problem Solving

Deciding Next Steps

I wanted two very different samples, so I applied these codes in the same way for days 30 to 34. I also wanted to see if the codes were applicable to the entire set, and to see if any new categories would emerge. I wanted multiple entry points into the data to see if there were 
relationships or differences between earlier and later days. There was more substantial writing in the earlier days, so it made sense to start in days one to five and then continue onward.

I later applied emotional codes and refined each of the codes in my codebook. I organized the codebook into four dimensions: 1) knowledge-building, 2) cognitive, 3) situate, 4) emotional. The codebook represented the knowledge schemes I was constructing (knowledgebuilding dimension), the processes I was employing (cognitive dimension), the situational context of my experiences (situated dimension), as well as the emotional context (emotional dimension). Appendix B represents the final refined codebook and Figure 11 below shows an illustration of how I applied these codes more generally across the storyboard. 


\section{Figure 11}

Storyboard with descriptive codes

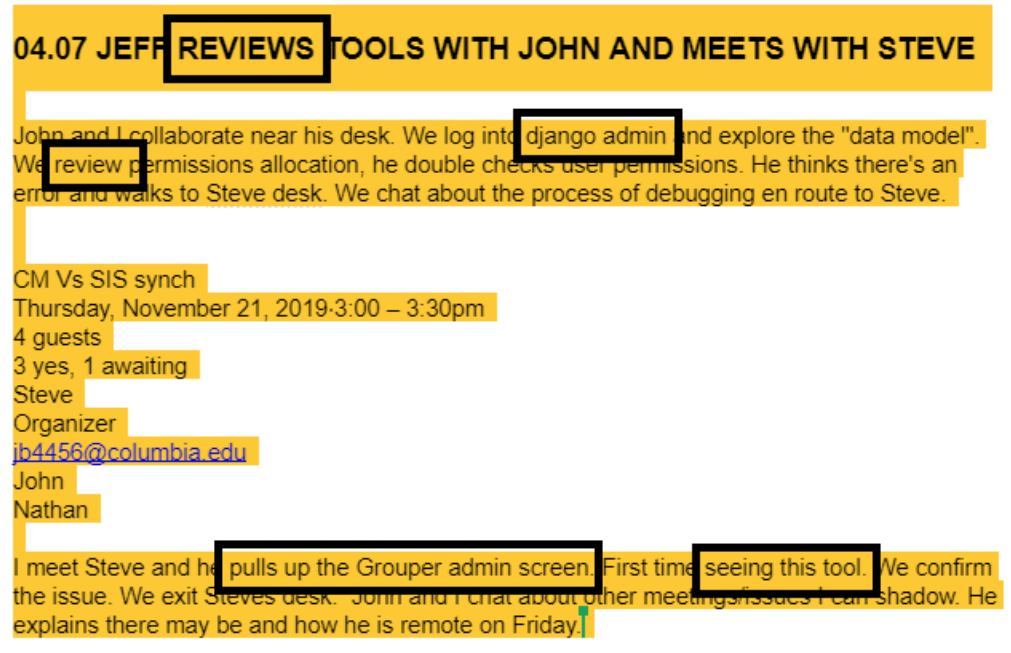

Jeffrey John Burgazz. 8:31 AM Mar 3

RECOGNITION - TOOLS AND ARTIFACTS

RECOGNITION - TOOLS AND ARTIFACTS

RECOGNITION - PROCESSES AND

RITUALS - DEBUGGING

RECOGNITION - HISTORY AND

CONTEXT - TERMS AND CONCEPTS -

DATA MODEL

RECOGNITION - HISTORY AND

CONTEXT - PROBLEMS AND CASES

RECOGNITION - ROLES AND

RESPONSIBILITIES - PEERS AND TEAM MEMBERS

Show less

Jeffrey John Burgazzoli Jr 8:31 AM Mar 3

COLLABORATIVE - EXPLORATION

COLLABORATIVE - PROBLEM SOLVING

Organizing my experiences into the storyboard document allowed me to browse the trajectory of experiences with respect to date, time, and context (e.g., who participated). It made clear boundaries between when one experience ended, and another began. Google Documents provided a convenient way to code my data by using the comments and replies features respectively and allowed me to indicate when themes were emerging and annotate these with reflections. As another way to organize my data, I created the storyboard export instrument. The export instrument generated the codes from the storyboard alongside the content, allowing me to search, filter, and organize these codes in a Google Spreadsheet format. Figure 12 showcases the storyboard export instrument. 


\section{Figure 12}

\section{Storyboard export instrument}

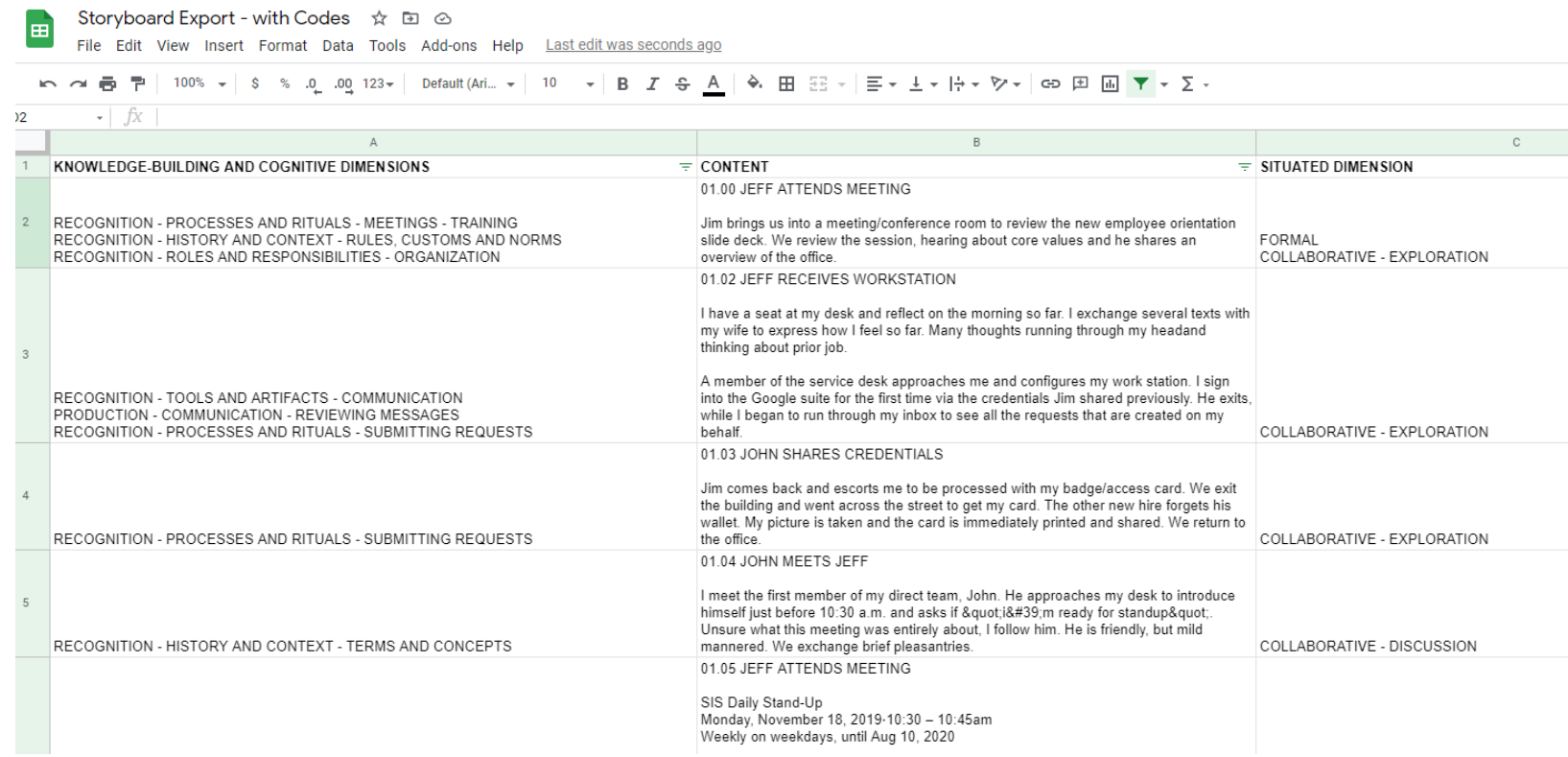

Appendix D contains the code that generated from the above Google Spreadsheet. Essentially

the instrument was used to analyze and present themes from my data. Reviewing the export instrument also led me to construct the conceptual map during my analysis in Figure 13. 


\section{Figure 13}

Conceptual map of cognitive, knowledge-building and situated dimensions

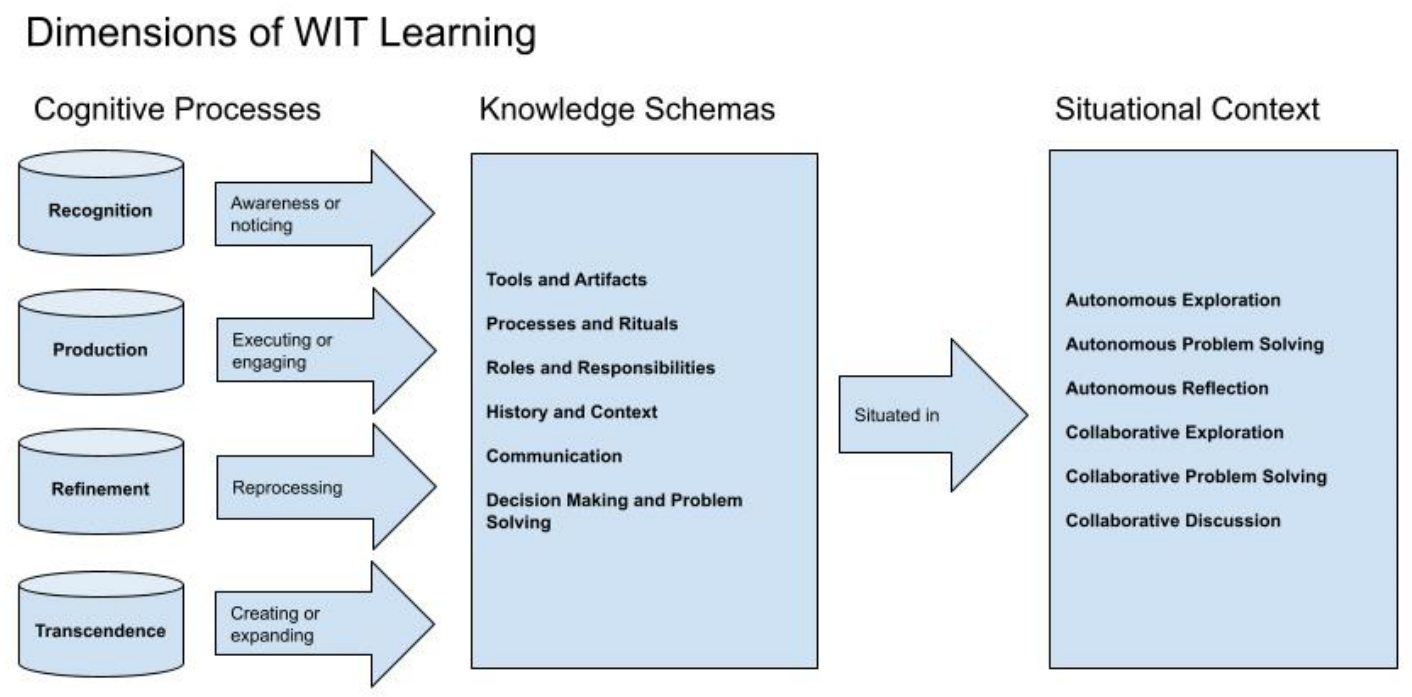

Creating this conceptual figure showed the interaction between each of the dimensions. It allowed me to create concepts and arguments from these themes as I continued applying codes to the entire data set, creating analytic memos, and iteratively revisiting the codebook as needed.

Finally, I turned my attention to the storyboard export instrument. I created distinct tabs in the storyboard export for each of these dimensions respectively. I created spreadsheet functions to identify and tally the presence of relevant codes. Figure 14 represents the spreadsheet functions that counted all the instances where codes appeared, for example, column A133 would indicate the presence of RECOGNITION, REFINEMENT, PRODUCTION, AND TRANSCENDENCE codes in the tab for the Cognitive Dimension. 


\section{Figure 14}

\section{Google Spreadsheet Functions}

$=\operatorname{SUM}(\operatorname{LEN}(\mathrm{A} 133)-$

LEN (SUBSTITUTE (A133, "RECOGNITION", " ") ) ) /LEN ("RECOGNITION")

Note. The functions were used for each dimension and tallied codes for respective rows and

cells. For example, the above code tailed the coding scheme on Column A, Row 133

These functions confirmed the existence of schemes [codes] across each dimension. I used the export data to rectify missing codes, to search and tally codes, and to output the graphical representations presented in the following chapter. Figure 15 demonstrates how I generated these across each dimension. 


\section{Figure 15}

Storyboard export with codes, functions and graphs

Storyboard Export - with Codes in

File Edit View Insert Format Data Tools Add-ons Help Last editwas seconds age

国 Share

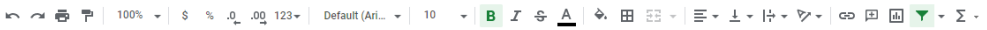

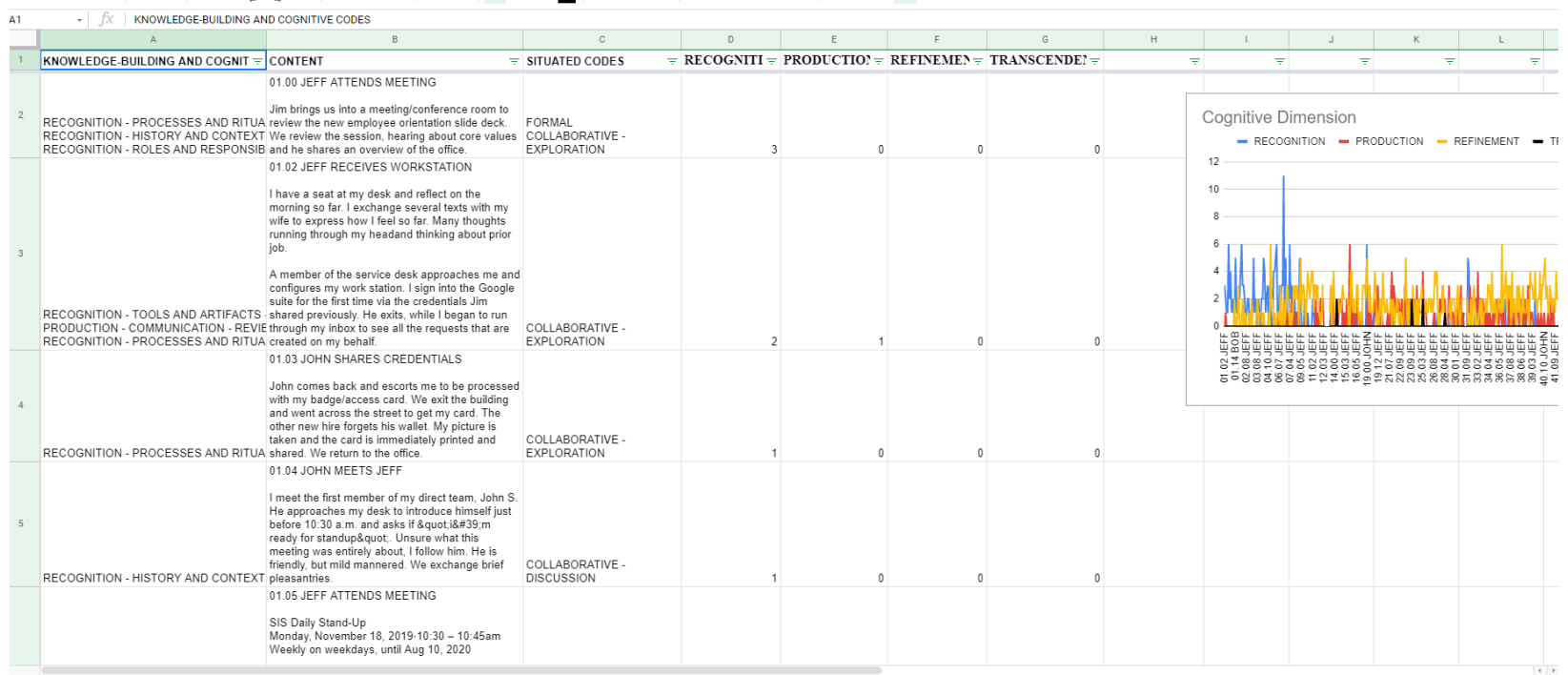




\section{Chapter 4. Results}

\section{The First Day}

I arrived early only to sit in the waiting area for 30 minutes. I felt anxious, the type of a nervous energy you would expect on the first day. I noticed the advertising of the new hires on a rotating slideshow that read: "Welcome to CUIT," with my name included here. Another new hire appeared shortly thereafter, and I was pleased to see someone else in my shoes as we continued to wait for the specialist to arrive. Eventually, he appeared, and we proceeded to introduce ourselves before the specialist accompanied us into a meeting room to present the values and mission of the office.

The specialist was cheerful and sincere. After a short presentation, we surveyed our respective workstations and the common areas of the office. Eventually, we received our identification badges, returned to our desks, and the first day officially started.

I was in somewhat of a sour mood, texting my wife to express disappointment about the workstation and my surroundings. Of course, I was used to the comfort of my home office, and this dramatic change became evident on day one. I wrote about "What I left behind" (01.02) while reflecting about the affordances of my prior consulting role.

Eventually, I shrugged off the disappointment and logged into my laptop for the first time (01.03). I surveyed the different tools and systems across CUIT, including the Google suite (calendar, documents, mail, and sheets). The software center and other miscellaneous desktop apps caught my attention. These were familiar sights and perhaps comforting to see as I had used them in my prior work. Reading through my inbox, I noticed ServiceNow tickets and other automated messages. There were several requests created on my behalf to access systems such as Jira, Slack and GitLab. I presumed I needed access to these systems to do my job. 
Suddenly, a cheerful colleague appeared by my desk to introduce himself (01.04). He exclaimed "Hi, I'm John, would you like to join me for the daily standup?" I was unsure what the meeting was about, but replied "Nice to meet you, and sure."

I accompanied him to the "project room" where I quickly realized I was joining the daily development meeting, or in other words, the forum where everyone sounded off about their work (01.05). I came to learn the project room housed all the developers for the student information system project. I never participated in a daily standup, and perhaps my obliviousness showed as I proceeded to introduce myself to the entire group. They seemed puzzled about my introduction. And, I felt uncomfortable and awkward, quickly realizing that I had a lot to learn about ordinary development rituals.

Returning to my desk (01.06), I immediately found the "org chart" to learn more about who I met with. I found John's name on the chart and noticed he was another director, perhaps in a similar role to mine. More colleagues approached my desk, introducing themselves and exchanging pleasantries. Some introduced themselves at length, expanding on their role with the project and history at Columbia, while others simply offered a warm welcome.

Lunch time arrived and I realized I did not see my boss yet. I made my way into his office to check in with him (01.08). He welcomed me, telling me that he was excited to have me on board, and eventually telling me I would shadow John over the next three weeks. We discussed expectations for my role and set up a goals document to track progress and share updates. He used words like "ownership" and "escalations" as we discussed goals for me over the next month and a half. He delved into the roles and responsibilities of some of the other colleagues I had just met. I made note of who owned what and their involvement with the project. Some folks worked on the project management side of the house, while others worked 
more closely with the development team and within adjacent groups in CUIT (e.g., identity management, deployment, etc.). I learned that CUIT served numerous clients ranging from administrative offices to decentralized academic schools and colleges around the entire university.

I returned to my desk, receiving more cheerful exchanges from approaching colleagues. My boss returned, and we toured the office to meet with the senior leadership team and "clients" from some of the student support offices (01.11).

Later in the day, around 30 folks gathered in a meeting room to introduce themselves (01.13). These were all the colleagues in the broader enterprise applications unit, the unit that housed the student system group. I was blown away by the depth and size of the office as it seemed vast and large, writing in my journal about "How big the office seemed". CUIT is home to nearly 380 employees. And thus, the org chart became a handy asset even on the first day.

Meetings throughout the day helped me establish some history and context surrounding the project. I met with the key stakeholders who had been supporting the student system, learning that I would replace some of their efforts. In between meetings, I continued reviewing calendar, email, and other communication channels as they became available (01.10). More meetings appeared on the calendar for the upcoming days, giving me a sense of who I would be working with and what the rest of the upcoming week had in store.

At the end of the day, John approached me to ask if I wanted to see a demo of the system. I agreed, and we set up a meeting for the next morning (01.12). Perhaps it was too much to browse the system on the first day given all that I had done to this point. Another calendar invite shortly followed and I glanced at the train schedule, eventually exiting the office to make my way home. I felt a sense of relief as the first day was officially in the books. 


\section{Getting Up To Speed}

I shadowed John and visited with other colleagues over the next two weeks. John and I met the following day (2.1) to review the student system, explore its components, and discuss the history of the system's implementation. John explained the system's features and its interconnected nature with other tertiary systems. We arranged more meetings so I could continue to shadow and observe him whenever possible. He was frequently occupied in different meetings, thus any chance I could shadow him became a valuable learning opportunity for me. Shadowing him brought me up to speed by shedding light on the various terms, concepts, and processes involved with supporting the system. In essence, he showed me what I needed to learn in order to do my job. We reviewed different "epics" (14.08), discussed problems such as lingering issues with permissions and access (11.02), and visited with other groups (e.g., identity management) which helped gather who I needed to work with for different tasks (13.05).

On the second day, my boss remarked in a group chat: "This may be a good event to bring Jeffrey up to speed on some of the active backlog items (02.08)." Getting up to speed was an emergent theme over the first two weeks. I still wasn't entirely sure where to assist or how to contribute to this point. I continued to meet with John, which helped me pick up on terms such as "data model", and concepts such as "frontend" and "backend" - jargon used in development circles to represent the nature of the development work. I attended weekly debrief sessions with the client (12.06) and ad hoc project meetings (11.08). My learning in these early days was guided by the support of other colleagues, who took the time to explain context and history around some of these meetings. These collaborative opportunities, both with John and other colleagues, were very beneficial in helping me come up to speed. In total, there were 55 collaborative experiences across the first two weeks, and several occasions where peers and team 
members approached my desk $(01.14,01.14,02.06$, and 04.08). When colleagues appeared suddenly by my desk, I assumed I would be working with them to some extent. These impromptu meetings also refined how I came to understand my role. For example, Bob appeared at my desk during 01.14 and shared a document. This brought the notion of a "requirements document" to my attention and gave me insight into how requirements were generated for the system. Interactions such as these illuminated how I was expected to review, and potentially even create certain types of documents and artifacts.

Outside of these collaborative opportunities, I also surveyed documents and resources on my own in an exploratory fashion. On 38 different occasions, I browsed tools and documents, which reinforced some of the same terms and concepts discussed with John. For example, on 15.07, I remarked to John "reading this and it all makes sense!" My knowledge was refined as I both observed John and then reflected on these experiences after the fact. Digging deeper into documents, the ticket system, and other channels helped me to understand the narrower, contextual details of my role. Figure 16 represents the trajectory of my knowledge growth over the first two weeks. 


\section{Figure 16}

Knowledge building categories during the consumer state, day one to 14

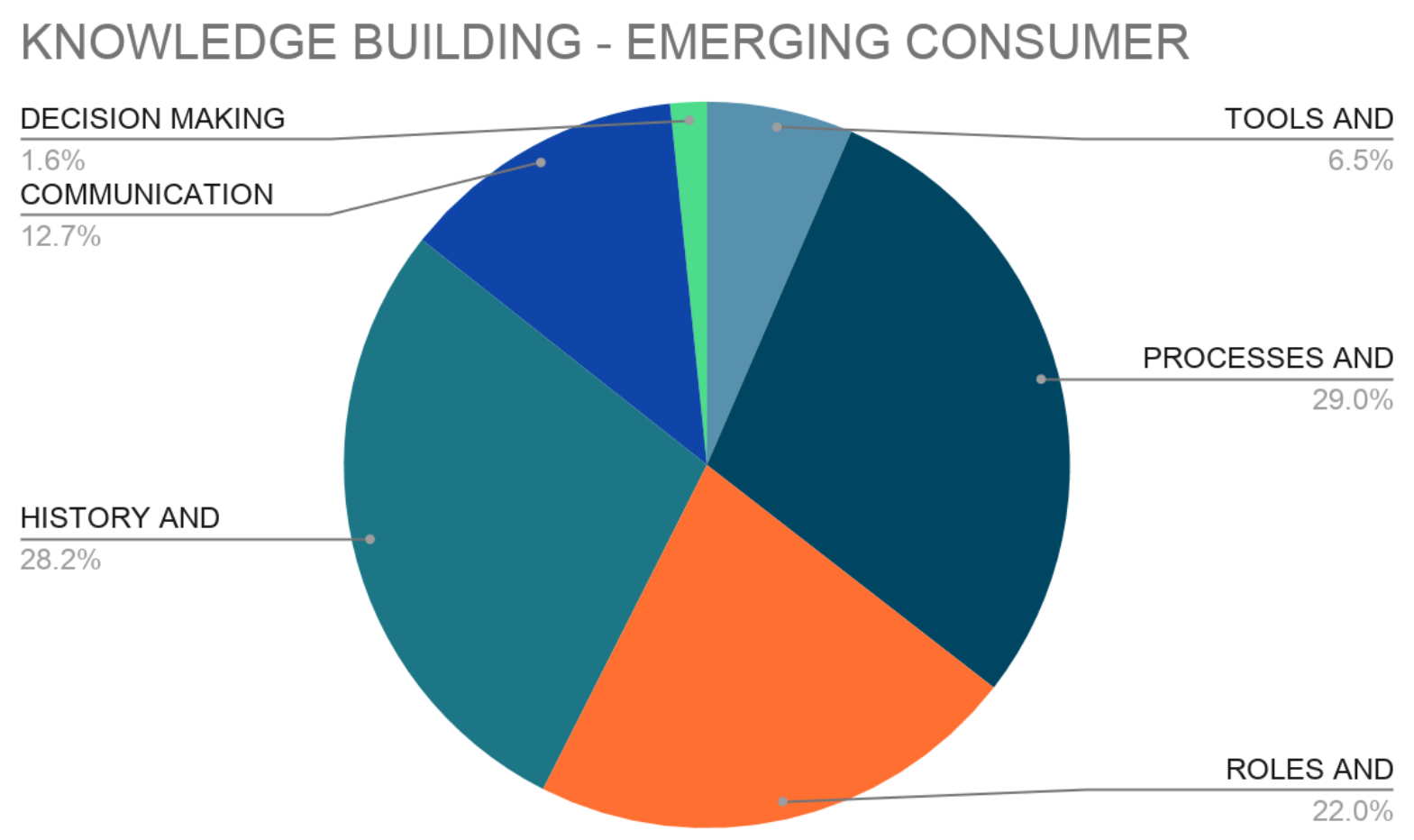

\section{Breakthrough}

As one might expect, my contributions were rather limited through the first two weeks. Updates on the daily standup were short and concise. I frequently thought about when I may start to contribute during these early days. I expressed feelings such as "Still trying to situate my place in the organization and how I might contribute" during writing on 06.01. Perhaps I was being too hard on myself. And to be fair, I never served in this sort of role before, thus many of the tools, processes, and rituals I was expected to perform were still new to me.

However, on day 15 something changed. As I became more aware of foundational subjects, terms, and concepts with the system, I finally arrived at making my first major 
contribution. Of course, this wasn't a product of happenstance or by accident. There was a clear trajectory of experiences that led me to this first major contribution and only days earlier our lead developer showed me a particular tool, known as Django admin, that led me to creating a novel process. The Django tool essentially allowed us to view backend database tables and fields in the system, and John had demonstrated it on several occasions (04.07). I practiced with it on my own during 13.02, and with others on (14.01). Eventually, I learned that we wished to develop a "deletion process" in the system that mimicked some of the same features that resided within the tool. I used the tool to trace these "deletion steps", on the 15th day, I documented the exact steps we need to develop the deletion process. Essentially, I used the tool to shed light on the programmatic requirements that were needed for the deletion process (e.g., GET, POST, etc.). The learning here was multi-faceted. First, I noticed the tool with John on 04.07, then I rehearsed with it during 13.02 and 14.01. During 15.00 and 15.02, I documented these steps and shared the contribution during the daily standup (15.03). I used what I had learned during the first two weeks to create the new process, or in other words, applied what I learned previously and refactored my knowledge in a novel way.

The lead developer was extremely impressed, remarking "This will be very helpful for us" during 15.03. I was so pleased about the contribution that I expressed feelings of joy and satisfaction in my journal writing. I wrote about how I felt "Like I am starting to contribute." I later went home and shared the contribution with my wife and family. Clearly this mattered to me, and I thought about how this was perhaps not only a breakthrough with my technical knowledge, but also how this moment served as a major inflection point. Wondering how I arrived here, I made connections between the $04.07,13.02$, and 14.01 experiences respectively 
that preceded this moment. Table 5 and Figures 17, 18, 19, and 20 present the entire trajectory of experiences that led me to create this novel "deletion process."

\section{Table 5}

Summary of trajectory of experiences for T1 - Deletion Process

\begin{tabular}{lll}
\hline Transcendent Episode & Trajectory of Experiences & Description \\
\hline T1 & 04.07 & 04.07 - The first RECOGNITION of \\
13.02 & design and development tools - django \\
14.01 & admin, shown by John. \\
15.00 & 13.02 - REFINEMENT and \\
15.02 & PRODUCTION of the same schema \\
15.04 & through COLLABORATIVE and \\
& AUTONOMOUS exploration \\
& 14.01 - More PRODUCTION and \\
& REFINEMENT to delete proposals \\
& 15.00 - Recognition of the breakthrough \\
& after deleting \\
& 15.02 further PRODUCTION and \\
& REFINEMENT \\
& 15.04 - presentation of the delete \\
& process \\
& \\
& \\
& \\
& \\
& \\
& \\
&
\end{tabular}




\section{Figure 17}

Emergence of T1 during experience 15.04

\subsection{JEFF ATTENDS MEETING}

SIS Daily Stand-Up

Tuesday, December 10, 2019 10:30 - 10:45am

Weekly on weekdays, until Aug 10, 2020

During stand up, I announced my achievement/task and it was well received.

I gained respect after I demonstrate my technical knowledge / ability to learn

Developer makes comment what I did is helpful

\section{Figure 18}

Cognitive dimension and trajectory of experiences leading up to Transcendent episode one (T1)

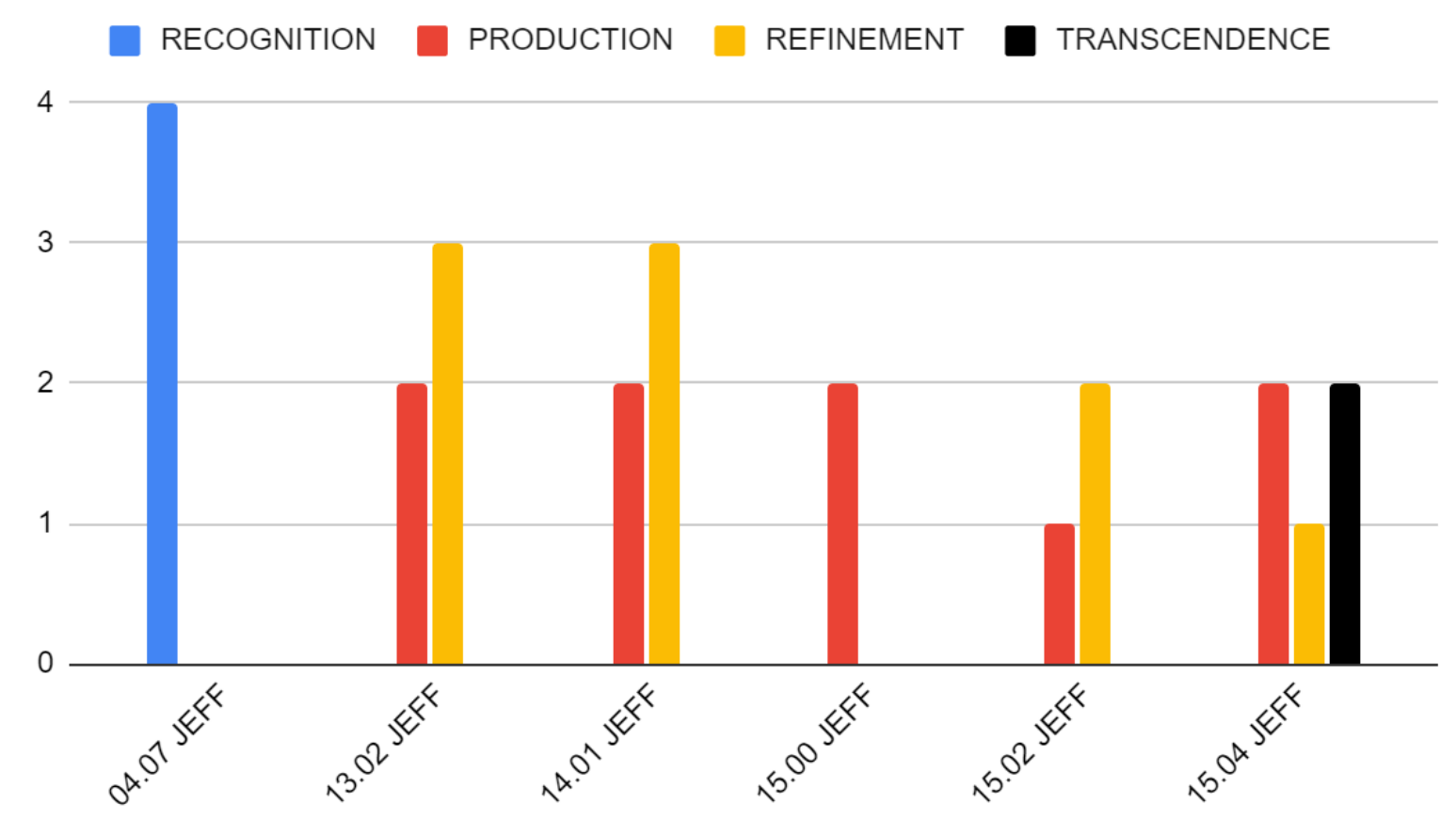




\section{Figure 19}

Knowledge-building dimension and trajectory of experiences leading up to Transcendent episode one (T1)
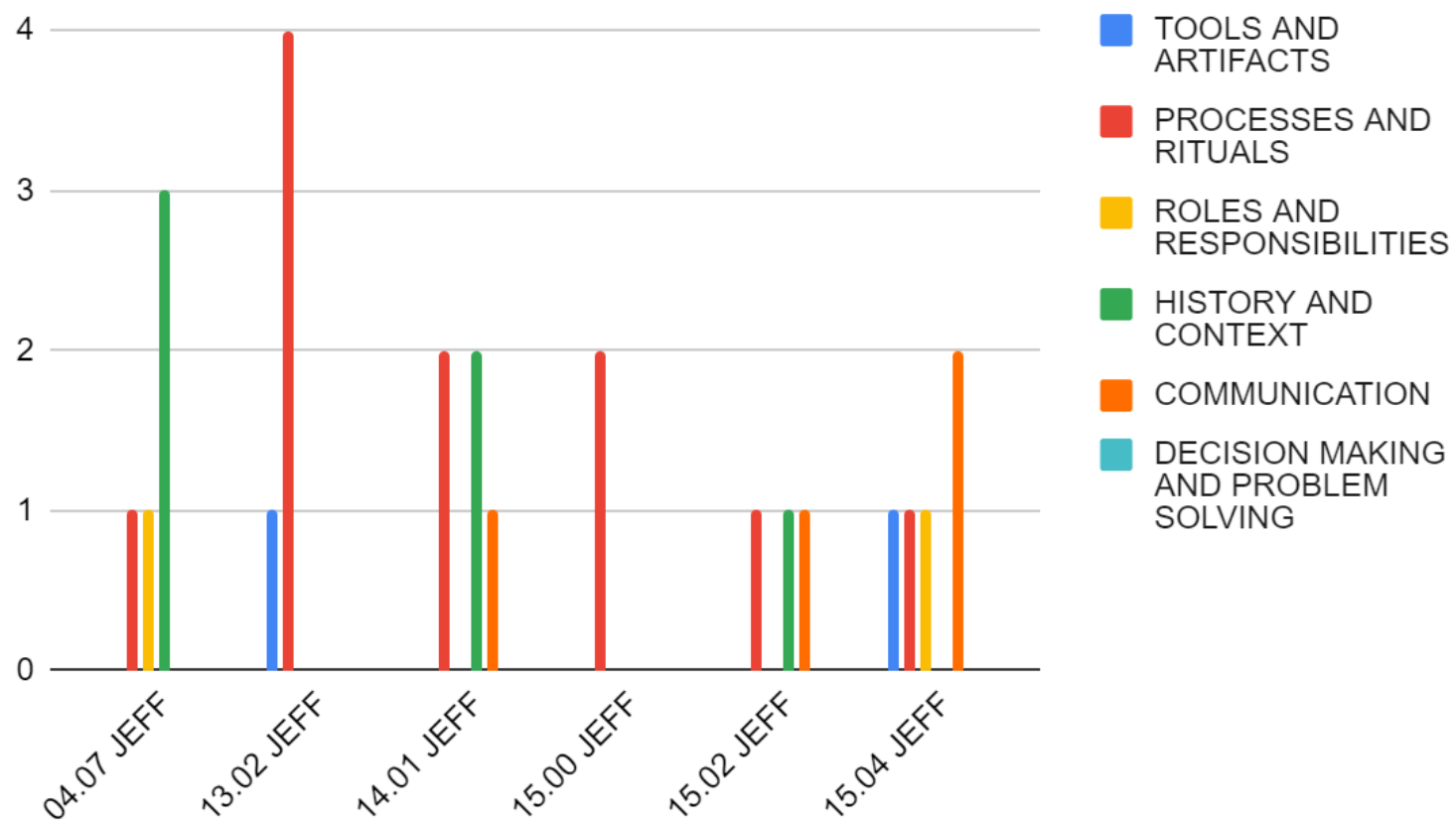


\section{Figure 20}

Situated dimension and trajectory of experiences leading up to Transcendent episode one (T1)
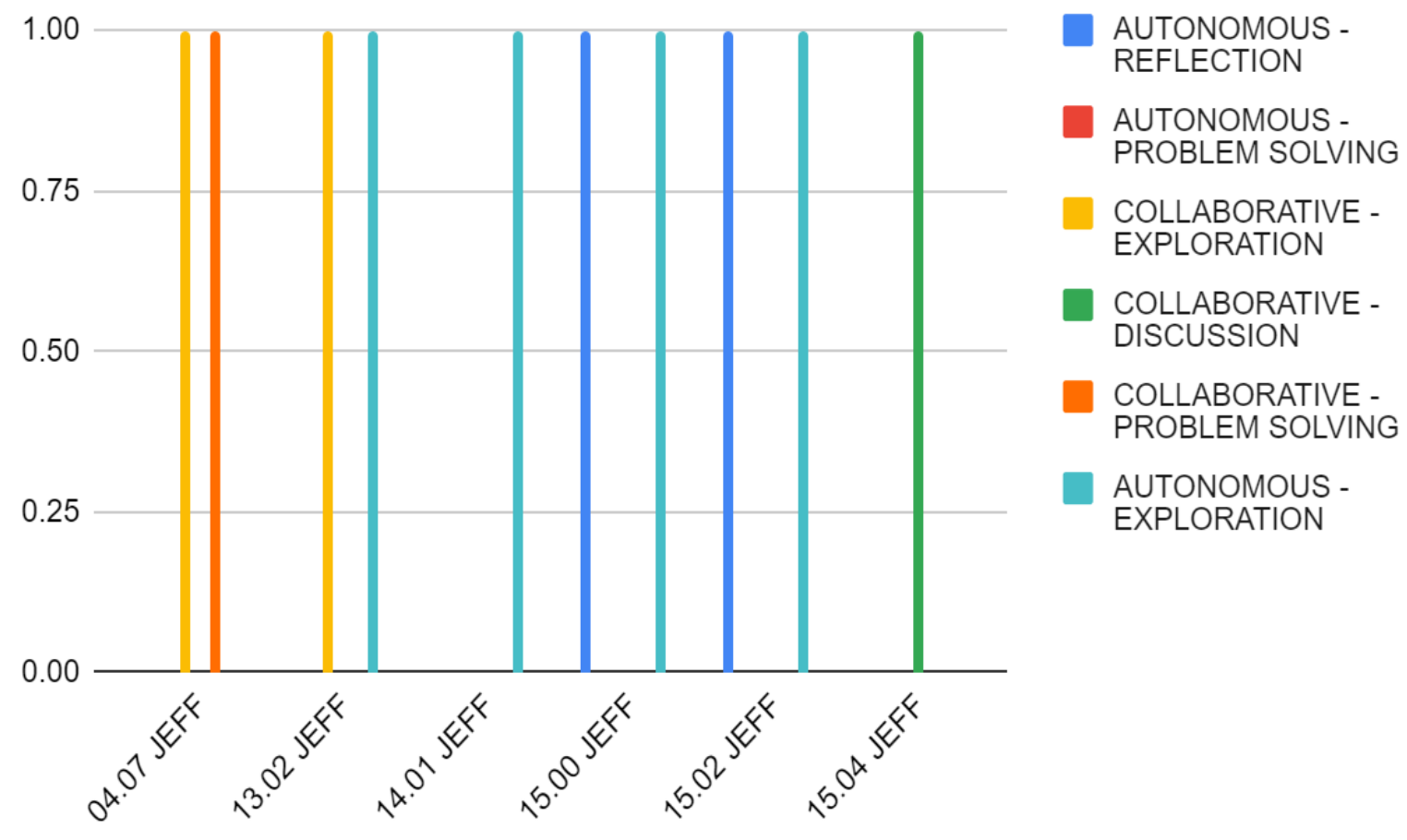


\section{Finding My Voice}

With one major contribution under my belt, I felt more empowered and emboldened. It allowed me to build confidence and gain a better sense of not only what I was expected to contribute, but how I could actually contribute with limited understanding of Columbia to this point. After this, I became more vocal with peers and team members, and during a meeting with my boss (16.01), I expressed how I was starting to "Find my voice."

Perhaps finding my voice led me to becoming more engaged in my work. I became more active in applying knowledge and speaking up in meetings. In some instances, I diagnosed, raised, and resolved issues rather quickly. Given my consulting background, my attention started to shift towards areas that were familiar to me, such as the diagnosing and debugging of problems. My attention wandered towards areas that were comfortable as these subjects dominated my writing, like because I felt I could operate within such confines, make decisions, and act.

For example, during 25.04 the client reported a potentially serious problem with a data feed in the system. When I alerted other colleagues to this problem, including folks who had been with the project for several years, folks were reluctant to believe we had an actual problem. I decided to dig deeper into the issue, eventually accessing the terminal server as I had done in my prior job at Ellucian. After delving into the server's logs, I realized that we, in fact, had a real problem on our hands. I eventually escalated, again, to my peers and team members. Exchanges with John during 07.00 and 11.01 led me to the potential solution for the issue. But the real breakthrough here was in my thinking and expressing what I felt. I challenged my colleagues' thoughts and opinions here, writing about how my colleagues "were skeptical but [the clients] alarm may be warranted" (26.04). This signified a breakthrough with finding my 
voice and I also learned that I could not blindly trust my colleagues' opinions and judgements. Rather, I would need to form my own opinions and judgements, and perhaps rely on my instincts to flesh out real problems when they surfaced as I continued to come up to speed.

To this end, I continued to seek out tasks and duties that were familiar to me. For example, during 20.00, 21.04 and 27.02, I engaged with testing of the system on my own, and without the support of others (i.e., autonomous exploration). Again, in my prior consulting role, I often did the same on my own. Such exploration and testing of the system felt comfortable for me. It perhaps led towards finding my voice in these middling weeks as I felt more confident in raising issues with John and asking questions as I tested the system. During 20.00, I asked him “did you connect this morning with the developer about ticket 708," and during 23.01 I remarked “are we testing with the developer?" These testing sessions allowed me to explore the system on my own, learning deeper about its components, while also consulting with John for particular tasks and strategies. These exchanges also symbolized growth in our relationship, which led to increased trust and an open line of communication with John. We even exchanged pleasantries and joked more over Slack messages on a more frequent basis, expressing interests outside of work like during 15.01. John scaffolded my thinking to a greater extent as I posed ad hoc questions and ideas while engaging more with the system.

Engaging with the testing sessions, a place where I was comfortable, also led me to perform other critical tasks and processes on my own that I had previously never engaged with, such as creating development tickets [tasks] for the developers. During 19.09 and 25.01, I eventually created my first "epic" ticket [task] with the support of John and another developer. I watched John generate tickets on several occasions, and leading up to this, I reviewed hundreds of tickets throughout the first several weeks. These review sessions led me to notice details that 
were typically included, such as how and whom work was allocated for, descriptions of development tasks, and associated commentaries between developers, analysts, and the client. These compounding review sessions led me to better understand the process of creating tickets. Consequently, they also revealed more terms and concepts related to the project more generally. While reviewing tickets in subsequent experiences, I noticed things such as the "grouper tool" (21.04), managing "permissions" (21.05 and 22.02), and the concept of "term sessions" (24.07). Recognizing these terms and concepts built towards comfort with creating development tickets, and eventually, I created an epic ticket with a series of development tasks during 25.01.

Eventually, I started to inquire more with other groups and team members. After observing another director, Ivan, request updates from one of the developers, it led me to do the same during 24.02. I became more vocal with John, asking him for input and advice during $21.05,21.12,22.10,23.01,29.00,29.02$, and 30.00, respectively. John pinged me during 31.02, questioning if a particular ticket that I escalated was "urgent," to which I replied, "It impacts the academic calendar admin screen, so possibly." This was another breakthrough and it was the first time I actually understood the interconnected nature of tasks and priorities. Further, I prioritized tickets with John, and we discussed the relevancy of this specific escalated ticket. These experiences led to more positive thinking as I expressed feeling "more comfort" about creating tickets and supporting the system (23.03).

As these events unfolded, colleagues started extending more words of encouragement. Again, the lead developer expressed how she was "Impressed with my thinking" (32.01). In this episode, we gathered details of a problem to debug an issue with a new feature. The developers were puzzled as to the root cause of the problem. While debugging, I thought about a prior search strategy from my time at Ellucian. I searched for relevant terms and subjects across 
tickets that were updated in the past two weeks, finding the potential culprits (tickets) that may have caused the problem. Eventually, we concluded it was one of the tickets I found, which led us towards eventually resolving the issue. Here again, I leaned on strategies and tactics used in my prior work.

Between days 15 and 33, the trajectory of my knowledge growth had once again shifted. Learning became more about control strategies, decision making, and problem solving, such as during the instance in 32.0. Figure 21 summarizes the trajectory of my knowledge growth to this point. 


\section{Figure 21}

Knowledge building categories during the producer state, day 15 to 33

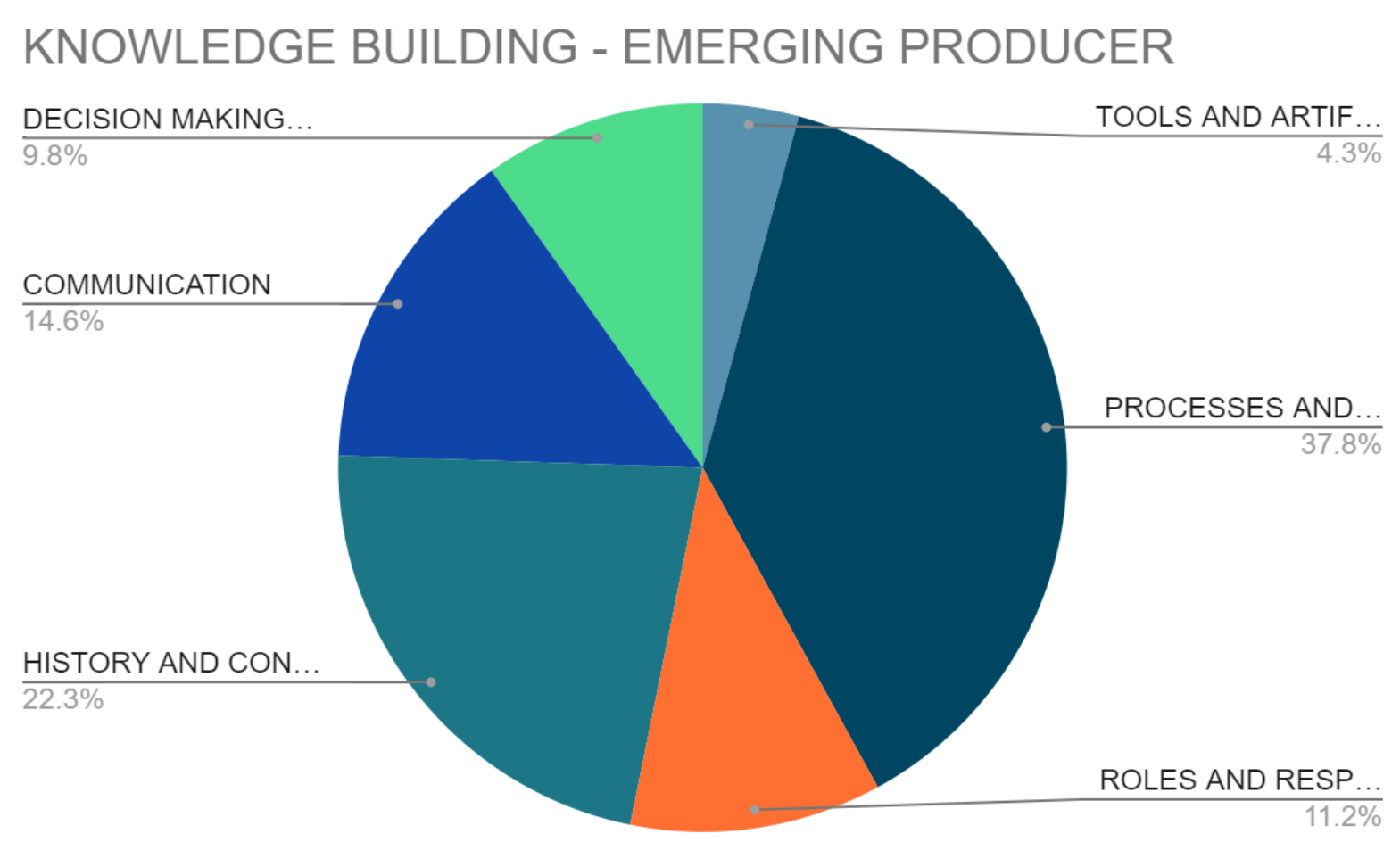

\section{Settling Into the Role}

As more contributions emerged during 26.04 and 32.01, respectively, my role refined and expanded. Even though it felt like I was starting to settle into my role, I still expressed anxiety over my level of worth and even concerns over how my boss felt about my performance thus far. After a meeting with a client on 28.06 , I wrote about how my boss was "Starting to expect me to contribute" and that I needed to "Assert myself more in these meetings." This anxiety led me to seek out more ways to contribute.

My experiences eventually broadened into other tertiary areas outside of my direct responsibilities. For example, during 49.04 I joined a meeting for which I was initially excluded 
from the invite. I knew I had some relevant prior knowledge about the contents of the meeting, so I ended up participating in a whiteboard session, and interesting enough, found more comfort with expressing my thoughts and beliefs. During 48.05, I joined another meeting that was "Unrelated to my role but my boss wanted me to be a part of the discussion." This enlightened me about the enterprise reporting team's responsibilities, and their role in supporting an adjacent data feed for the system. Some of these same moments became a part of secondary goals that my boss defined, including to become more comfortable with the office culture and to meet with constituents around the university.

As the 60-day checkpoint approached, I became more independent and confident in my thinking. I started to prioritize issues and problems on my own, and even my own time. For example, I rejected a meeting for the first time during 37.00. My boss and I also refined goals and discussed expectations for the upcoming year during 41.10. Each of these were signs that I achieved his initial goals and expectations that were outlined during the onboarding process.

Even though I had perhaps made significant strides, I still relied on John's support to address complex and ambiguous problems with the system (41.03). John's consulting and mentorship persisted even as I felt more comfortable and grew more capable of solving issues and making decisions. John was not necessarily directing my actions, but rather, subtly influencing my understanding of unstructured problems. His intervention scaffolded how I viewed myself as well as the roles of peers, team members, and clients. For example, during 43.11 John asked me "Who's on standby for testing," and during 52.04 we had a conversation about who should attend a particular client meeting. His input bolstered my capacity to make decisions and solve issues during 43.00, 43.06, 44.00, 44.01, 44.02, and 45.01. It also perhaps led me towards breakthroughs with clients, such as during 53.01 . 
Eventually, I led the rollout of an entire "release" of new features in the system during 52.00. I wrote about this with excitement, exclaiming: "Deployment day, 2nd deployment with complete control." John also started to rely on me more for things that were critical to his own work. He delegated me specific assignments during 43.02 and 43.03 and asked me specific questions about tools he introduced to me during 56.02. These moments led me to feel like I was making real progress. I asserted that this was "A big step in my thinking and I am starting to mentally arrive in my role" during 53.07.

This settling into my role also became more evident as I expressed concerns about project priorities during 50.00, 51.02 and 54.02. The literal location of my workspace also changed as I became more involved with the developers, such as during 53.00 when I "Sat in the project room all morning." Some negative emotions surfaced during these latter days as I noticed more internal dysfunction during 51.00 and 57.00. Perhaps this was due to how I established history and context in the weeks prior. Context simply may simply have been absent during these early days where I didn't notice dysfunction or turmoil.

Some other notable events accompanied these latter days. I made a critical error in not allowing enough time to prepare the release of new features during 57.06. I also became more engaged in off-hour work, such as during a "working lunch" on 56.04 with the enterprise reporting team to explore the systems data models and structure. Outside the office, I reviewed messages and documents during 54.00 and 56.00, which perhaps led me to believe I had "more control" as I expressed during 53.07. Figure 22 represents the trajectory of my knowledge growth, which again shifted towards decision making and problem solving. 


\section{Figure 22}

Knowledge building categories during the contributor state, day 34 to 58

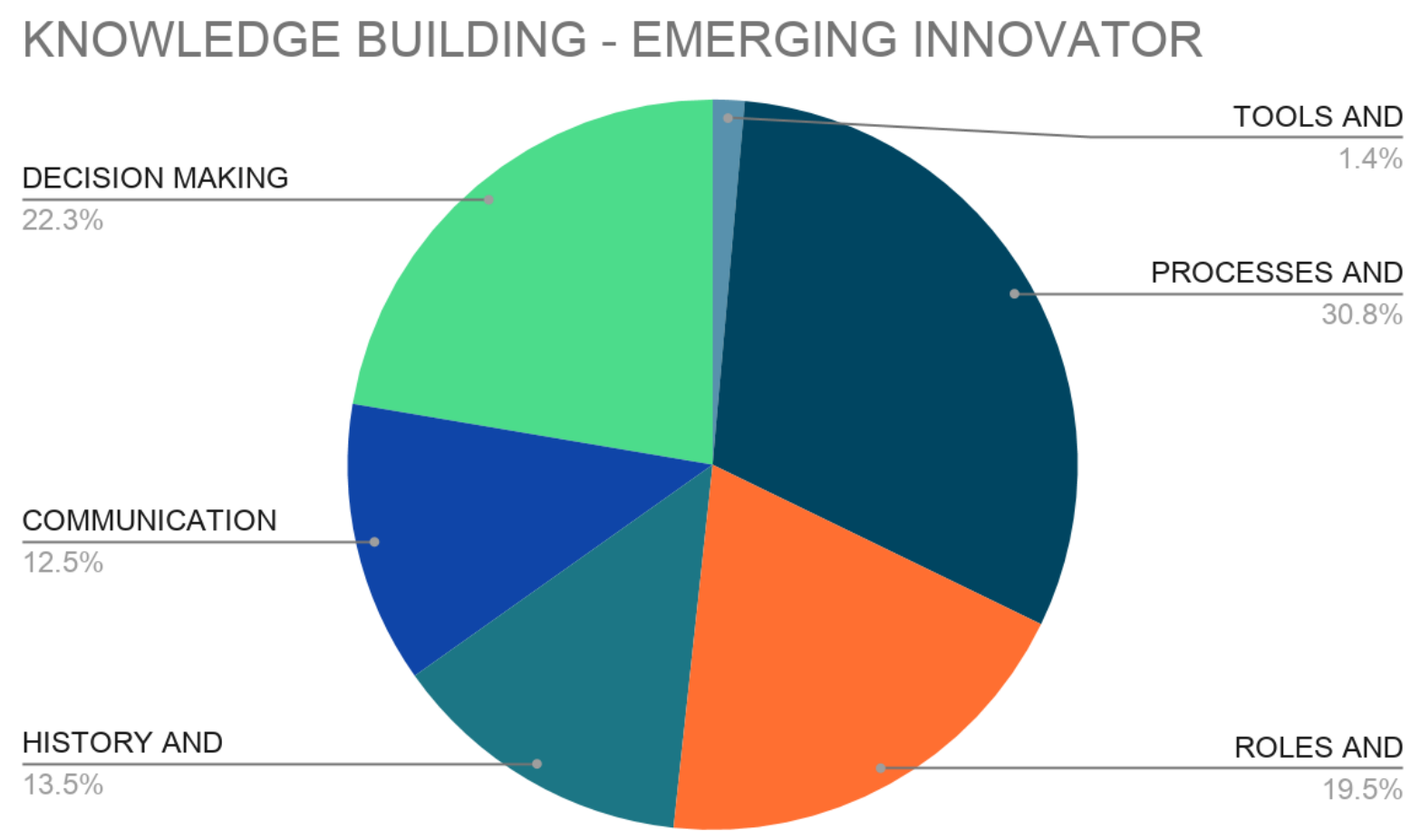




\section{Chapter 5. Discussion}

The purpose of the study was to generate a more personalized and detailed account workplace transition (Fenwick, 2013). I used my own transition experience to help instructional designers, program developers, human resource professionals, and employee mentors better understand how people learn during transitional scenarios. Schema development, situated learning, and constructivist lenses were used to describe how learning occurred and changed throughout the transition process. To reiterate, the following research questions guided me:

RQ1: What knowledge is constructed?

RQ2: How is it constructed? In other words, which experiences supported my learning?

RQ3: How does this change throughout the transition?

\section{Dimensions of Learning}

There were multiple dimensions of my learning. The results here were derived from multiple rounds of coding that were both immersive and iterative. In analyzing my data, four aspects of my learning became apparent:

1) knowledge building: finer, grained knowledge growth and development

2) cognition: the internal processes utilized to learn

3) situational context: social and contextual circumstances that influenced learning

4) emotional context: emotions that affected knowledge growth and development

In the following sections, I summarize and discuss each of these elements, respectively. 


\section{Knowledge-building}

With respect to RQ1-what knowledge is constructed, six broad categories of knowledge were constructed. Figure 23 represents these schemas from day one to 58 . In total, I coded 21 tools and artifacts, 108 processes and rituals, 82 roles and responsibilities, 190 history and context, 131 communication, 125 decision making and problem-solving schemas.

\section{Figure 23}

Knowledge building dimension for day one to 58

\section{Knowledge-Building Dimension}

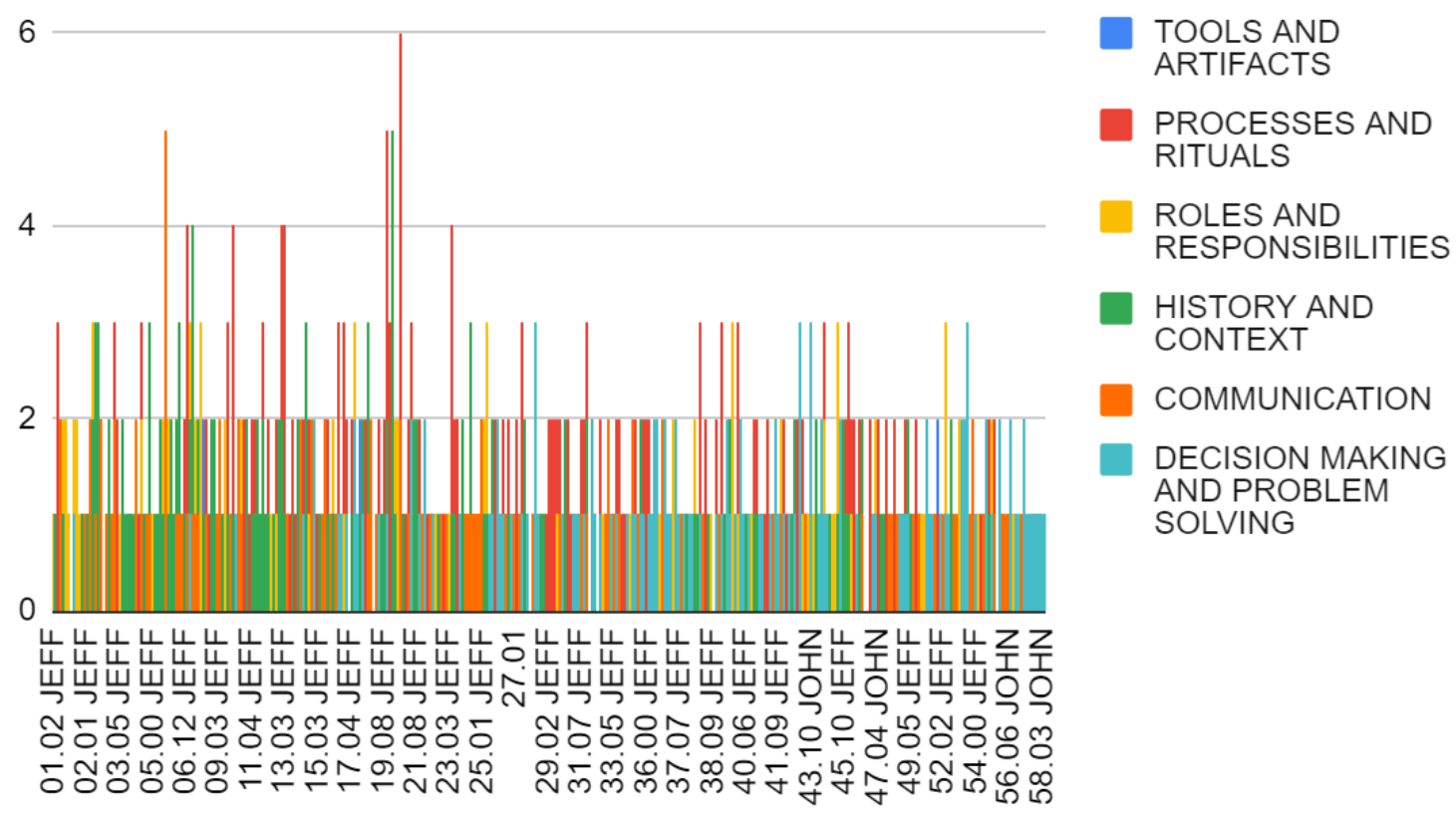

Organizing the codes into these categories was a generative approach that helped me display narrower elements of my learning as well as overarching themes. Table B1 in Appendix $\mathrm{B}$ represents these elements and associated subcategories across the entire knowledge building dimension. 
With respect to RQ3-how did this change over time, it turns out, I did not worry about everything on day one. Different elements were introduced to me over time, and Figure 23 represents how the trajectory of my knowledge growth changed over the first 90 days. In the beginning, it was more about processes and rituals (red) and establishing history and context (green). Later, it became more about decision making and problem solving (e.g., debugging the system issue described in Chapter 4), which is seen in the turquoise color from day 29 and onward.

\section{Cognitive}

With respect to RQ2-how is knowledge constructed, knowledge building was situated in how I processed phenomena around me. Two things became apparent here: 1) the internal structures used here (e.g., reflection), and 2) how learning was situated in ordinary work (e.g., in the context of solving a problem). This was congruent with Eraut (2004) assertion that much of workplace learning is deliberate and reactive. The elements of the cognitive dimension are presented in Table B2. Figure 24 represents how the cognitive dimension of my learning changed from day one to 58 . 


\section{Figure 24}

Cognitive dimension for day one to 58

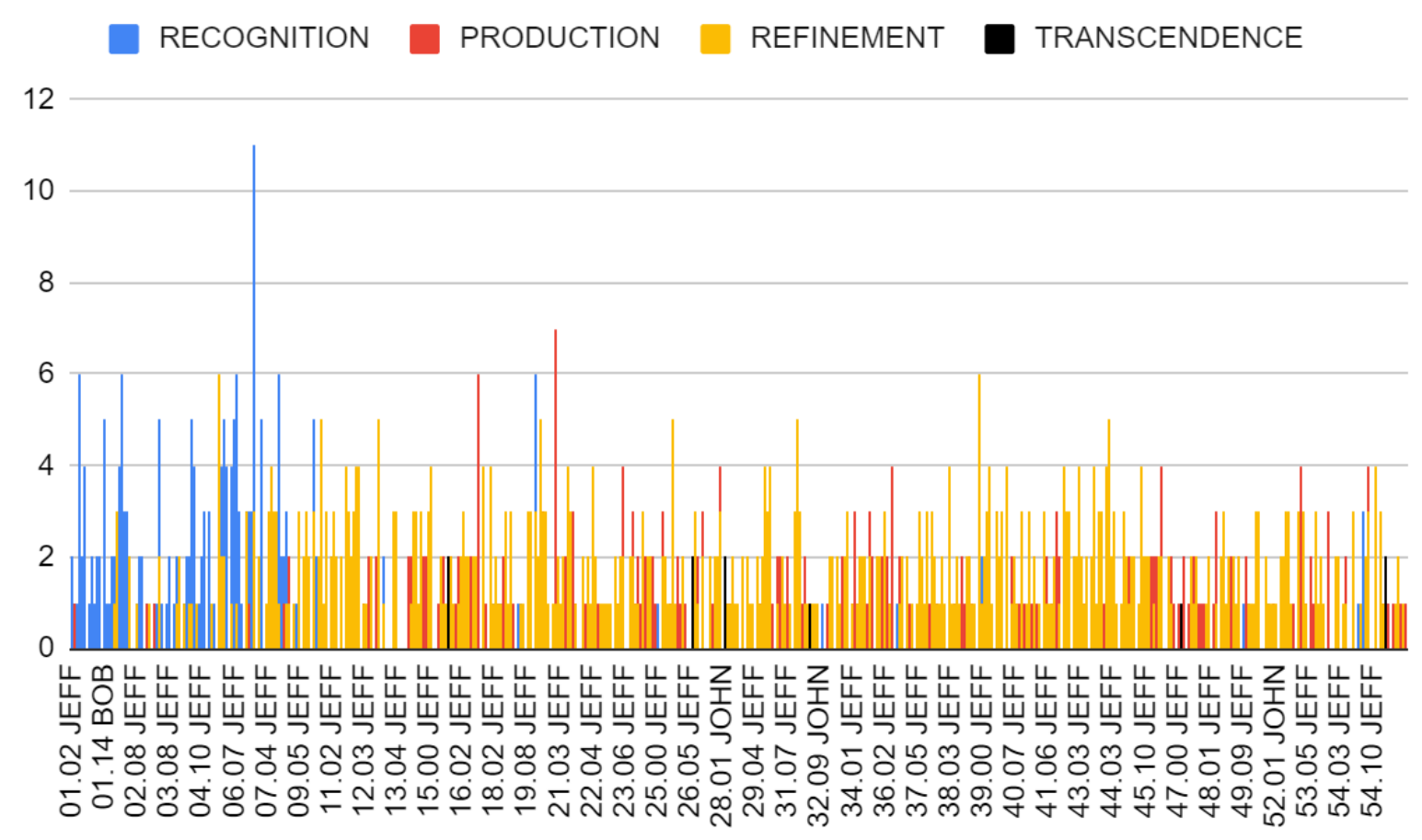

It also turns out, I processed things differently in the early days. Look at the overwhelming blue, for recognition (becoming aware of knowledge), on the left side of Figure 16. Later, more red and yellow appear as production (applying knowledge) and refinement (developing knowledge) begin to emerge. Eventually you see some slivers of black which represent transcendent episodes and my emerging contributions. This figure shows that major contributions (transcendence) were simply absent in the early days, and how the arrival of my first contribution (day 15), changed how I processed things around me. It also changed how I emotionally felt as feelings of uncertainty and anxiety were apparent in my writing. I also started to "find my voice" and settle into my role" after these contributions, feeling more comfortable with my performance to this point and as more contributions emerged towards the middle of the end of the transition periods on days $28,32,47$ and 55. 


\section{Situated}

The analysis shows how situational context mattered. Table B3 and Table B4 in Appendix B represent the range of experiences I engaged with. These situations were exploratory and reflective, occurring during formal training, solving problems with colleagues, away from the workplace, and on my own. I thought about these events after they occurred. I also surveyed many different areas in an effort to get my bearings. This makes sense given what we know about how learning is situated in ordinary routines and processes (Lave Wenger, 1991; Eraut, 2004). We can see how my learning space changed with respect to these situational factors. Figure 18 represents how the characteristics of my learning space transformed over the first 90 days. 


\section{Figure 25}

Situated dimension for day one to 58

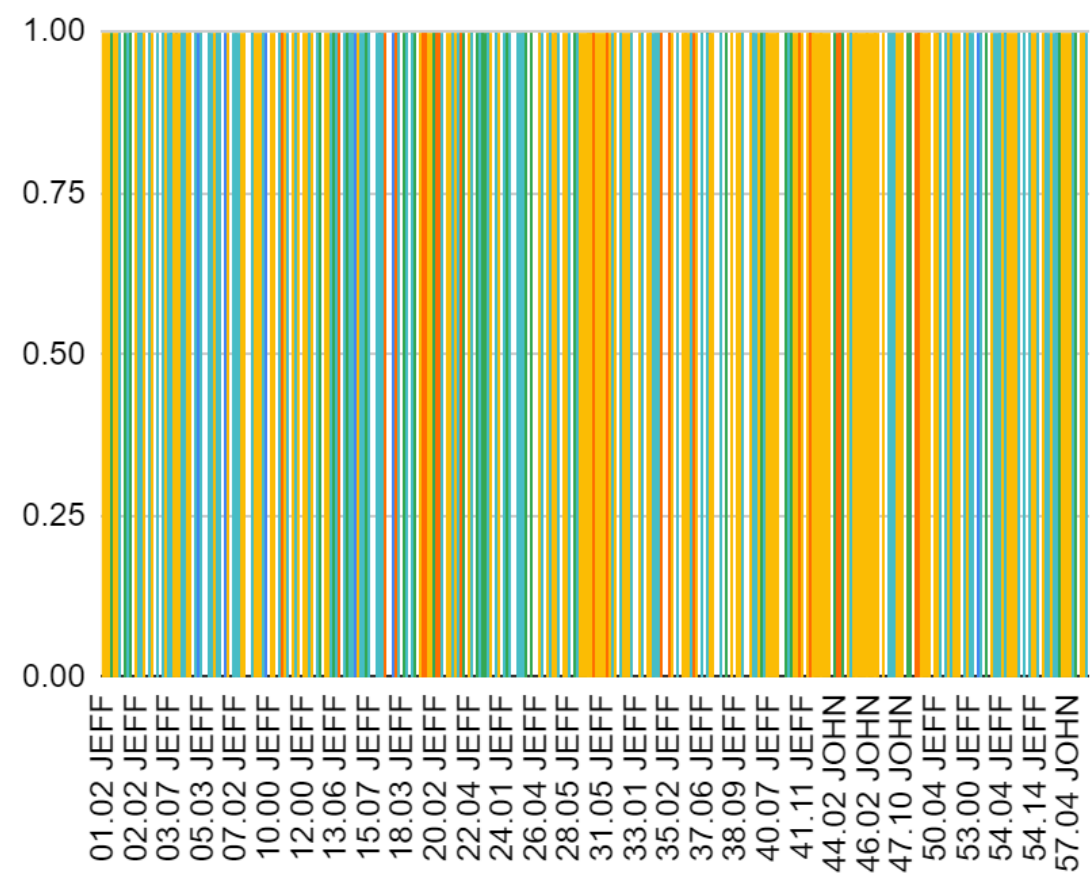

AUTONOMOUS REFLECTION

AUTONOMOUS PROBLEM SOLVING

COLLABORATIVE EXPLORATION

COLLABORATIVE DISCUSSION

COLLABORATIVE PROBLEM SOLVING

AUTONOMOUS EXPLORATION

What is clear in Figure 25 is a healthy combination of experiences in the early part of the transition (e.g., autonomous exploration, autonomous reflection, autonomous problem solving, collaborative exploration, collaborative discussion and collaborative problem solving). Around day 30 , a great deal of yellow surfaces, and we can see the impact of collaborative exploration as it becomes more and more prominent. This, of course, aligns with the contributions I described in Chapter 3, and reinforces how and why my learning space mattered. These contributions perhaps coincided with the emergence of more collaborative and exploratory opportunities. 


\section{Emotional}

Finally, there were emotional factors that affected my learning. Heightened emotions during or after experiences impacted me. For example, I expressed "struggles", "pressure", and "desperation" in my writing. These negative emotions were present during instances when I was struggling to come up to speed and searching for ways to contribute. Consequently, I sought tasks that were more comforting to me, such as rallying around debug sessions and engaging with ad hoc testing measures that I had performed in my prior work. During such scenarios, I expressed "excitement", "comforting", and "gratefulness". These positive emotions emerged during breakthroughs or while receiving positive feedback from colleagues.

These emotional states influenced my learning in both a micro and macro sense. I more narrowly expressed positive and negative feelings during specific experiences (e.g., receiving my workstation). But, in a macro sense, I felt literal shifts during the transition. Around day 15, I thought I was making significant strides with coming up to speed, or as Ahern (2002) put it, as if I was traversing distinctly different learned states. For example, after my first major contribution during 15.04, I was more active in meetings and debriefs with clients. I felt more comfortable with these exchanges and expressed how I was "finding my voice."

The last two months were occupied with a range of positive and negative emotions, some of which were brought on by my early contributions and increasing refinement within my learning space. Noticing dysfunction led me to cast my experiences in a negative light. For example, thinking about how others perceived my work mattered, and I expressed desires to contribute when I felt uncertain about my worth. Conversely, I expressed happiness when I felt like I was starting to become a productive member. Figure 26 represents how the emotional aspects of my learning changed over the first 90 days. 


\section{Figure 26}

Emotional dimension for day one to 58

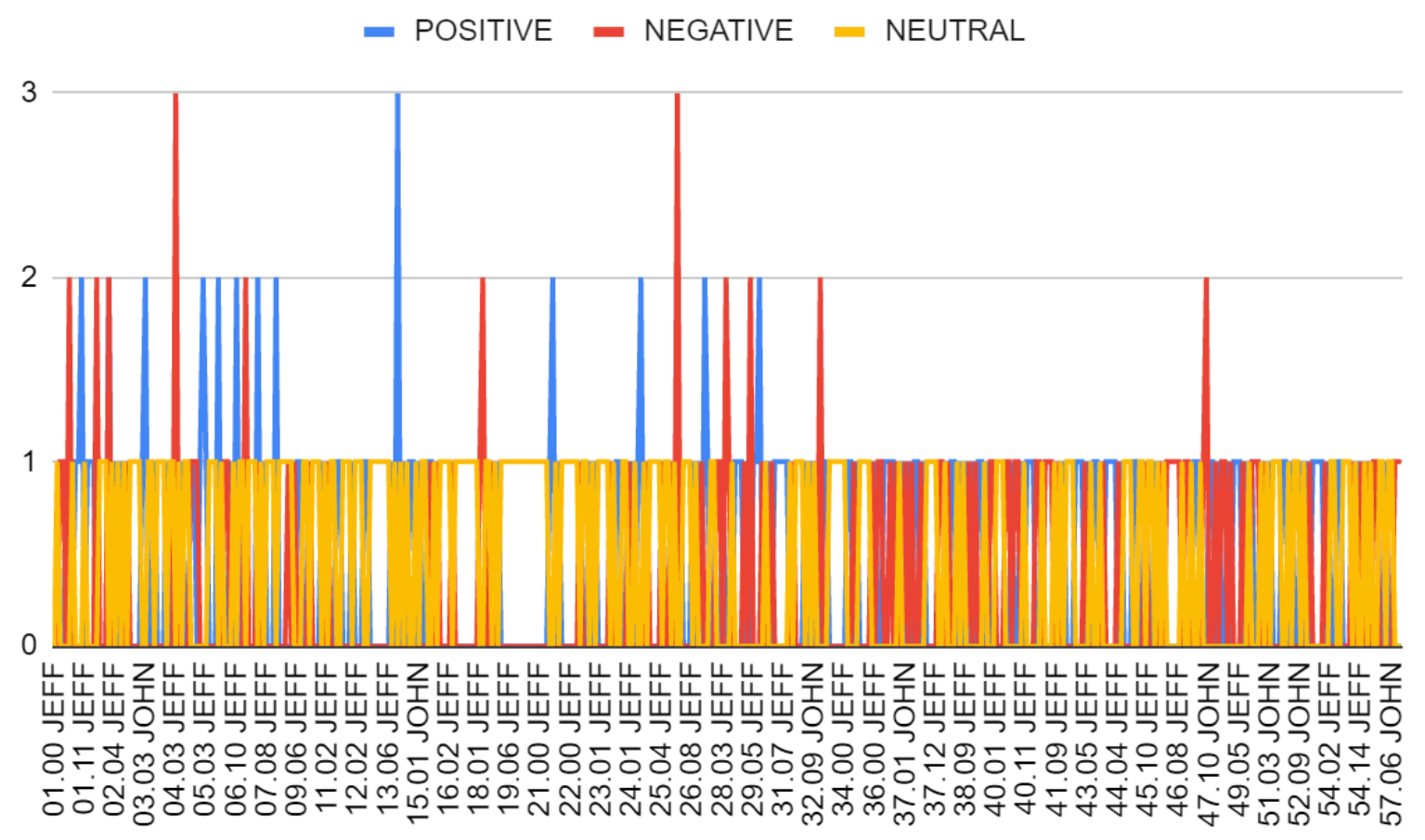

\section{Transcendence}

I thought about how my knowledge growth changed alongside emerging breakthroughs and contributions. Table 6 describes the notion of transcendence with respect to creating original thoughts and ideas. As previously discussed, I took this into consideration in my analysis. 


\section{Table 6}

Code and description of Transcendence, a part of the Cognitive dimension

\begin{tabular}{ll}
\hline CODE & DESCRIPTION \\
\hline TRANSCENDENCE & $\begin{array}{l}\text { (novel contributions and thinking) Exceeding boundaries of existing } \\
\text { schemata, applying knowledge in a novel way }\end{array}$ \\
\hline
\end{tabular}

Recognizing, refining, and applying knowledge was critical towards arriving at these moments whereas a trajectory of different experiences led me to transcendence. My emotions were also heightened during or after these breakthroughs. I described feelings of pressure to contribute knowing that innovation mattered to both my team and my organization. My boss and I openly talked about creating new models and processes. He asked me to think about "gaps" in the project, some of which ended up being a part of my early contributions (e.g., a new support model he felt we needed). In achieving these goals, I felt happy and satisfied viewing their arrival as real signs of progress and especially as team members showed their appreciation for my creative thinking.

With this in mind, I identified all seven instances where transcendence appeared. Of 474 distinct experiences, seven experiences were coded with transcendence (T1 - T7). This also made me question what happened leading up to these moments, and thus ignited my interest about the trajectories that led towards such innovation. I wanted to know more about the characteristics of my experiences that preceded these moments. Therefore, I gathered these ranges and inputted them into the storyboard export instrument for analysis across each of the dimensions. Appendix F contains the entire result set (trajectories) for T1 to T7. 


\section{Characteristics of Transcendent Episodes}

In analyzing each transcendent episode, I summarized the shared characteristics of these experiences. The experiences leading up to transcendence had the following characteristics:

- Multiple collaborative and autonomous experiences leading up to the contribution.

- Three or more knowledge categories involved, and in some cases, all six knowledge categories.

- At least some prior knowledge was applied from previous work, for example, 01.00-tools and artifacts-Postman, processes and rituals-search strategy; 03.00- process-search strategy, 04.00-processes and rituals, 06.00-tools and artifacts-spreadsheet.

- All occurred within the processes of work and some trajectories contained external moments $(26.08,54.11)$.

- Emerging recognition, refinement, production [cognitive dimension] leading up to the contribution.

- Realization or awareness of the contribution during or after.

What do these characteristics tell us? Well, they were not entirely linear. I expected a developmental trajectory, such as phase 1, 2, and 3, but instead found cycles of learning (e.g., refinement, recognition) that were overlapping and iterative. I thought about Ahern's (2002) model in Figure 3 and wondered how the design of my learning space was leading me towards major breakthroughs. Ahern's (2002) model re-framed my thinking regarding what phases or states of learning could look like. I considered each phase of knowledge growth alongside how I felt, when these contributions emerged, and characteristics of the learning space. I tagged these with overarching categorizations, bringing all the levels of my analysis together into a single place to output "states" of my learning. 


\section{States of Learning}

The emergence of a novel contribution signified the arrival of a new learned state. With respect to RQ3, I thought about how my learning changed as there were certain days, I felt a literal shift in my thinking. I also expressed emotions such as excitement and anxiety in my writing. During 06.01 and 11.12 I thought about "How I might contribute in my role," and then during the breakthroughs in 15.02, 21.00 and 23.03, I felt like "I am starting to contribute". These emotions were clear and obvious signs that I was moving forward into a new learned state. I wanted to conceptualize these distinct "learned states" using Ahern's (2002) framework, and when I applied this lens towards my data, here were the results. Table 7 summarizes the shared characteristics of my learning space, including aspects of knowledge growth and the emergence of transcendent episodes. 
Table 7

Summary of WIT Learning Space and Knowledge Building

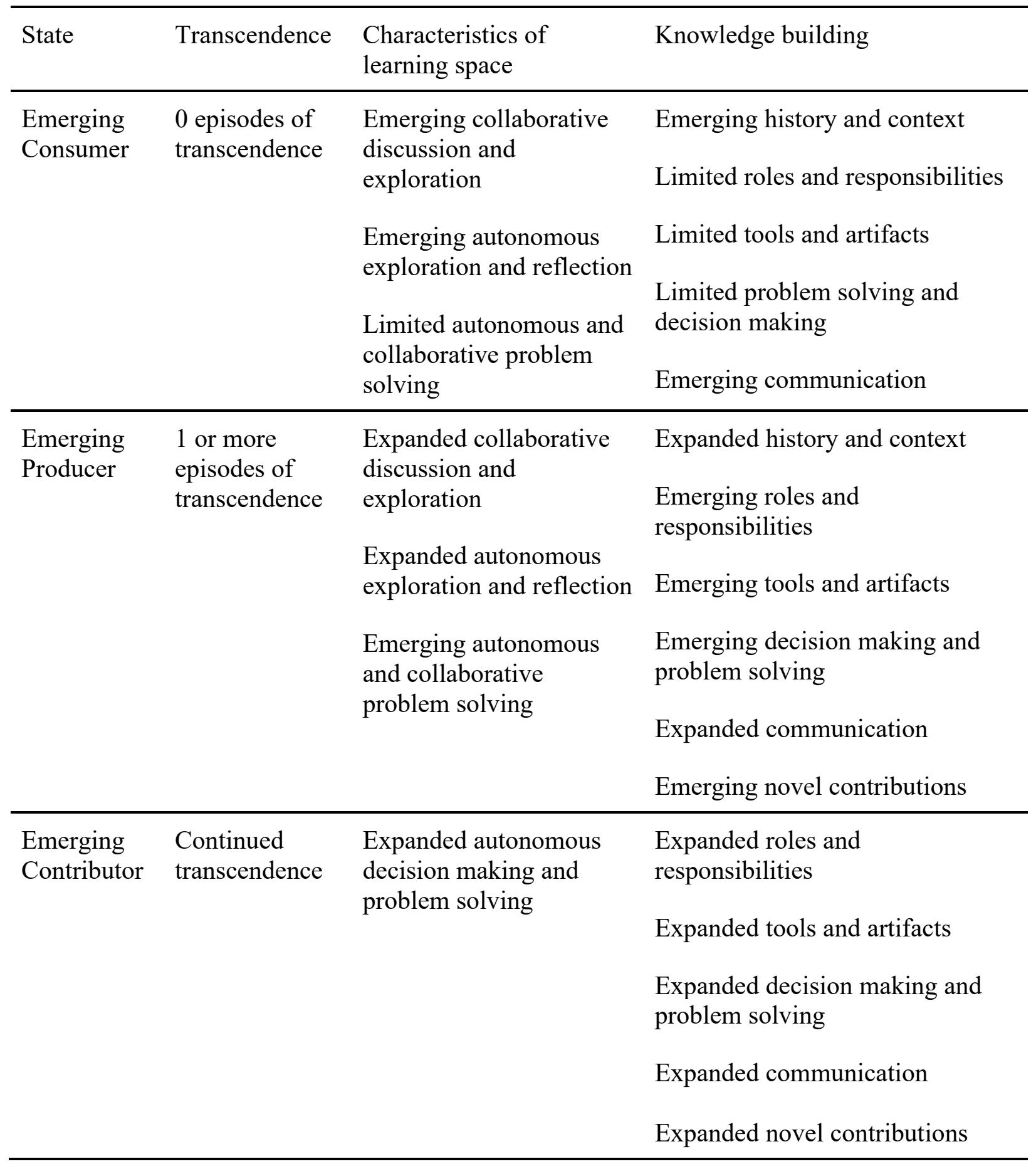




\section{Implications}

It is important to revisit the broader social and economic context surrounding this study. The landscape of the workplace has changed, and along with it, the ways in which people are learning and can learn. Workers are operating within spaces where ordinary routines are being reconfigured to meet the demands of shifting economic and social norms. The COVID-19 pandemic has caused thousands of organizations to rethink work across a range of different occupations, and such decisions will have far reaching consequences towards onboarding and supporting workplace learning as we move forward.

We are no longer primarily operating within spaces of reproduction, but rather, in spaces of construction and production. Therefore, organizations are increasingly valuing our novel ideas, approaches, and contributions. The results show how my own colleagues shared words of affirmation and encouragement, and valued my early contributions, as I continued to construct more meaningful and novel thoughts and ideas. Therefore, organizations have come to expect more creative thinking and insight, challenging us to innovate and expand the boundaries of our existing knowledge. We should think about ourselves as architects instead of as factory workers or builders. This is not to discount prescribed and prearranged job requirements, but rather, to call attention to how the processes of today may change tomorrow, and as a result of shifting work skills, requirements, and technologies in our workspaces. Institutions such as Columbia are seeking refreshing and improved models that transcend the ones of the recent past, and some of my most significant contributions in the early weeks were theoretical models and prospective strategies for how to support and better manage the student system (e.g., the deletion process). Although we should continue valuing existing knowledge, such as the subjects that I learned prior to joining Columbia, we should also be promoting and encouraging wider application of 
knowledge between the old and new spaces. Wider application of knowledge will help new workers address and solve emerging problems and issues in these new spaces. As we continue to shift between different lines of work (Gee, 2005), it is imperative that we promote the flexible application and transfer of knowledge across a range of different settings and disciplines.

In the following sections, I conclude by raising considerations for the design of WIT learning spaces, including the use of reflective writing as both a methodological instrument and pedagogical tool to supplement the onboarding process. I also raise the theoretical implications of the results here by summarizing how my experiences help conceptualize the learning process to a greater extent.

\section{Practical Implications.}

In Chapter 4, I discussed my knowledge growth alongside the notion of constructing novel contributions (i.e., transcendence). I raised the notable inflection points that occurred during the first 90 days and conceptualized these moments alongside learned states, extending Ahern's (2002) model. Transcendence is an important part of the learning process and perhaps the pinnacle of WIT learning. Hence, I will discuss how the results here can be extended into design considerations for WIT learning.

\section{Design of WIT Learning Spaces.}

We should be paying closer attention to the ways in which workers arrive at making novel contributions as facilitating these same types of experiences is how we can better support WIT learning. Organizations are increasingly valuing innovative thoughts and ideas. Therefore, we can take the shared characteristics of my learning experiences, and specifically the ones that 
led me towards creating novel thoughts and ideas, and extend these results into formal design recommendations for WIT learning spaces.

Designers should promote a range of collaborative and autonomous episodes during the first 90 days. As discussed in Chapter 4, some of the most meaningful learning occurred when I had a chance to partake in a collaborative exercise and then digest what happened in another moment of reflection or exploration. These joint experiences were critical in that they allowed me to both notice the processes of work, understand what was expected, and then refine my understanding within new contexts (e.g., watching John create tickets, reviewing tickets, and then creating tickets on my own). This is congruent with situated learning theory (Lave \& Wenger, 1991) with respect to how my learning was situated in ordinary routines.

Designers should facilitate opportunities that engage workers across many different knowledge categories (e.g., tools, processes, decision making, etc.). In other words, we should be diversifying content and subject matter throughout the first several weeks and should refrain from consolidating and narrowing focus. It became clear that external and secondary opportunities helped me settle into my role (i.e., opportunities outside of my direct area of responsibility). These moments expanded knowledge growth and allowed me to understand the roles and responsibilities of other units across CUIT.

Designers should elongate shadowing and mentoring assignments as these experiences supported my decision making and problem solving, especially during the final 30 days, and only after I had already developed a foundational awareness about the setting (e.g., history and context, processes and rituals). Consider the influence of John during days 30-58. His scaffolding and nudging me in the right direction when he interjected about who should be involved with certain tasks. Contrary to what Grow's (1991) model suggests, designers should 
be elongating mentoring assignments even well after learners have started to become selfsufficient in their own learning. Becoming self-sufficient is not a sign that mentorship and shadowing assignments are no longer needed. Rather, this is a sign that learners are ready to expand understanding about more complex and ill-structured decision making. Extending apprenticeships during later stages can help support workers to this end. John scaffolded my decision making and made me feel more comfortable with acting during the final 30 days.

Designers should encourage learners to think about processes, rituals, tools, artifacts, and problem-solving strategies from previous lines of work. On several occasions, I reached deep into my toolkit to leverage such items from the past. In fact, many of my major contributions organized around at least some prior knowledge from my previous roles. The results in Chapter 4 demonstrate how I gravitated towards areas that were comfortable and familiar. Perhaps, we should be encouraging workers to organize more around these familiar areas in the early stages, as doing so promotes more positive feelings and early contributions.

Designers should promote external opportunities such as the working lunch and officewide social gatherings. As I started to settle into my role, these moments supplemented days that became longer and more rigorous. I made more use of external and informal opportunities to come up to speed. The train ride home became an important space for reflection and review. The working lunch and informal social gatherings were useful towards rehearsing with colleagues, consuming terminology and concepts, and establishing further history and context which may have escaped more formalized and planned meetings.

Finally, designers should strongly encourage the use of reflective instruments, such as learning journals. These promote greater awareness about our emotions, contributions, and challenges. My reflections were critical in unearthing meaningful breakthroughs and 
contributions, and if not for actively reflecting on these they may have been lost in the many details of the transition. Reflective writing not only served as an evaluation tool, but also as a pedagogical one. It was so impactful that I touch on more affordances of reflective writing in the following section.

\section{The Affordances of Reflective Writing.}

The results here raised several possibilities for how reflective writing can be used to support workplace learning, as well as the design of onboarding programs. As Lutz (2017) suggested, we must consider how reflective writing can offer a rich descriptive summary of the transition process. Autoethnography is a powerful approach for illuminating the real and unfiltered experiences of workers. Most of my meaningful learning experiences emerged from day-to-day, ordinary routines (Eraut, 2004). This piece builds on these assumptions as well as Lutz's (2017) assertion to incorporate reflective writing into qualitative inquiries. Moving forward, designers should consider executing something similar as reflective writing can be used to support the assessment and evaluation process. Participant writing can also be used to redesign the onboarding process. I encourage the adoption of reflective writing instruments, and at minimum, notes, jottings or high-level summaries. Such writing disseminates perceptions about the transition process and sheds light on informal and tacit worker experiences.

More sources should be leveraged around such writing. Stakeholders should acquire access to calendar entries and communication channels (e.g., Slack). These same sources create a multi-dimensional representation of the same learning experiences. Only by reviewing calendar entries, messages and documents, was I able to correct inconsistencies in my writing, and examine the diverging perspectives that emerged from my experiences. Combining these sources in more settings and contexts will help us better understand how workers operate across 
different fields and disciplines. My journal entries also became a useful resource for sharing feedback with human resource stakeholders, as I called upon my entries to report details during the 30,60, and 90-day check-ins. To this end, the descriptive nature of autoethnography can be used more to survey workplace learning and examine workers' experiences across the social sciences (Laslett, 1999). Organizations should be promoting workers to engage with more reflective writing during workplace transitions.

Lastly, the affordances of reflective writing are not exclusive to designers and program developers. I also benefited from the recursive process of engaging, reflecting, and applying new understandings. Reflective writing supported my recognition and refinement in each of the knowledge categories. Writing supported my reflection-in-action (Schon, 1987) and made me become aware of why my colleagues were behaving in certain ways (Polkinghorne, 1988). Therefore, the affordances of reflective writing extended well beyond assessment and evaluation, and such writing should be used to promote active recognition and refinement.

\section{Theoretical Implications}

\section{Conceptualizing the Learning Process.}

My analysis raised the core knowledge categories constructed, the cognitive processes used to learn, the situational context around learning, and the emotional nature of the transition experience.

Because of this, a new theoretical construct was generated to explain how each of these dimensions interacted. I transcended boundaries of existing knowledge in the first several weeks. Transcendence shows how my learning changed with respect to knowledge growth, and 
how I came to feel more comfortable and proficient in my role from an emotional perspective. Transcendent episodes were aligned with actual shifts in knowledge growth (see dimensions of learning early in this chapter). They were also aligned with emotional changes in my writing, and especially as more positive collaborative experiences emerged in the final 30 days.

I built on Rumelhart and Ortony's (1977) interpretation of schema theory to better understand the narrower knowledge schemas that were constructed. Coding these schemas helped me identify and categorize my learning more generally into six distinct categories. These overarching categorizations are both representative of the types of knowledge that workers need to possess in a similar information technology role, and perhaps are also generalizable across other disciplines. This schema-theory driven approach can be applied in other contexts, and it seems reasonable to suggest that other workers develop comparable core and abstract schemes within these same areas (e.g., tools, artifacts, processes, rituals, roles, responsibilities, history, context, communication, decision making, and problem solving). Therefore, the schemes presented here are a useful starting point for introducing a formal taxonomy of WIT learning. They may be generalizable to other settings, and therefore, these categories are representative of the broader knowledge schemas that workers construct while transitioning.

I applied cognitive and situated constructs of learning to account for how knowledge building occurred through recognizing, refining, and applying what I learned. Analyzing my own experiences unearthed more contemporary examples of informal and external learning in the workplace. This is a notable implication considering that most prior research has failed to raise narrower personal details about informal transitional learning in the workplace. The results in Chapter 4 provide more refreshing and recent examples of informal learning scenarios, and in 
turn, fill gaps in previous research that has described off-the-job, unstructured, and active experiences (Jacobs and Park, 2009).

\section{States of WIT Learning}

Finally, transcendence was a focal point that spoke to how my learning changed throughout the transition. I engaged with trajectories of experiences that lead me towards emergent contributions (T1 - T7). It also represented how I felt about coming up to speed and finding my voice. Therefore, Transcendence offers a way to conceptualize the entire learning process by establishing boundaries between when a given "learned state" (Ahern, 2002, p. 2) ends and another begins. This is important as progress while transitioning may be ambiguous depending on the role. This may especially be the case when moving into a role that lacks clarity in the job description (Olson, 2015). We should consider how emerging contributions better articulate when and how a worker is making real progress with their learning. Perhaps then, there are distinct "states" that we must traverse. The emergence of transcendent episodes helped to identify these inflection points which took into consideration how I molded myself around the role just as much as the role molded itself around me. My early contributions were organized around feelings of comfort and satisfaction. Later, more feelings of anxiety and uncertainty surfaced, signifying the arrival at a new learned state. Perhaps, then, we should rethink how traditional transition milestones are framed as conventional wisdom suggests that the transition period lasts approximately 90 days in most cases. I disagree with these milestones as surely this will vary from setting to setting. Thus, the states of learning, grounded in emerging breakthroughs and thinking, offer a new way to conceptualize, and perhaps even quantify, the critical milestones that are a part of the transition period. Notable inflection points are not restricted by the boundaries of time or space, and given that transition experiences may differ by 
the individual, setting, and occupation, we should consider reframing the traditional 30, 60, 90day check in.

\section{Limitations}

While this study may provide a rich descriptive summary of my learning experiences, it could be enhanced further. It would be helpful to have access to the tools and artifacts of my mentor, John. His calendar entries and Slack messages may have shed light on some of the details that escaped my early writing. Context was absent in early days when I was attending meetings that were exclusively on his calendar.

Conversely, some experiences were not explicitly mentioned in my writing, but were made available in other sources, such as calendar entries or messages with John. Reviewing messages about one experience led me to discover another experience that had escaped writing during day 14. This lack of writing in some cases hindered my capacity to view the same experiences from multiple perspectives. Because of this, I had to refrain from coding select, incomplete entries.

Finally, as the participant-research I had complete control over what was captured and included in my writings, and because of this, some important perspectives from the field may have been lost, misconstrued or exaggerated. Of course, with any empirical design there are tradeoffs. Critics of autoethnographies will cite the "overreliance on the potential of a personal writing style to evoke direct emotional responses in readers but offer no deeper levels of reflection or analytic scholarship" (Duncan, p. 36, 2004). While some entries may not have offered substantial findings, emotion was undeniably a valuable piece for unearthing the turning points of my transition. There were literal shifts in my thinking and these emotions made such shifts palpable as I traveled through different states of mind in route to making more meaningful 
contributions, and eventually settling into my role. To some extent, I aimed to objectively study my own learning process. Yet, personal emotions and feelings were a critical piece to understanding how my knowledge developed, how learning changed, and how I was making progress, especially with respect to novel contributions. Perhaps, there is no way to disentangle thoughts and emotions from the writing process, or when thinking about transitional scenarios more generally, as transitions are simply a cognitive and emotional experience.

\section{Opportunities for Future Research}

There are several opportunities for future research and more questions to be considered. What were the actual tools, systems, and artifacts that supported me? While some of these were exposed and directly referenced in my writing, not all resources, documents, and artifacts were uncovered. Olson (2015) made a deliberate attempt to gather these from her participants, and moving forward, we should continue working to obtain such work tools, processes, and artifacts. Curating these will help us better understand how workers use these to learn and how they support the transition process.

I agree with Lutz (2017) endorsement of reflective writing, insofar that it can be leveraged to study real-world transition experiences. Autoethnography is a viable methodological approach for executing inquiries related to transitions. The study demonstrates the affordances of this approach as a viable strategy for illuminating the contextual and emotional details of workplace transitions. Leveraging multiple sources, such as calendar entries, documents, Slack messages, and other mediums, captured the total range of my experiences. Researchers should combine as many sources as possible in future studies as reflexive writing did not exclusively capture all the diverse exchanges from my experiences, and 
if not for these other sources, certain critical perspectives from the field may have escaped the study.

How did external experiences, outside of the processes of work, support learning? I found that external experiences were a part of my story. Such experiences refined history and context during social gatherings, and during reflective episodes on the bus ride home where I thought about what was learned each day. Future studies could perhaps leverage the codebook and dimensions of learning here to further analyze the transition scene with special attention to these external moments. These external opportunities will perhaps become more important as remote-based work opportunities continue to emerge, and as the workplace becomes more distributed. In this new world of remote work, we must better understand how knowledge building is promoted away from the workplace. Workers are becoming increasingly dependent on self-directed tools and resources, and therefore, organizations must adjust to this shifting landscape of work that is bringing workers farther away from the organization's brick and mortar.

Lastly, how can autoethnography be used to better understand the transition experiences of other workers? The results unearthed many of the informal and external episodes that supported me. This is an important consideration given how each profession may have its own unique combination of external phenomena and variables within the learning space. Thus, we must consider how the process of becoming a teacher may differ from that of an engineer. And we should continue to delve deeper into more workers' experiences and drive towards a more comprehensive understanding of the transition process, and with respect to how it may differ across different fields and sectors. This study builds on inquiries from Lutz (2017) and Dethloff (2007) to recount the experiences of one information technology director. Certainly, more 
ethnographic and autoethnographic works can help us explore the untold experiences of other educators, engineers, administrators, and professionals. The study offers a guiding framework for how to potentially execute future studies of this kind across other organizations. Qualitative methods help us generate new variants and can expand the dimensions raised here. Therefore, I offer my instruments in Appendices B to E so that they can be applied in future research. These instruments include the codebook for my analysis, snippets from the storyboard document, the storyboard script, and the storyboard export. Moving forward, I strongly encourage the use of these instruments. 


\section{References}

Ahern, T. C. (2002). Learning by design: Engineering the learned state. In N. Callaos \& W. Lesso (Eds.), 6th World Multiconference in Systemics, Cybernetics and Informatics, (pp. 308-313). Orlando, FL: International Institute of Information and Systemics.

Abu-Arja, S. L. (2018). An Exploration of Leaders' Experience with the Informal Learning Process during Role Transition at a K-12 Private, Non-profit, Co-educational, Bilingual School in Jordan [Doctoral dissertation, Northeastern University]. ProQuest Dissertations Publishing.

Ashley, C., Brown, A., Halcomb, E., \& Peters, K. (2018). Registered nurses transitioning from acute care to primary healthcare employment: A qualitative insight into nurses' experiences. Journal of clinical nursing, 27(3-4), 661-668. doi:10.1111/jocn.13984

Boud, D., \& Garrick, J. (1999). Understanding learning at work. London \& New York: Routledge

Bowles, C., \& Candela, L. (2005). First job experiences of recent RN graduates: improving the work environment. JONA: The Journal of Nursing Administration, 35(3), 130-137. doi:10.1097/00005110-200503000-00006

Bureau of Labor Statistics (2019). Number Of Jobs, Labor Market Experience, and Earnings Growth: Results From a National Longitudinal Survey. U.S. Department of Labor. Retrieved from https://www.bls.gov/news.release/pdf/nlsoy.pdf

Bureau of Labor Statistics (2020a). Employee Tenure in 2020. U.S. Department of Labor. Retrieved from https://www.bls.gov/news.release/pdf/tenure.pdf 
Bureau of Labor Statistics (2020b). Americans At Age 33: Labor Market Activity, Education and Partner Status Summary. Department of Labor. Retrieved from https://www.bls.gov/news.release/nlsyth.nr0.htm

Bureau of Labor Statistics (2020c). Job Openings and Labor Turnover - March 2020. U.S. Department of Labor. Retrieved from https://www.bls.gov/news.release/archives/jolts_05152020.pdf

Clark, M. C., \& Rossiter, M. (2008). Narrative learning in adulthood. New Directions for Adult \& Continuing Education, 2008(119), 61-70. doi:10.1002/ace.306

Crotty, M. (1998). The Foundations of Social Research: Meaning and Perspective in the Research Process. London: Sage Publications.

Duncan, M. (2004). Autoethnography: Critical appreciation of an emerging art. International Journal of Qualitative Methods, 3(4), 28-39. doi:10.1177/160940690400300403

Dethloff, C. H. (2007). A principal in transition: An autoethnography [Doctoral dissertation, Texas A\&M]

Elder Jr, G. H. (2003). The life course in time and place. In W. R. Heinz and V.W. Marshall (Ed.), Social dynamics of the life course: Transitions, institutions, and interrelations (pp. 57-71). New York, NY: Aldine De Gruyter

Ellis, C. (2009). Revision: Autoethnographic reflections on life and work. Walnut Creek, CA: Left Coast Press, Inc.

Ellis, C., \& Bochner, A. (2000). Autoethnography, Personal Narrative, Reflexivity: Researcher as Subject. In N. K. Denzin \& Y.S. Lincoln (Eds.), Handbook of Qualitative Research (2nd ed., pp. 733-769). Thousand Oaks, CA: Sage Publications. 
Emerson, R. M., Fretz, R. I., \& Shaw, L. L. (2011). Writing ethnographic fieldnotes. Chicago, IL: The University of Chicago Press.

Eraut, M. (2004). Informal learning in the workplace. Studies in Continuing Education, 26(2), 247-273. doi:10.1080/158037042000225245

Erikson, E. H. (1980). Identity and the life cycle. New York, NY: W. W. Norton \& Company.

Evetts, J. (2009), "New professionalism and new public management: changes, continuities and consequences”, Comparative Sociology, Vol. 8, pp. 247-266.

Evetts, J. (2011). Sociological Analysis of Professionalism: Past, Present and Future. Comparative Sociology, 10(1), 1-37. doi:10.1163/156913310X522633

Fenwick, T. (2013). Understanding transitions in professional practice and learning. Journal of Workplace Learning. 25(6), 352-367. doi:10.1108/JWL-06-2012-0047

Galanek, J.D., Gierdowski, D.C., and Brooks, D.C. (2019). The Higher Education IT Workforce Landscape, 2019. Research report. Louisville, CO: ECAR. Retrieved from https://library.educause.edu//media/files/library/2019/2/ers1901.pdf?la=en\&hash=F4BFE55F57F22CBFFBF9D19145 27B447C6E600C2

Gallup, Inc. (2017). State of the American Workplace. Retrieved from https://www.gallup.com/workplace/238085/state-american-workplace-report-2017.aspx Gee, J. P. (2006). Self-Fashioning and Shape-Shifting: Language, Identity, and Social Class. In D. E. Alvermann, K. A. Hinchman, D. W. Moore, S. F. Phelps, \& D. R. Waff (Eds.), Reconceptualizing the Literacies in Adolescents' Lives (2nd ed., pp. 165-185). Mahwah, NJ: Lawrence Erlbaum.

Glaser, B. G., \& Strauss, A. L. (1971). Status Passage. London: Routledge \& Kegan Paul. 
Govaerts, N., Kyndt, E., Dochy, F., \& Baert, H. (2011). Influence of learning and working climate on the retention of talented employees. Journal of Workplace Learning, 23(1), 35-55. doi:10.1108/13665621111097245

Grow, G. O. (1991). Teaching learners to be self-directed. Adult Education Quarterly, 41(3), 125-149. doi:10.1177/0001848191041003001

Vergara, R.A. (2014, February). Providing the Apple Experience: Enhancing organizational performance through employee engagement and empowerment. 8th Global Business Conference.

https://scholar.google.com/scholar?oi=bibs\&cluster=1256654250365567971\&btnI=1\&hl $=\mathrm{vi}$

Hager, P. (2004). Conceptions of learning and understanding learning at work. Studies in Continuing Education, 26(1), 3-17. doi:10.1080/158037042000199434

Hillman, L., \& Foster, R. R. (2011). The impact of a nursing transitions programme on retention and cost savings. Journal of Nursing Management, 19(1), 50-56. doi:10.1111/j.13652834.2010.01187.x

Hill, L. A., \& Sawatzky, J. A. V. (2011). Transitioning into the nurse practitioner role through mentorship. Journal of Professional Nursing, 27(3), 161-167. doi:10.1016/j.profnurs.2011.02.004

Ten Hoeve, Y., Kunnen, S., Brouwer, J., \& Roodbol, P. F. (2018). The voice of nurses: Novice nurses' first experiences in a clinical setting. A longitudinal diary study. Journal of clinical nursing, 27(7-8), e1612-e1626. doi: 10.1111/jocn.14307 
Jacobs, R. L., \& Park, Y. (2009). A proposed conceptual framework of workplace learning: Implications for theory development and research in human resource development. Human resource development review, (2), 133-150. doi: 10.1177/1534484309334269

Johnson, M., \& Senges, M. (2010). Learning to be a programmer in a complex organization: A case study on practice-based learning during the onboarding process at Google. Journal of Workplace Learning, 22(3), 180-194. doi:10.1108/13665621011028620

Kilminster, S., Zukas, M., Quinton, N., \& Roberts, T. (2010). Learning practice? Exploring the links between transitions and medical performance. Journal of health organization and management. doi: 10.1108/14777261011088656

Tachibana, C., (2020, May 6). The Changing Role of Nursing Expands Even More During Pandemic. Daily Nurse. https://dailynurse.com/the-changing-role-of-nursing-expandseven-more-during-pandemic/

Kolb, D. A. (1984). Experiential Learning: Experience as the Source of Learning and Development. Englewood Cliffs, NJ: Prentice Hall.

Laslett, B (1999). Personal narratives as sociology. Contemporary Sociology, 28(4), 391-401. doi: $10.2307 / 2655287$

Lave, J., \& Wenger, E. (1991). Situated learning: Legitimate peripheral participation. Cambridge university press.

Louis, M. R. (1980). Career transitions: Varieties and commonalities. Academy of Management Review, 5(3), 329-340. doi:10.5465/amr.1980.4288836

Lutz, B. D. (2017). Into the workplace: Exploring the learning experiences of newcomer engineers during the school-to-work transition [Doctoral dissertation, Virginia Tech] 
Marsick, V., Watkins, K., \& O'Connor, B. N. (2011). Researching workplace learning in the United States. In The SAGE Handbook of Workplace Learning (pp. 198-209). Sage Publications. doi:10.4135/9781446200940.n14

Merseth, K. K. (1990). Case studies and teacher education. Teacher Education Quarterly, 17(1), 53-62. doi:10.1080/00131728809335489

Moen, P. (2011). From 'work-family' to the gendered life course' and 'fit': five challenges to the field. Community, Work \& Family, 14(1), 81-96. doi:10.1080/13668803.2010.532661

Muncey, T. (2005). Doing autoethnography. International Journal of Qualitative Methods, 4(1), 69-86. doi:10.1177/160940690500400105

Nicholson, N. (1984). A theory of work role transitions. Administrative Science Quarterly, 29(2), 172-191. doi: $10.2307 / 2393172$

Olson, J. (2015). "No One Really Knows What It Is That I Need": Learning a New Job at a Small Private College. Journal of Continuing Higher Education, 63(3), 141-151. doi:10.1080/07377363.2015.1085947

Pietsch, B. (2020, July 8). What It's Like to Enter the Workforce From Your Childhood Bedroom. The New York Times. http://www.nytimes.com

Polkinghorne, D. E. (1988). Narrative Knowing and the Human Sciences. Albany, NY: SUNY Press.

Progoff, I. (1975). At a Journal Workshop: The Basic Text and Guide for Using the Intensive Journal Process. New York, NY: Dialogue House Library. Rivers, D. L. (2018). A grounded theory of millennials job-hopping. Saldaña, J. (2015). The Coding Manual for Qualitative Researchers. Thousand Oaks, CA: Sage Publications. 
Schlossberg, N. K. (1981). A Model for Analyzing Human Adaptation to Transition. The Counseling Psychologist, 9(2), 2-18. doi:10.1177/001100008100900202

Schön, D. A. (1987). Educating the reflective practitioner: Toward a new design for teaching and learning in the professions. San Francisco, CA: Jossey-Bass.

Schwarts, D. N. (2020, June 21). New Hope for White-Collar Job Seekers? It Depends on the Job. The New York Times. http://www.nytimes.com

Seng, C. V., Zannes, E., \& Pace, R. W. (2002). The contributions of knowledge management to workplace learning. Journal of Workplace Learning, 14(4), 138-147. doi:10.1108/13665620210427267

Shulman, J. (Ed.). (1992). Case Methods in Teacher Education. New York, NY: Teachers College Press.

Sofer, C. (1970). Men in mid-career: A study of British managers and technical specialists. The Economic Journal, 80(320), 975-976. doi:10.2307/2229930

Sparkes, A. C. (2000). Autoethnography and Narratives of self: Reflections on Criteria in Action. Sociology of Sport Journal, 17(1), 21-43. doi:10.1123/ssj.17.1.21

Sweet, S., \& Meiksins, P. (2013). Changing Contours of Work: Jobs and Opportunities in the New Economy (2nd ed.). Los Angeles, CA: Sage Publications.

Smith, M. C., Bohonos, J. W., \& Patterson, M. B. (2020). Call for papers: Adult and continuing education's response to the global Covid-19 pandemic. New Horizons in Adult Education and Human Resource Development, 32(2), 1-3. doi: 10.1002/nha3.20280

Trede, F., \& McEwen, C. (2015). Early workplace learning experiences: what are the pedagogical possibilities beyond retention and employability? Higher Education, 69(1), 19-32. doi:10.1007/s10734-014-9759-4 
Van Maanen, J., Schein, E. (1979). Toward a Theory of Organizational Socialization. In B. M. Staw (Ed.), Research in organizational behavior (pp. 209-264). Greenwich, CT: JAI.

Wall, S. (2008). Easier Said than Done: Writing an Autoethnography. International Journal of Qualitative Methods, 7(1), 38-53. doi:10.1177/160940690800700103

Winfield, C., Melo, K., \& Myrick, F. (2009). Meeting the challenge of new graduate role transition: clinical nurse educators leading the change. Journal for Nurses in Professional Development, 25(2), E7-E13. doi:10.1097/NND.0b013e31819c76a3

Wood, L. N., Psaros, J., French, E., \& Lai, J. W. (2015). Learning experiences for the transition to professional work. Cogent Business \& Management, 2(1), 1-16. doi:10.1080/23311975.2015.1042099 


\section{Appendix A. Consent form}

\section{WestVirginiaUniversity.}

OFFICE OF HUMAN RESEARCH PROTECTION

Principal Investigator (PI) |

Department

WVU IRB Protocol \#

Study Title
Dr. Malayna Bernstein, Ph.D.

Learning Sciences and Human Development

1912833539

Learning and Workers in Transition (WIT)

Why is this research being done and what is involved?

This research examines workplace learning. I am documenting experiences in our workplace that relate to my own learning. You will not be asked to participate in any specific tasks or activities outside of your normal responsibilities; however, in the process of documenting my own experiences through fieldnotes I may occasionally write about an experience that I had with you. I will never use your name or collect any personal information in these fieldnotes.

\section{Do I have to participate and what are the risks?}

Your participation in this research study is completely voluntary and you are free to withdraw from the research at any time. There is no direct benefit for participation in this study. There is no risk for participating. If you choose not the participate, I will never write about you in my fieldnotes.

\section{Will I be compensated for my participation?}

You will not be compensated in any way for participation in this study.

What will happen to my research information and data?

Any information about you that is obtained as a result of your participation in this research will be kept as confidential as legally possible. In any publications that result from this research, neither your name nor any information from which you might be identified will be published without your consent.

\section{Who can I talk to if I have questions or concerns?}

If you have any questions or concerns about this research, you can contact the principal investigator, Dr. Malayna Bernstein at Malayna.Bernstein@mail.wvu.edu from the Dept. of Learning Sciences and Human Development at West Virginia University, or me the co-investigator, Jeffrey Burgazzoli at jburgazz@mix.wvu.edu, jb4456@columbia.edu, or 646-335-3933.

For information regarding your rights as a participant in research or to talk about the research, contact the WVU Office of Human Research Protection (OHRP) at (304) 293-7073 or by email at IRB@mail.wvu.edu. 


\section{Appendix B. Codebook}

Table B1

Knowledge-building Dimension

\begin{tabular}{|c|c|c|}
\hline CATEGORY & CODE & SUB-CODE \\
\hline \multirow[t]{6}{*}{ TOOLS AND ARTIFACTS } & COMMUNICATION & \\
\hline & DOCUMENTATION & \\
\hline & $\begin{array}{l}\text { PLANNING AND } \\
\text { ORGANIZATION }\end{array}$ & \\
\hline & $\begin{array}{l}\text { DESIGN AND } \\
\text { DEVELOPMENT }\end{array}$ & DJANGO ADMIN \\
\hline & & GROUPER \\
\hline & & POSTMAN \\
\hline \multirow{11}{*}{$\begin{array}{l}\text { PROCESSES AND } \\
\text { RITUALS }\end{array}$} & SUBMITTING REQUESTS & ACCESS \\
\hline & MEETINGS & PROJECT PLANNING \\
\hline & & TRAINING \\
\hline & $\begin{array}{l}\text { DESIGN AND } \\
\text { DEVELOPMENT }\end{array}$ & ADMINISTRATION \\
\hline & & $\begin{array}{l}\text { STEPS AND } \\
\text { PROCEDURES }\end{array}$ \\
\hline & REVIEWING TICKETS & \\
\hline & SEARCHING TICKETS & \\
\hline & CREATING TICKETS & \\
\hline & $\begin{array}{l}\text { REVIEWING KNOWLEDGE } \\
\text { PAGES }\end{array}$ & \\
\hline & $\begin{array}{l}\text { USING DEVELOPMENT } \\
\text { TOOLS }\end{array}$ & \\
\hline & INSTALLING & \\
\hline
\end{tabular}


DEVELOPMENT TOOLS

CONFIRMING

REQUIREMENTS

TESTING

DEPLOYING

DEMONSTRATING

\begin{tabular}{ll}
\hline ROLES AND & ORGANIZATION \\
RESPONSIBILITIES & \\
& MY ROLE \\
& PEERS AND TEAM \\
MEMBERS & SUPERVISORS \\
& CLIENTS \\
\hline
\end{tabular}

\begin{tabular}{ll}
\hline HISTORY AND & PROJECT DETAILS \\
CONTEXT & RULES, CUSTOMS AND \\
& NORMS \\
& PROBLEMS AND CASES \\
& TERMS AND CONCEPTS \\
\hline COMMUNICATION & SENDING MESSAGES \\
& REVIEWING MESSAGES \\
& CREATING \\
& DOCUMENTATION \\
& REVIEWING \\
DOCUMENTATION \\
REQUESTING UPDATES \\
PROVIDING UPDATES \\
RECEIVING UPDATES \\
PROVIDING INPUT OR \\
ADVICE
\end{tabular}


SCHEDULING MEETINGS

\begin{tabular}{ll}
\hline DECISION MAKING & IDENTIFYING ISSUES OR \\
AND PROBLEM & PROBLEMS \\
SOLVING & \\
& PRIORITIZING ISSUES OR \\
& PROBLEMS \\
& DECIDING NEXT STEPS \\
& PLANNING AND GOAL \\
& SETTING \\
\hline
\end{tabular}

Note. This is the final version of the knowledge building dimension. Only some "codes" contain sub-codes but the sub-codes can be expanded further. 


\section{Table B2}

Cognitive Dimension

\begin{tabular}{ll}
\hline CODE & DESCRIPTION \\
\hline RECOGNITION & $\begin{array}{l}\text { (cognitive dissonance) Awareness, acknowledgement or noticing of } \\
\text { phenomena }\end{array}$ \\
REFINEMENT & $\begin{array}{l}\text { (developing or refining schemata) Processing or reprocessing of } \\
\text { phenomena }\end{array}$ \\
PRODUCTION & $\begin{array}{l}\text { (applying schemata) Performance or enactment with phenomena } \\
\text { (novel contributions and thinking) Exceeding boundaries of existing } \\
\text { TRANSCENDENCE }\end{array}$ \\
\hline
\end{tabular}




\section{Table B3}

Situated Dimension

\begin{tabular}{|c|c|c|}
\hline CODE & DESCRIPTION & SUB-CODE \\
\hline \multirow[t]{4}{*}{ AUTONOMOUS } & On my own & $\begin{array}{l}\text { EXPLORATION - in the act of } \\
\text { traveling through an unknown area or } \\
\text { space (Oxford Languages, 2021) }\end{array}$ \\
\hline & & $\begin{array}{l}\text { REFLECTION - in the act of thinking } \\
\text { about current / prior experience }\end{array}$ \\
\hline & & $\begin{array}{l}\text { PROBLEM SOLVING - in the act of } \\
\text { solving issues or problems }\end{array}$ \\
\hline & & $\begin{array}{l}\text { DISCUSSION - in the act of } \\
\text { exchanging updates, concerns, } \\
\text { information }\end{array}$ \\
\hline \multirow[t]{4}{*}{ COLLABORATIVE } & With the support of others & EXPLORATION \\
\hline & & REFLECTION \\
\hline & & PROBLEM SOLVING \\
\hline & & DISCUSSION \\
\hline
\end{tabular}


Table B4

Situated Dimension (cont.)

\begin{tabular}{|c|c|c|}
\hline CODE & DESCRIPTION & SUB-CODE \\
\hline FORMAL & $\begin{array}{l}\text { Promoted by the } \\
\text { organization, structured - } \\
\text { "done in accordance with } \\
\text { rules of convention or } \\
\text { etiquette; suitable for or } \\
\text { constituting an official or } \\
\text { important situation or } \\
\text { occasion" (Oxford } \\
\text { Languages, 2021) }\end{array}$ & FORMAL \\
\hline \multirow[t]{2}{*}{ INFORMAL } & $\begin{array}{l}\text { Within the processes of } \\
\text { work, unstructured }\end{array}$ & IN SITU \\
\hline & $\begin{array}{l}\text { Outside of the processes of } \\
\text { work, unstructured - "having } \\
\text { a relaxed, friendly, or } \\
\text { unofficial style, manner, or } \\
\text { nature." (Oxford Languages, } \\
\text { 2021) }\end{array}$ & EXTERNAL \\
\hline
\end{tabular}


Table B5

Emotional Dimension

\begin{tabular}{|c|c|c|}
\hline CODE & DESCRIPTION & SUB-CODE \\
\hline POSITIVE & $\begin{array}{l}\text { "Pleasant or desirable } \\
\text { situational responses, ranging } \\
\text { from interest and } \\
\text { contentment to love and joy, } \\
\text { but are distinct from } \\
\text { pleasurable sensation and } \\
\text { undifferentiated positive } \\
\text { affect" (Oxford Languages, } \\
2021 \text { ) }\end{array}$ & $\begin{array}{l}\text { FRIENDLY } \\
\text { CHEERFUL } \\
\text { LAUGH } \\
\text { SMILES } \\
\text { HAPPY } \\
\text { COMFORTING } \\
\text { WELCOME } \\
\text { INTRIGUED } \\
\text { APPRECIATION } \\
\text { GRATEFUL } \\
\text { HUMOR } \\
\text { EXCITED } \\
\text { ENTHUSIASM } \\
\text { PLEASANT } \\
\text { POSITIVE FEEDBACK } \\
\text { BUILDING TRUST }\end{array}$ \\
\hline \multicolumn{3}{|l|}{ NEUTRAL } \\
\hline NEGATIVE & $\begin{array}{l}\text { "Any feeling which causes } \\
\text { you to be miserable and sad. } \\
\text { These emotions make you } \\
\text { dislike yourself and others, } \\
\text { and reduce your confidence } \\
\text { and self-esteem, and general } \\
\text { life satisfaction." (Oxford } \\
\text { Languages, 2021) }\end{array}$ & $\begin{array}{l}\text { ANXIOUS } \\
\text { FEARFUL } \\
\text { LEFT BEHIND } \\
\text { UNSURE } \\
\text { TENSE } \\
\text { AWKWARD } \\
\text { DISCONNECT } \\
\text { HISTITANT } \\
\text { FRUSTRATED } \\
\text { STRUGGLES } \\
\text { UNCERTAINTIES } \\
\text { PROBLEMS } \\
\text { FEELING SOME TENSION } \\
\text { DESPERATELY } \\
\text { PRESSURED } \\
\text { STRANGE } \\
\text { SOUR }\end{array}$ \\
\hline
\end{tabular}




\section{Appendix C. Storyboard Document (Google Document)}

\section{Figure C1}

Storyboard Entries for Day Two

\section{Day 2 - Tuesday, November 19, 2019}

Decide to navigate to work using a different route. Looking at the bus station via apple maps, I find the * train (subway) connects via a pedestrian tunnel. I read online and it seems to be a better alternative to walking above ground to the *.

\subsection{JEFF REVIEWS DOCUMENTS}

I enter the office at approx. 8:40am. I glance at my goals document again. The office is noticeably quieter at this time compared to when I arrived yesterday. I login to ** for the first time. I browse the app and await my first meeting with John. I use developer tools and strategies from my past work to orient myself. I revisit the specs/summary documents shared by **. I exit my chair and approach John's desk.

\subsection{JEFF ATTENDS MEETING}

SIS overview

Tuesday, November 19, 2019 9:30 - 10:15am

John's desk

John forwards me more meeting invites for a $2 \mathrm{pm}$ (moved to 11am) and 4pm meeting. He explains these are weekly, recurring meetings. He proceeds to demonstrate how to use *. He lectures about the nature of the tool, it's history, the different features, how they are connected, and more. Many of these concepts are foreign to me. He demonstrates features and introduces several tools/technologies associated with the project. We exit his desk and attend standup.

\subsection{JEFF ATTENDS MEETING}

SIS Daily Stand-Up

Monday, November 19, 2019·10:30 - 10:45am

Weekly on weekdays, until Aug 10, 2020

The developers sound off and voice work they accomplished since the day prior and work for the current day. Surprised, John calls upon me. I exclaim "reviewing documents and getting my work station setup." The rest of the team continues. Some issues are raised and John consults with the developers. The meeting ends.

\section{Figure C2}




\section{Day 21 - Wednesday, December 18, 2018}

\subsection{JEFF REFLECTS}

Thinking about my progress through the first month. How I was able to contribute in yesterdays meeting or my troubleshooting strategies used for steps towards resolution of problems faced.

Thinking about the evolution of my work - being mostly a casual observer in the first month to more of a voice/contributor in recent days

\subsection{JEFF REVIEWS TICKETS AND DOCUMENTATION}

Reviewing issues/tickets - looking to follow up on pressing issues. Pushing to prod today and ill lead the change call - submitted the change request for the first time yesterday w the assistance of Steves model. Reviewing notes from yesterdays meeting so I can connect w John and discuss next steps. Reviewing organization update/creation steps in confluence, understanding this notion of an org more now

Meetings all morning and discussion/demo about new catalog and degree audit

\subsection{JOHN MESSAGES JEFF}

John S.: 8:30 AM

I am remote today, but if you are available I'm adding to the backlog and would be happy to do a sreenshare

Jeff B 8:30 AM

yea, give me one moment and we'll connect

John S.: 8:31 AM

sure

Jeff B 8:39 AM

\subsection{JEFF ATTENDS MEETING}

SIS: Review Catalog Requirements

Wednesday, December 18, 2019 9:30 - 10:30am

Location: 
Studebaker 502 and https://meetings.ringcentral.com/j/1490530221

Studebaker-502

13 guests

13 yes

Functionality, q/a and questions posed by group

Catalog technical reqs prompted a great deal of discussion about structure of table

\subsection{JEFF TESTS WITH JOHN}

John explains the grouper rules and parent/child. I take a screenshot. We test coi doc upload.

Meeting with BE developers yesterdays helps me situate their roles and expertise e.g. BE development.

John S.: 10:04 AM

I'm testing $\mathrm{COI}$ docs now

10:04

will turn over to Huruma once my testing is complete

Jeff B 10:05 AM

is it in test?

John S.: 10:05 AM

Yes

Jeff B 10:05 AM

i cna't do anything

John S.: 10:05 AM

oh?

10:05

what UNI, what are you trying to do and when did you test?

Jeff B 10:07 AM

my uni, in test, just now, this is what I see

10:07

image.png

image.png

10:07

unless i'm totally missing what should be seen here 10:09

looks like I can only view 
John S.: 10:09 AM

hm...

10:09

$\mathrm{OK}$

Jeff B 10:32 AM

who is leading standup, lol

John S.: 10:35 AM

Nancy

\subsection{JEFF MESSAGES JOHN}

Jeff B 10:51 AM

any update on COI docs?

$10: 51$

is it really ready or still working on it

John S.: 10:58 AM

The permissions script was not run during the dpeloy

10:58

Waiting for $* * *$ to run that

Jeff B 10:59 AM

soundsgood@

$10: 59$

$*$ !

John S.: 11:02 AM

RUn complete

Jeff B 11:04 AM

$\log$ out and $\log$ in, and I should see it?

11:04

or need to wait $5 \mathrm{~min}$

John S.: 11:07 AM

Looks like we are view only

11:07

Will discuss with **

11:07

Works as a final-approver though :slightly_smiling_face: (edited) 
Jeff B 11:08 AM

http://instantrimshot.com/index.php?sound=downer

John S.: 11:08 AM

$\mathrm{HAH}$

11:08

I suspect the fact the ** and Super can add/,odify was lost in translation

21.06 JEFF ATTENDS MEETING

SIS: Data Model

Wednesday, December 18, 2019·11:00am -

\subsection{JEFF ATTENDS MEETING}

CUIT Weekly CAB Meeting

Wednesday, December 18, 2019 12:00 - 1:00pm

Weekly on Thursday

John S.: 12:05 PM

DO you want me to call in to the cab? (edited)

Jeff B 12:05 PM

im on the call already

12:06

i think I have it, but up to you

John S.: 12:06 PM

If you need me ping me an I'll call in

Jeff B 12:06 PM

thanks

John S.: 12:06 PM

otherwise I trust you got it covered

Jeff B 12:20 PM

approved 
John S.: 12:22 PM

:) (edited)

\subsection{JEFF MESSAGES AND CALLS JOHN}

Jeff B 12:25 PM

do you know why all those Course tickets were changed from done $->$ to do

John S.: 12:26 PM

nope

$12: 26$

have been in testing and not JIRA

Jeff B 12:29 PM

and we didn't deploy

$12: 29$

yesterday right

John S.: 12:29 PM

correct

Jeff B 12:29 PM

and not yet today?

$12: 30$

right?

$12: 30$

if so, problem: the change request ended yesterday

$12: 30$

and we didnt update the ticket yet

$12: 30$

so we need to do so one way or another asp

$12: 30$

asap

John S.: 12:31 PM

We did a deploy yesterday

$12: 31$

and need to so dome more later

$12: 31$

We have a few changes open

Jeff B 12:31 PM

right, but technically we aren't finished yet :slightly_smiling_face:

$12: 31$

and the window is closed 
John S.: 12:31 PM

I'd need to see what's what

Jeff B 12:31 PM

Ivan is afk

$12: 31$

going to connect $\mathrm{w} / \mathrm{him}$ as soon as he's back

$12: 36$

something odd im seeing $\mathrm{w} /$ doc upload

$12: 36$

Harold added a doc earlier under AMLP

$12: 37$

I went in, and could pull it up on the list and saw/view the documents

$12: 37$

i just now went in again to view the documents, and I don't have the option to select AMLP anymore.. it's nowhere on the list

John S.: 12:40 PM

Call me

Call Ended

Ended at 1:22 PM - Lasted 36 minutes

21.09 JEFF ATTENDS MEETING

Architecture Assessment Group ( AAG ) Bi-Weekly Meeting

\subsection{JEFF TESTS FEATURE}

Jeff B 3:18 PM

COI doc's super user permissions working

$3: 18$

any update on $* * *$ stuff?

John S.: 3:25 PM

Nope

3:25

There is a permission issue

$3: 25$

working on it 


\subsection{JEFF ATTENDS MEETING}

SIS Development Tracking

Wednesday, December 18, 2019 3:30 - 4:00pm

Weekly on Wednesday

\subsection{JEFF MESSAGES JOHN}

Jeff B 5:00 PM

do $u$ want me to update banner

John S.: 5:00 PM

I got it

Jeff B 5:01 PM

thank you sir

John S.: 5:06 PM

fixed

5:07

In my speed I accidental re-posted with the same end date. 5:08

Thankfully a quick(ish) fix

Jeff B 5:16 PM

Wasn't it like a generic date anyway eg. end of week?

John S.: 5:19 PM

It was yesterday

$5: 19$

now its tomorrow 


\section{Figure C3}

Storyboard Entries for Day 40

\section{Day 40 - Tuesday, January 21, 2020}

\subsection{JEFF REVIEWS TICKETS}

I start the day off checking on tickets from Friday evening, some devs update late in the day. Prepping for questions for dev's. Thinking about when its best to approach them e.g. 10am and later.

New issues opened friday and tuesday by business. I dig into some of these - gathering details and thinking about troubleshooting strategies

\subsection{JEFF MESSAGES JOHN}

I chat with John about weekend. I show him some of the issues we discovered.

Agree to touch base w FE lead after stand up.

\subsection{JEFF ATTENDS MEETING}

John and I head to standup. Developers begin to sound off. I report what I am doing. Paying more attention to $* *$ updates, ticket 2239

\subsection{JEFF ATTENDS MEETING}

I connect $\mathrm{w} * *$ and $* *$ after standup. Brief discussion about 2239. I tell FE lead to join us after all. We review an issue via screenshare. Discussion ensues. Developers are clearer on the issue. I exit the standup.

John.: 10:46 AM

Call

Call Ended

Ended at 11:03 AM - Lasted 17 minutes

3 people joined

\subsection{JEFF ATTENDS MEETING}

Weekly CHG for Tuesday Prod Deploy Tuesday, January 21, 2020 11:30am - 12:00pm 
Weekly on Tuesday, until Jul 28, 2020

I enter breakout room w John, **, **and I.

\subsection{JEFF ATTENDS MEETING}

John S.: 11:32 AM

Can we borrow you are ** desk?

Qa ed app to app, but need some input from **. Make note of what I've tried via Postman.

\subsection{JEFF ATTENDS LUNCH}

John invites me to lunch. We run into ** and **. They join us.

Long lunch, but opportunity to spend more time with them.

\subsection{JEFF ATTENDS MEETING}

We return and I head over to chat $\mathrm{w}^{* *}$ and will follow up with backfill tickets.

\subsection{JEFF ATTENDS MEETING}

SIS - Service Introduction Kick Off

Tuesday, January 21, 2020 2:30 - 3:00pm

*-532

5 guests

4 yes, 1 awaiting

*

Organizer

$*$

I meet with project managers, $* *$ and others. They introduce the process for onboarding new services. They wish to learn more about *. I screen share and demo *, first time leading collaborative screenshare of this sorts. We schedule a working session follow-up.

\subsection{JEFF SENDS MESSAGES}

I return to my desk. I chat with business via Slack. Cancelled status meeting but business is happy with my presence so far. Positive feedback received. 


\subsection{JOHN MESSAGES JEFF}

John.: 3:24 PM

If you are free in a bit we can walk over to ** to talk once I'm out of my 3:00 $:+1$ :

1

\subsection{JEFF DEPLOYS CHANGES}

Qa FE fixes and coordinates for push to prod. Staying later until 6 - office very quiet and eventually left on delayed trains, Poor experience home. 


\section{Appendix D. Storyboard Script (Google Script)}

\section{Figure D1}

\section{Google Script Code to Generate the Storyboard Export}

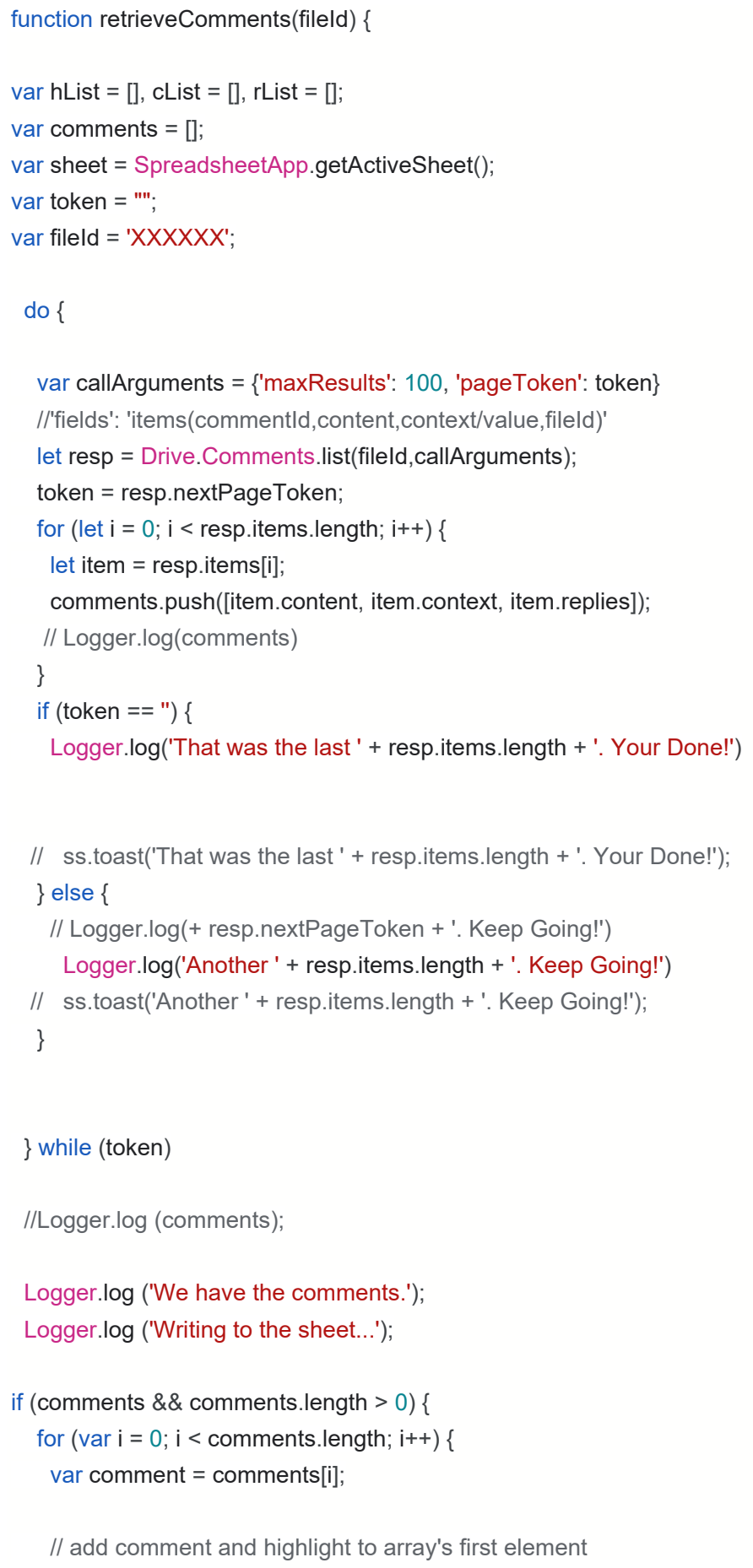




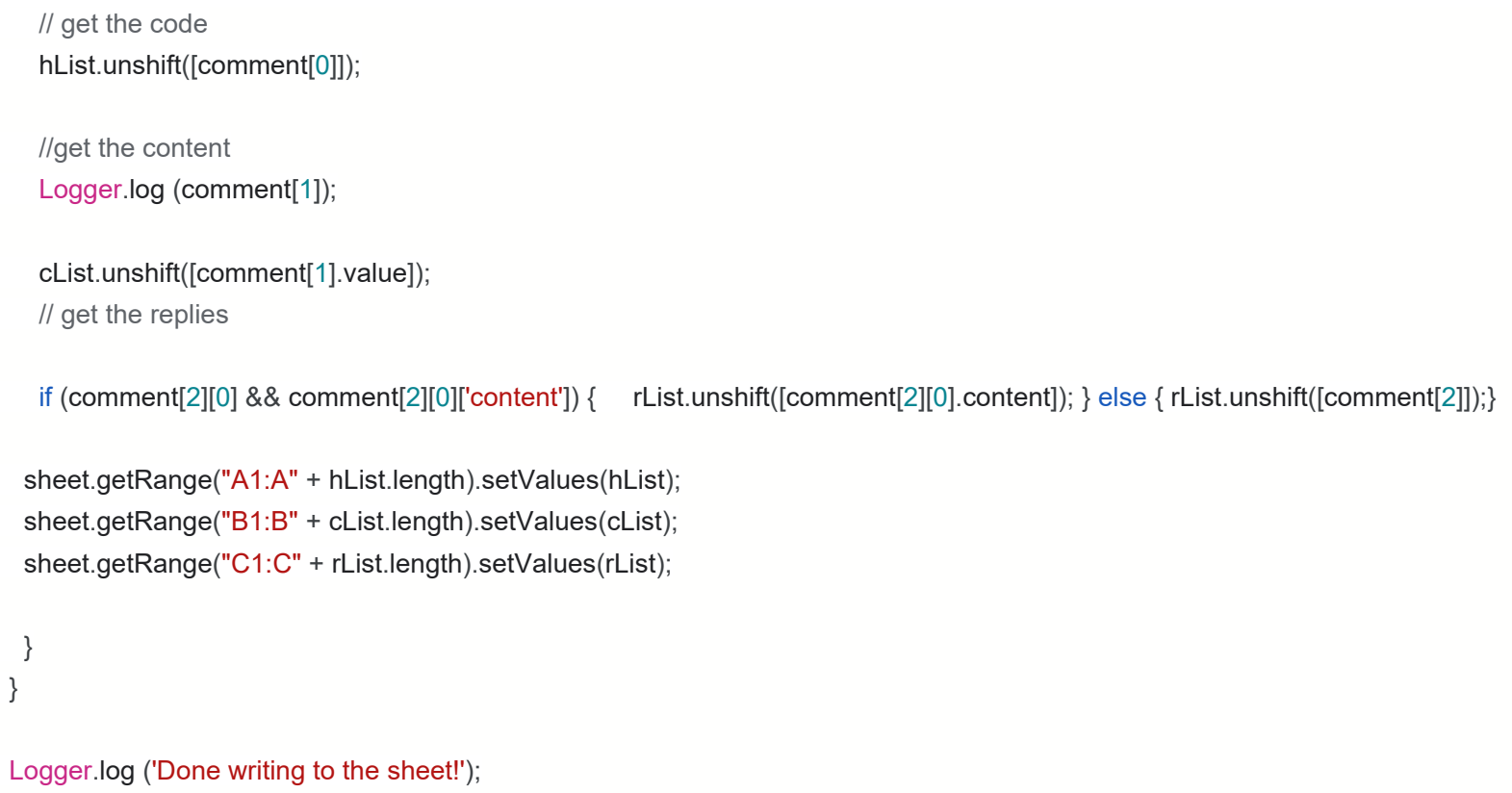




\section{Appendix E. Storyboard Export (Google Sheets)}

Sample of Storyboard Export, Day Two, Experience 02.00

\begin{tabular}{|c|c|c|c|c|c|c|}
\hline $\begin{array}{l}\text { KNOWLEDGE- } \\
\text { BUILDING AND } \\
\text { COGNITIVE } \\
\text { CODES }\end{array}$ & CONTENT & $\begin{array}{l}\text { SITUATED } \\
\text { CODES }\end{array}$ & RECOGNITION & PRODUCTION & REFINEMENT & TRANSCENDENCE \\
\hline $\begin{array}{l}\text { RECOGNITION - } \\
\text { PROCESSES AND } \\
\text { RITUALS - } \\
\text { MEETINGS - } \\
\text { PROJECT } \\
\text { PLANNING } \\
\text { RECOGNITION - } \\
\text { HISTORY AND } \\
\text { CONTEXT - } \\
\text { PROJECT } \\
\text { DETAILS } \\
\text { RECOGNITION - } \\
\text { TOOLS AND } \\
\text { ARTIFACTS - } \\
\text { DOCUMENTATI } \\
\text { ON }\end{array}$ & $\begin{array}{l}\text { 02.00 JEFF REVIEWS } \\
\text { DOCUMENTS } \\
\text { I enter the office at } \\
\text { approx. 8:40am. I } \\
\text { glance at my goals } \\
\text { document again. The } \\
\text { office is noticeably } \\
\text { quieter at this time } \\
\text { compared to when I } \\
\text { arrived yesterday. I } \\
\text { login to * for the first } \\
\text { time. I browse the app } \\
\text { and await my first } \\
\text { meeting with John. I use } \\
\text { developer tools and } \\
\text { strategies from my past } \\
\text { work to orient myself. } \\
\text { I revisit the } \\
\text { specs/summary } \\
\text { documents shared my *. } \\
\text { I exit my chair and } \\
\text { approach Johns desk. }\end{array}$ & $\begin{array}{l}\text { AUTONOM } \\
\text { OUS - } \\
\text { EXPLORATI } \\
\text { ON }\end{array}$ & 2 & 0 & 0 & 0 \\
\hline
\end{tabular}




\section{Appendix F. Transcendent Episodes T1 to T7}

\section{T1 - Deletion Process}

\section{F1}

Summary of trajectory of experiences leading up to T1 - Deletion Process

\begin{tabular}{lll}
\hline Transcendent Episode & Trajectory of Experiences & Description \\
\hline T1 & 04.07 & 04.07 - The first RECOGNITION of \\
13.02 & design and development tools - django \\
14.01 & admin, shown by John. \\
15.00 & $13.02-$ REFINEMENT and \\
15.02 & PRODUCTION of the same schema \\
15.04 & through COLLABORATIVE and \\
& AUTONOMOUS exploration \\
& 14.01 - More PRODUCTION and \\
& REFINEMENT to delete proposals \\
& 15.00 - Recognition of the breakthrough \\
& after deleting \\
& 15.02 further PRODUCTION and \\
& REFINEMENT \\
& 15.04 - presentation of the delete \\
& process \\
& \\
& \\
& \\
& \\
& \\
& \\
&
\end{tabular}

Figure F1

Emergence of $T 1$ during experience 15.04

\subsection{JEFF ATTENDS MEETING}

SIS Daily Stand-Up

Tuesday, December 10, 2019·10:30 - 10:45am

Weekly on weekdays, until Aug 10, 2020

During stand up, I announced my achievement/task and it was well received.

I gained respect after I demonstrate my technical knowledge / ability to learn

Developer makes comment what I did is helpful 


\section{Figure F2}

Cognitive dimension and trajectory of experiences leading up to Transcendent episode one (T1)

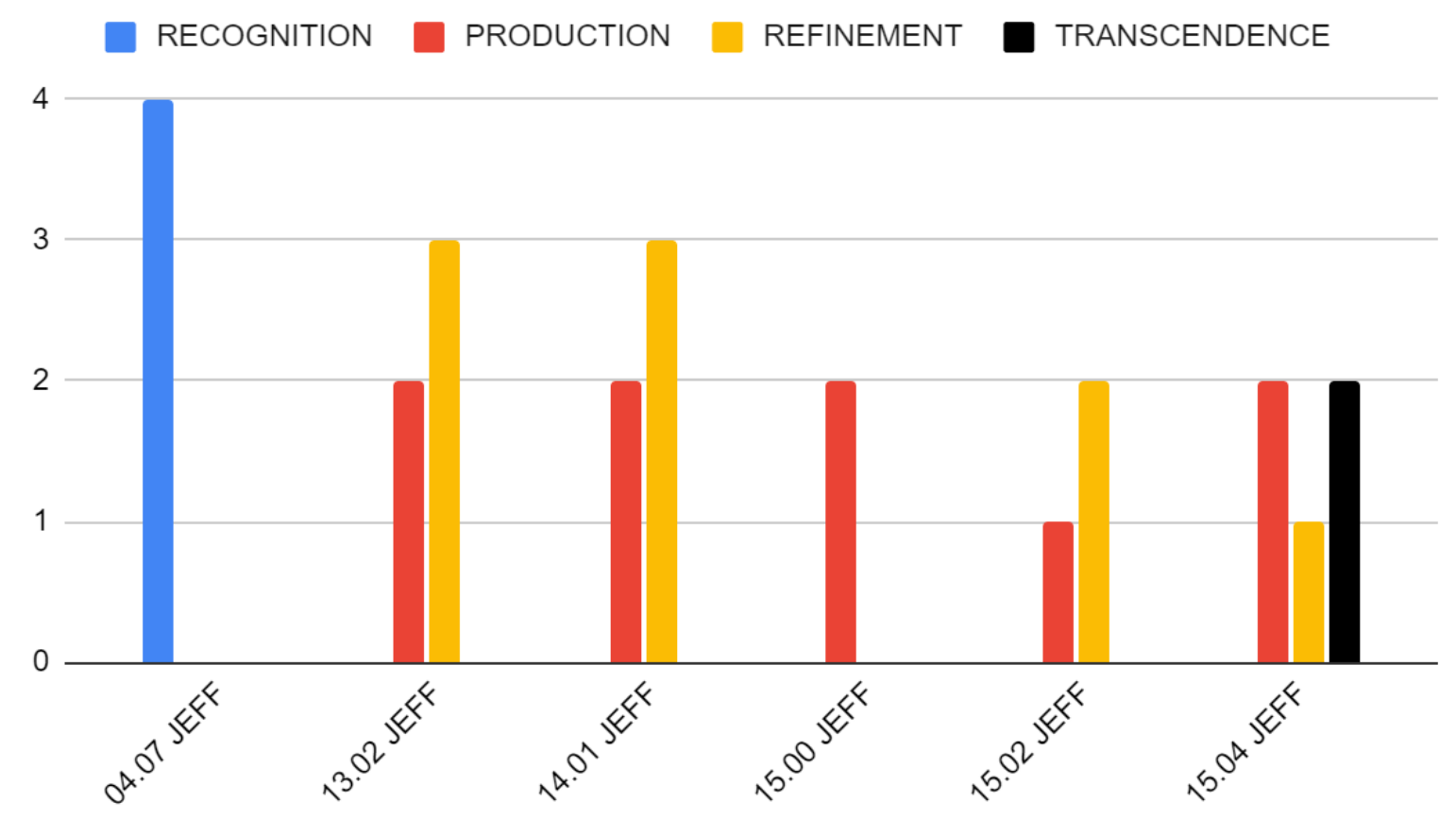




\section{Figure F3}

Knowledge-building dimension and trajectory of experiences leading up to Transcendent episode one (T1)
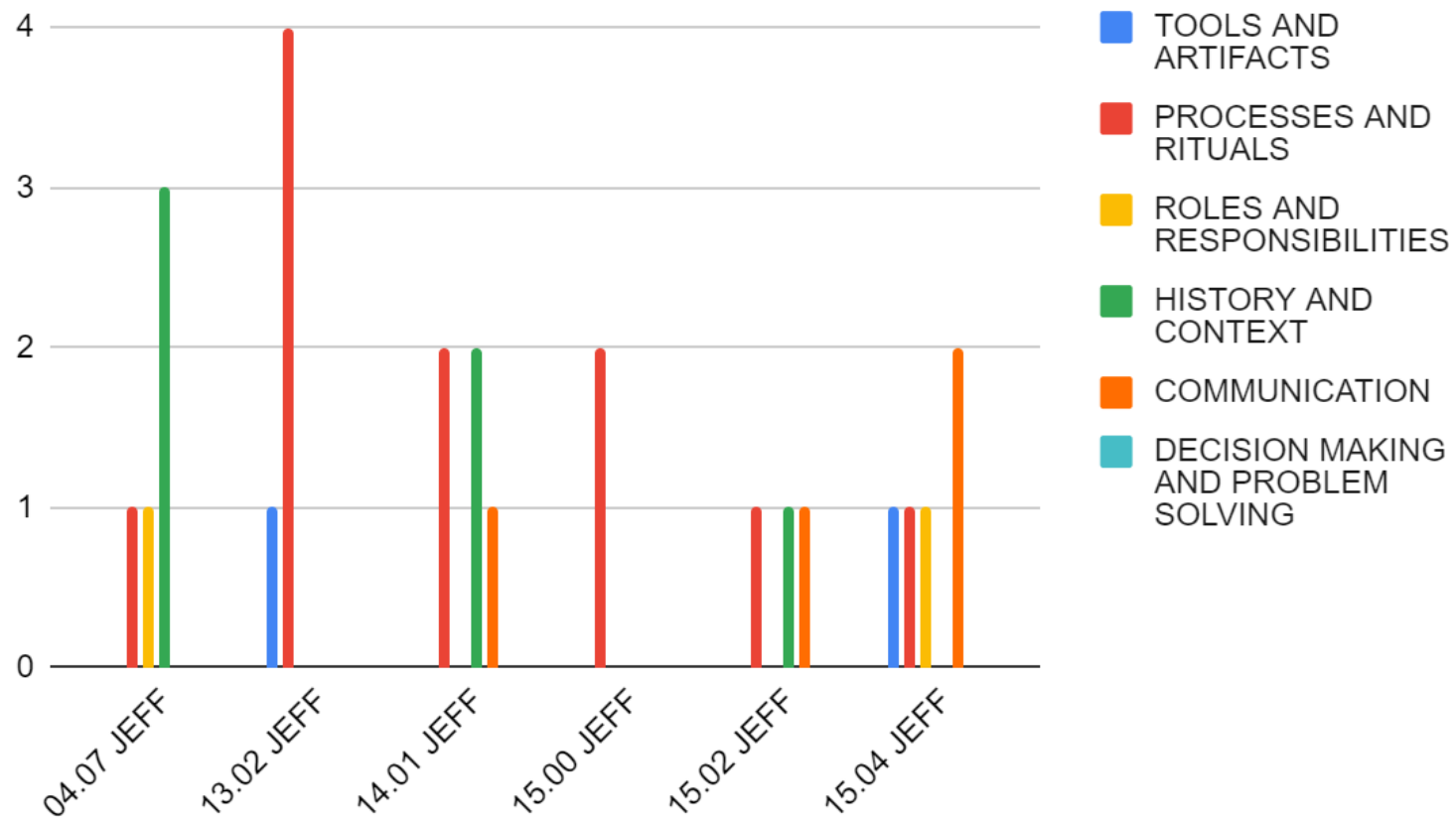


\section{Figure F4}

Situated dimension and trajectory of experiences leading up to Transcendent episode one (T1)
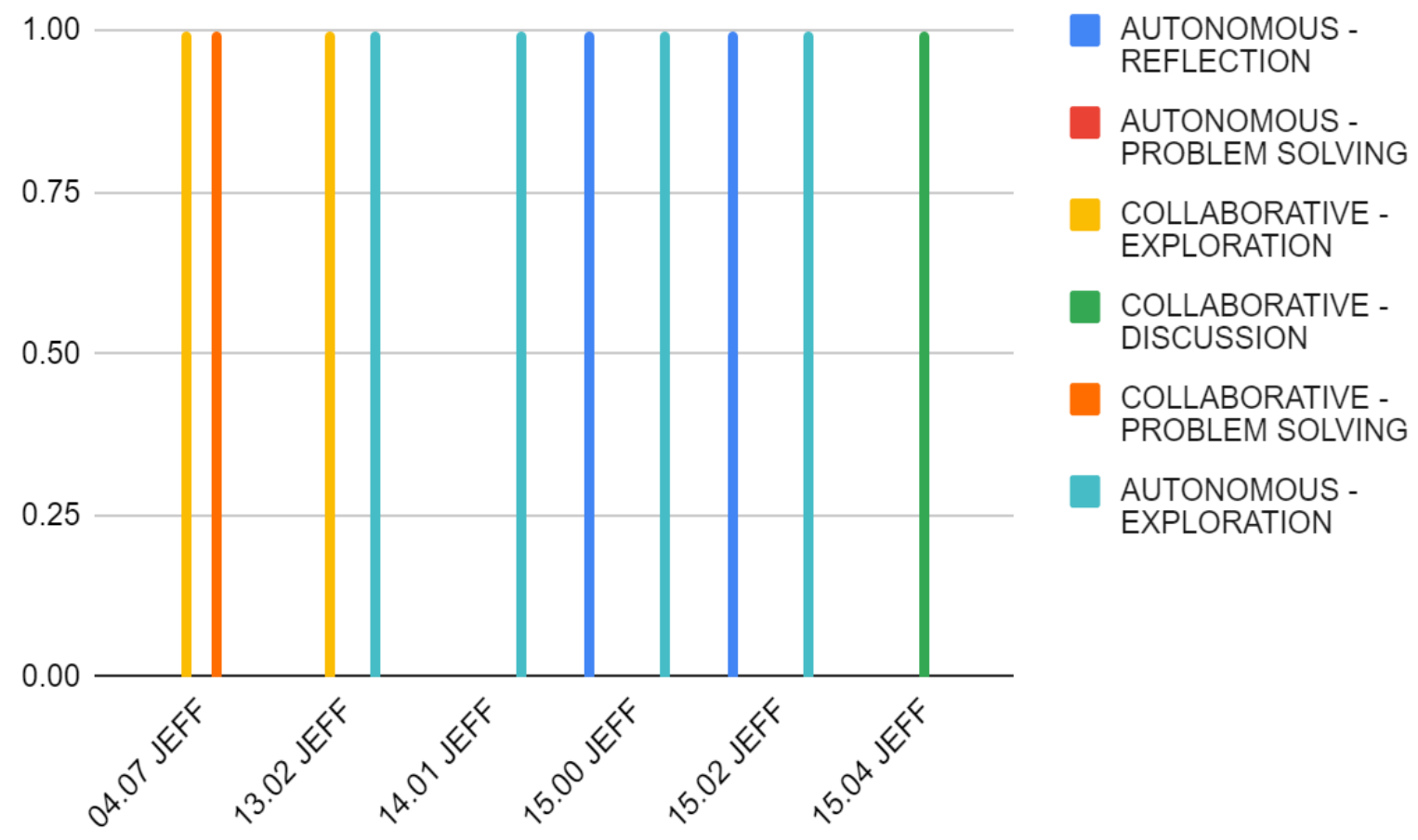


\section{T2 - New Judgements}

\section{Table F2}

Summary of trajectory of experiences leading up to T2 - New Judgements

\begin{tabular}{|c|c|c|}
\hline Transcendent Episode & Trajectory of Experiences & Description \\
\hline T2 - New Judgements & $\begin{array}{l}06.13 \\
07.06 \\
25.04 \\
26.04\end{array}$ & $\begin{array}{l}06.13 \text { - Added to alerts tool, recognized } \\
\text { processes running and the alert feature } \\
07.06 \text { - Context around governance of } \\
\text { the system } \\
25.04 \text { - Discussed these processes and } \\
\text { alerts with others, issue reported by } \\
\text { client, leads to refinement about } \\
\text { steps/procedures, making decisions and } \\
\text { next steps, no action taken as advised by } \\
\text { others and collaborative exploration } \\
26.04 \text { - Autonomous and collaborative } \\
\text { exploration, decided further investigation } \\
\text { is needed. Revisited this again and } \\
\text { questioned the rules, customs, norms. } \\
\text { Recognized there was a problem. }\end{array}$ \\
\hline
\end{tabular}

\section{Figure F5}

Emergence of $T 2$ during experience 26.04

\subsection{JEFF REVIEWS TICKETS}

I circle back to business issue w concern over ** integration - ** and ** were skeptical but her alarm may be warranted. Looking into this. 


\section{Figure F6}

Cognitive dimension and trajectory of experiences leading up to Transcendent episode two (T2)

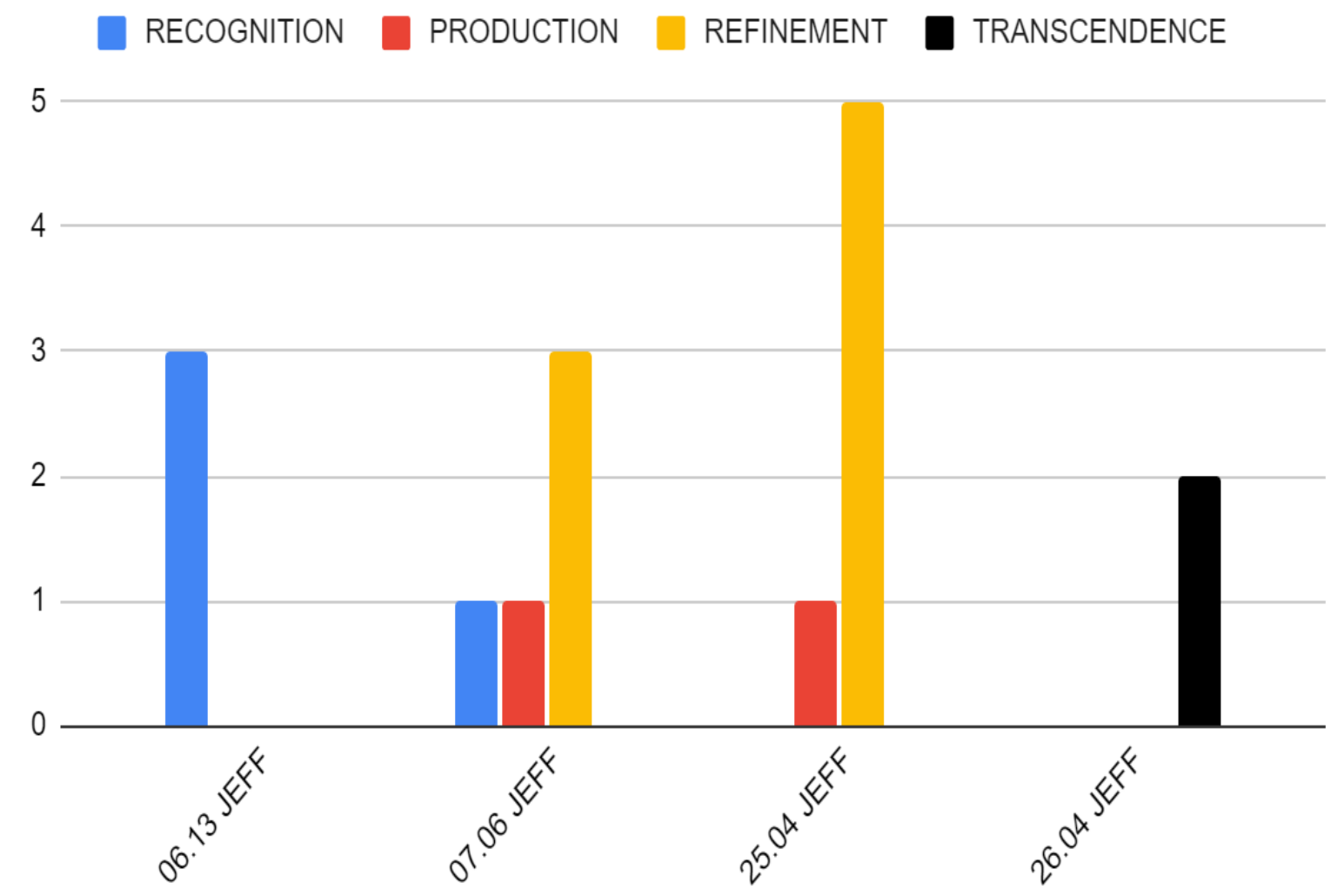




\section{Figure F7}

Knowledge-building dimension and trajectory of experiences leading up to Transcendent episode two (T2)

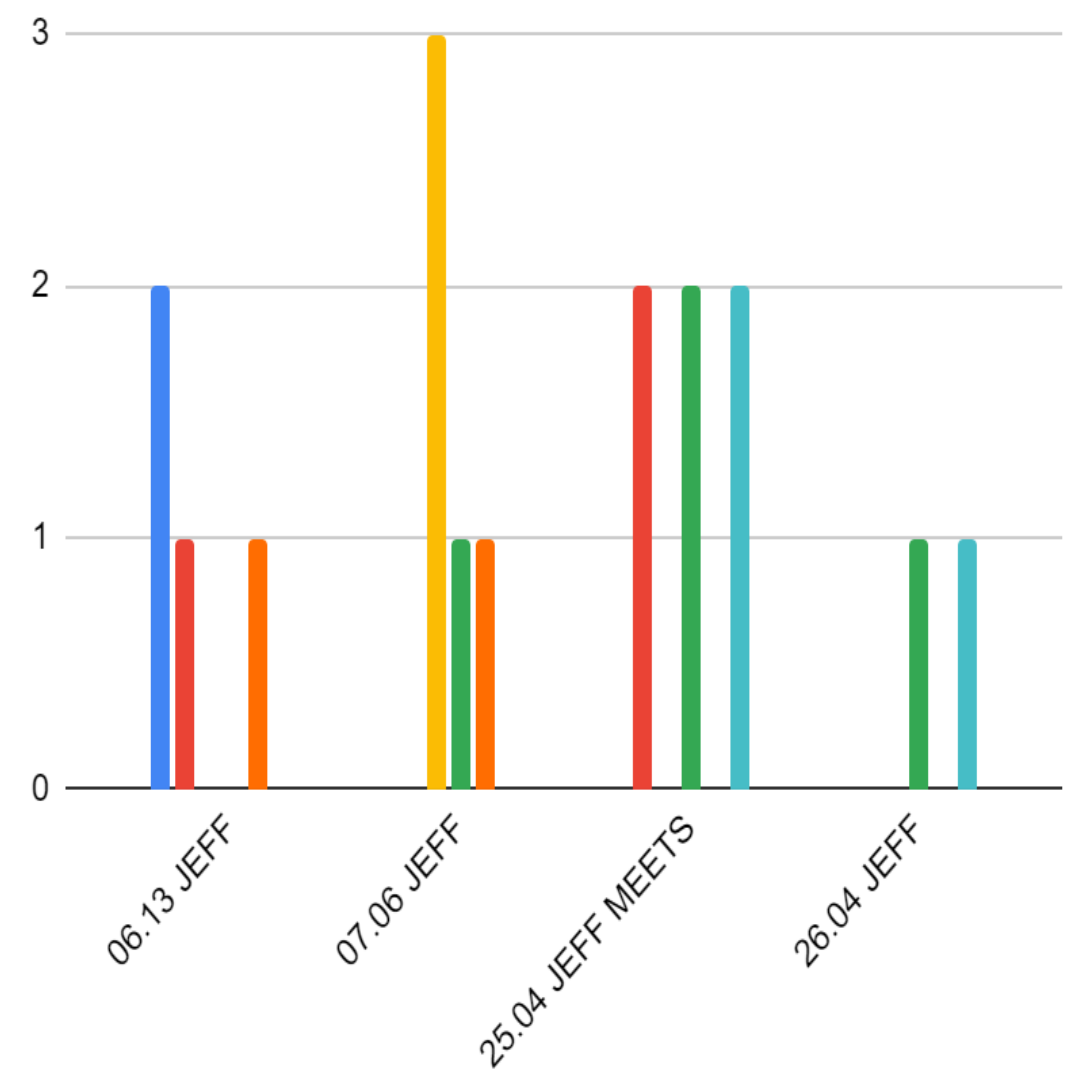

TOOLS AND

ARTIFACTS

PROCESSES AND RITUALS

ROLES AND RESPONSIBILITIES

HISTORY AND CONTEXT

COMMUNICATION

DECISION MAKING AND PROBLEM SOLVING 


\section{Figure F8}

Situated dimension and trajectory of experiences leading up to Transcendent episode two (T2)

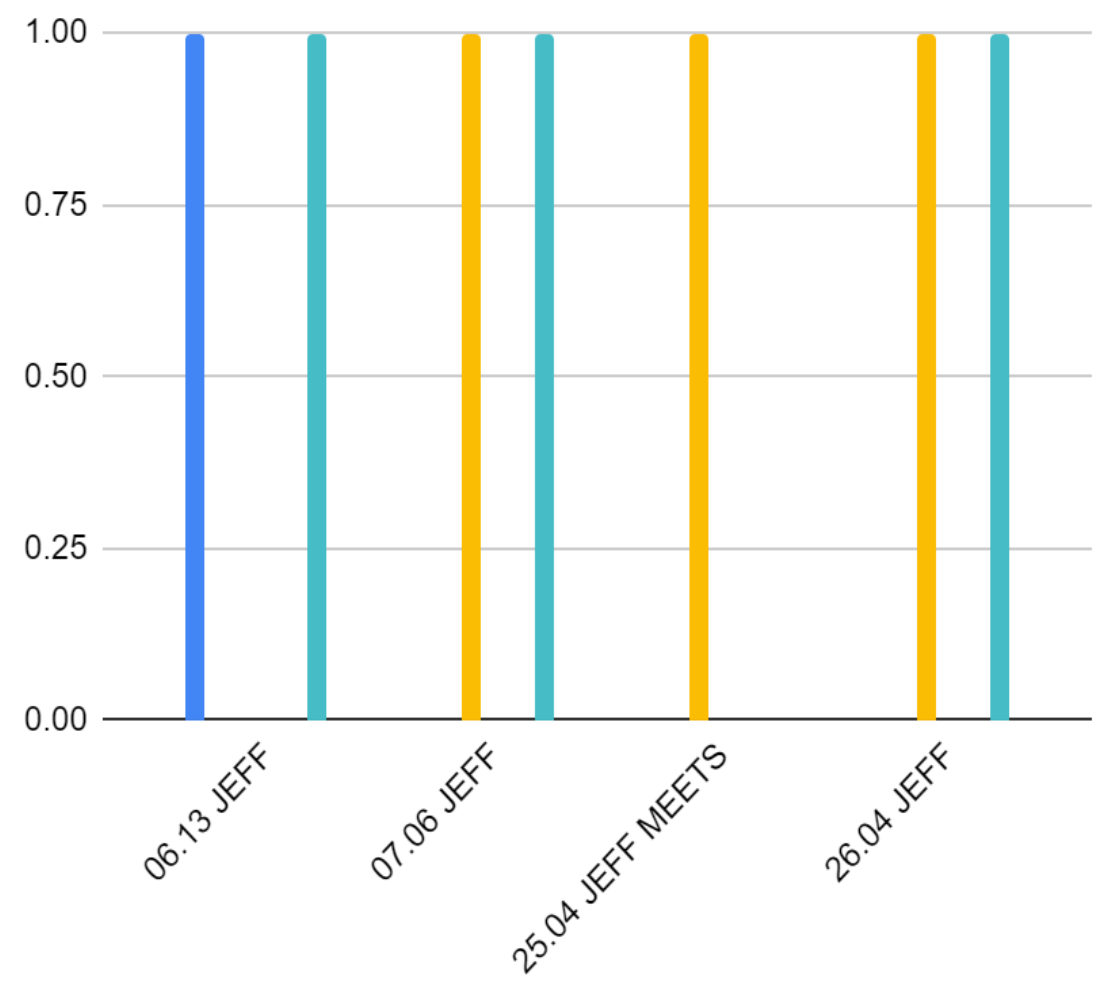

AUTONOMOUS REFLECTION

AUTONOMOUS PROBLEM SOLVING

COLLABORATIVE EXPLORATION

COLLABORATIVE DISCUSSION

COLLABORATIVE PROBLEM SOLVING

AUTONOMOUS EXPLORATION 


\section{T3 - Dashboard}

\section{Table F3}

Summary of trajectory of experiences leading up to T3 - Dashboard

\begin{tabular}{lll}
\hline Transcendent Episode & Trajectory of Experiences & Description \\
\hline T3 - Dashboard & 24.02 & 24.02 - Recognition of steps and \\
& 25.00 & procedures, creating tickets \\
25.01 & 25.00 - Training - recognition of steps \\
25.05 & and procedures in their world \\
26.00 & 25.01 \\
26.03 & 25.05 \\
26.04 & 26.00 \\
26.07 & 26.03 \\
26.08 & 26.04 \\
28.00 & 26.07 \\
& 26.08 \\
& 28.00 - Creation of my dashboard, most \\
& recent issues, releases, etc \\
\hline
\end{tabular}

\section{Figure F9}

Emergence of $T 1$ during experience 28.00

\subsection{JEFF REVIEWS TICKETS AND CREATES DOCUMENTS}

Reviewing tickets and cleaning up old ones. Organizing to connect w John and ** about last week

- ** led the standups, 7-8 ish dev's on thurs/fri calls

- 2162 - dupe topics count from prod pretty high, 515 records, bandaid code solution.. worried about this. * realizing this is a bigger issue.

What's the business requirement here?

- Backfill/name issue? 2202 .. 228 instances where names don't match **

- Scoped tasks for $*>*$ integration

- Started to gather requirements for 2020 catalog

- Sick days! and 2013.... !!!!!!!!!

- * issue reported, */*, or a smokescreen? 
Thought of how using INC functionality here saves Jira tix ->

https://jira.cuit.**.edu/jira/browse/*_*

- ** training! But the incident system.. e.g.

- QA'ing - especially data cleanup, given the name issue

- Deploy for today..

- $\mathrm{CHG}^{* *}$.. service-alert! we don't want this..

- Dev complete but.. ? https://jira.cuit.**.edu/jira/browse/*_*?jql=project\%20\%3D\%20C*

- My dashboards - want to roll these out by next week...

\section{Figure F10}

Cognitive dimension and trajectory of experiences leading up to Transcendent episode three (T3)

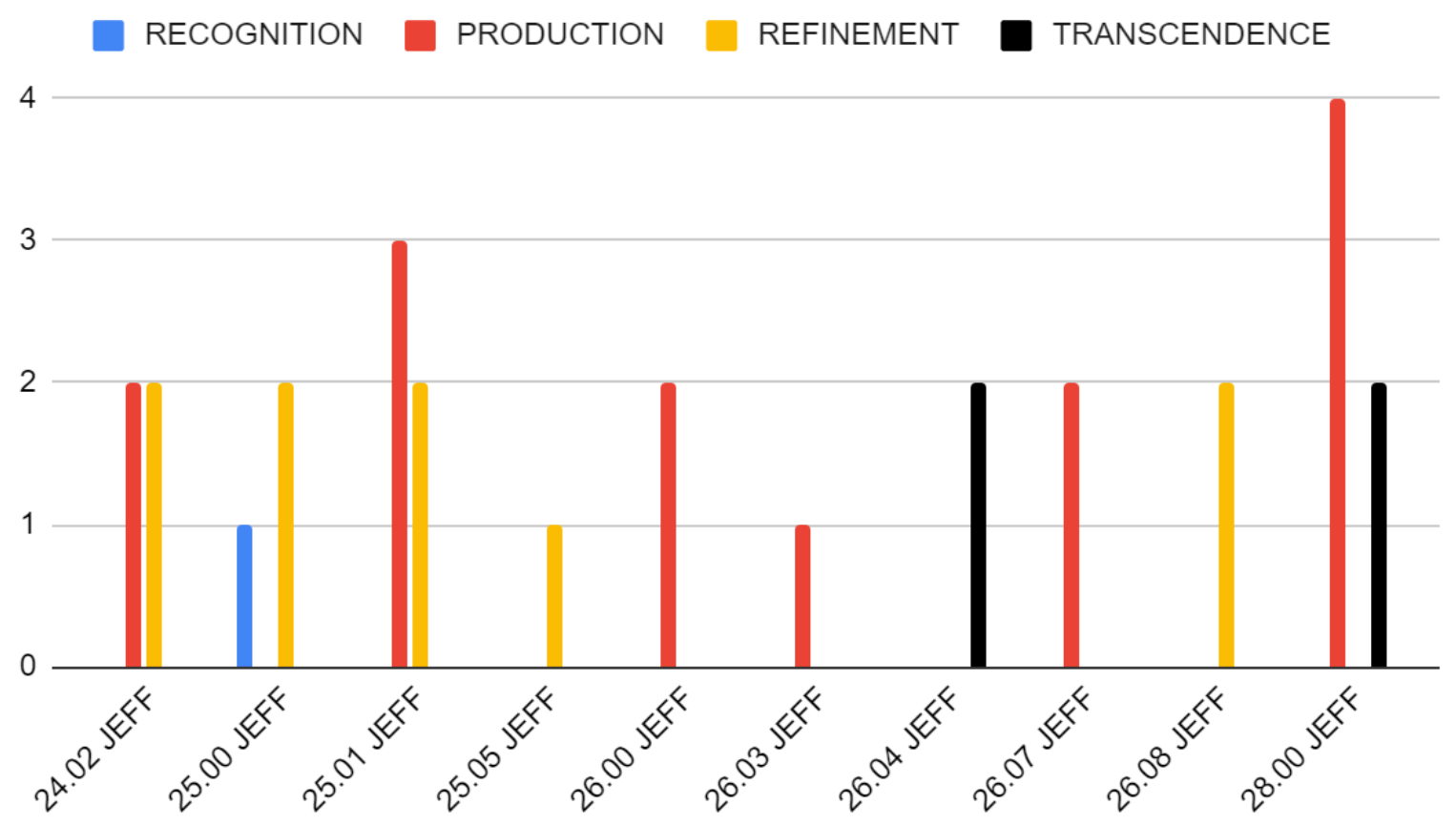




\section{Figure F11}

Knowledge-building dimension and trajectory of experiences leading up to Transcendent episode three (T3)

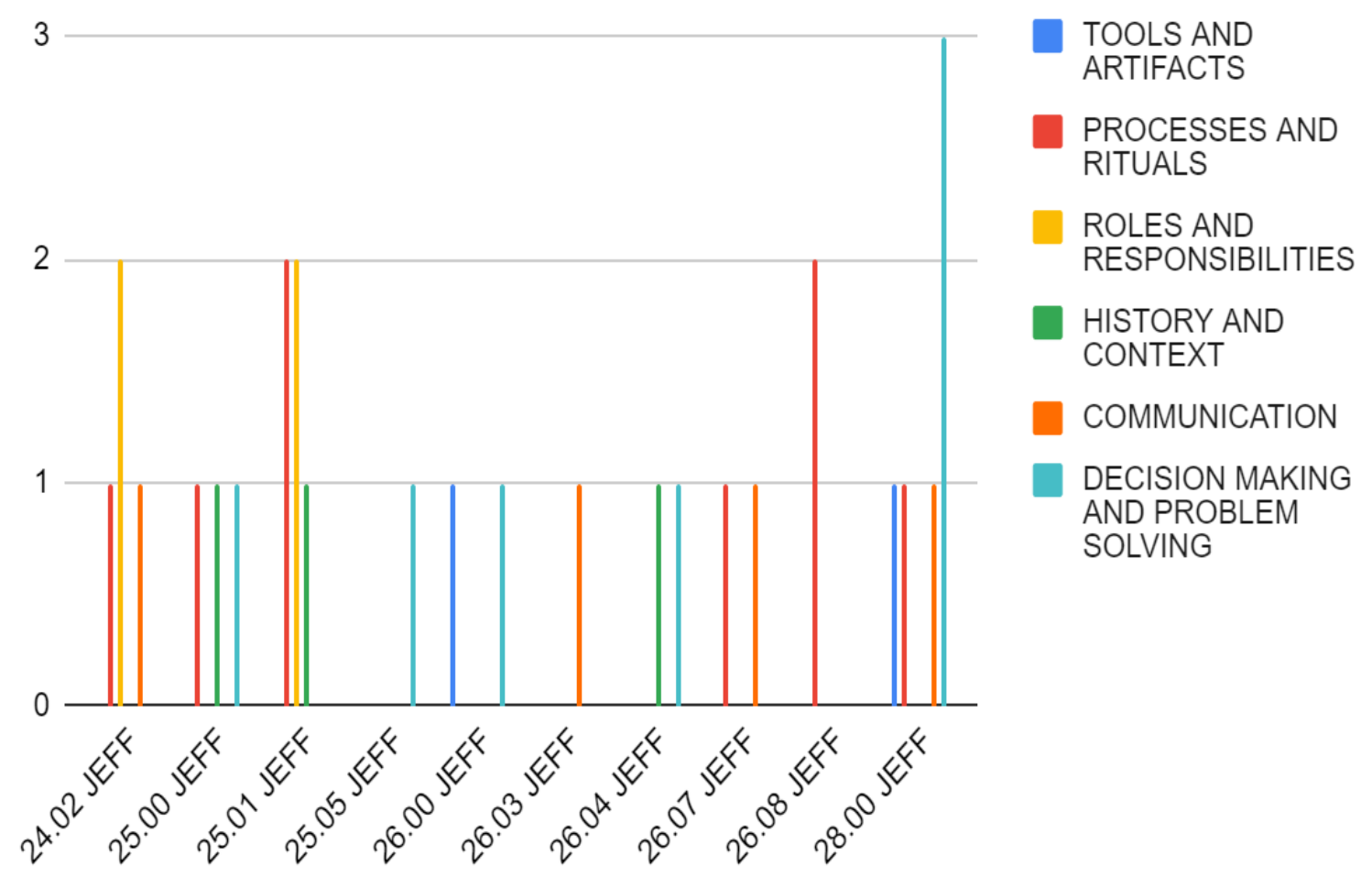




\section{Figure F12}

Situated dimension and trajectory of experiences leading up to Transcendent episode three (T3)
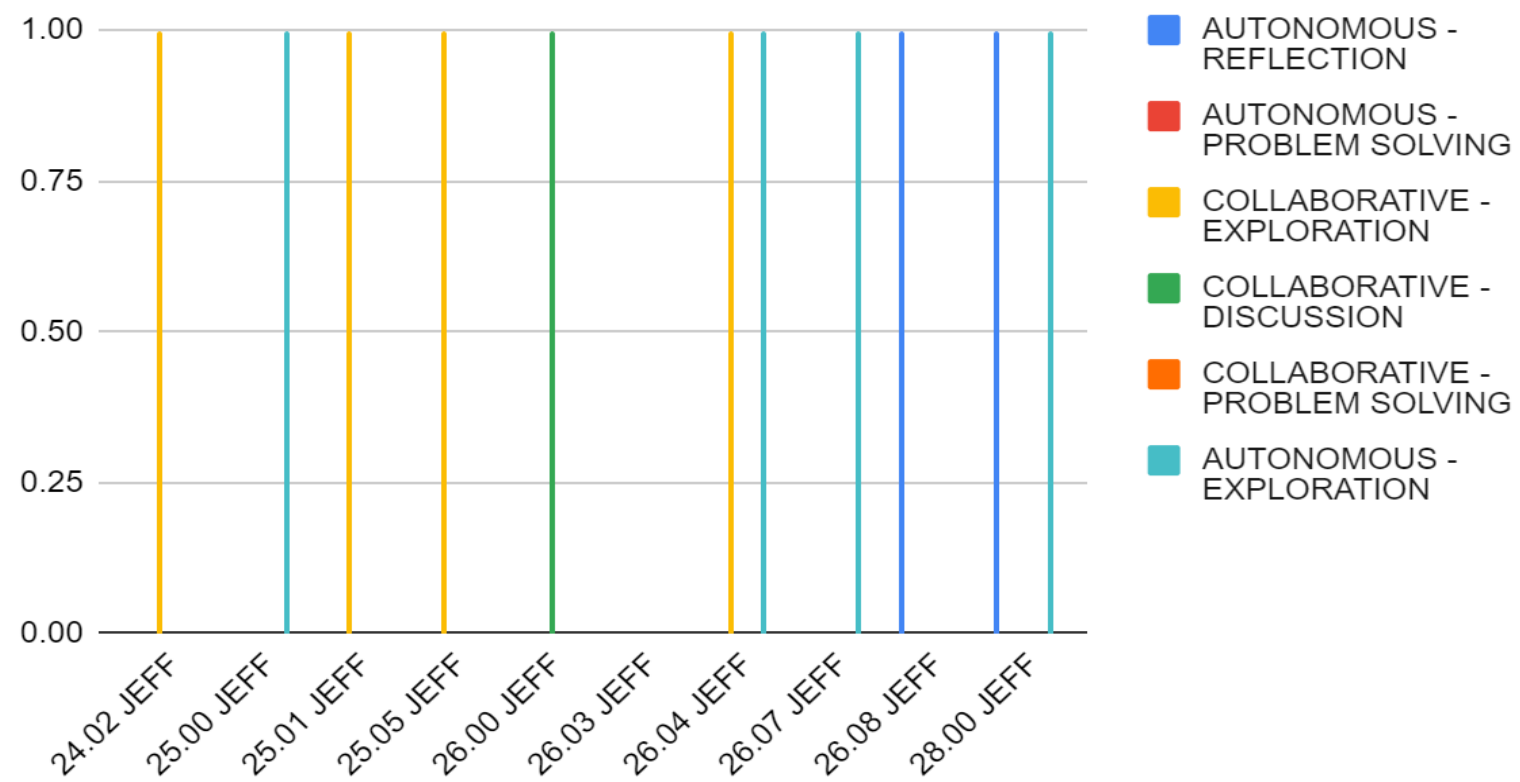


\section{T4 - Debugging}

\section{Table F4}

Summary of trajectory of experiences leading up to T4 - Debugging

\begin{tabular}{lll}
\hline Transcendent Episode & Trajectory of Experiences & Description \\
\hline T4 - Debugging & 09.03 & 09.03 \\
& 09.07 & 09.07 \\
10.01 & 10.01 \\
17.01 & $17.01<$ - Rehearsal \\
18.01 & 18.01 \\
19.07 & 19.07 \\
21.04 & 21.04 \\
21.05 & 21.05 \\
21.10 & 21.10 \\
32.01 & $32.01-$ TRANSCENDENCE - \\
& COMMUNICATION - PROVIDING \\
& INPUT OR ADVICE \\
\hline
\end{tabular}

\section{Figure F13}

Emergence of T4 during experience 32.01

\subsection{JOHN MESSAGES JEFF}

John S.: 8:38 AM

Lets meet with $* *, * *$ and possibly $* *$ to discuss this first thing this morning.

Used a prior search strategy today to resolve developer issues but $\mathrm{i}$ only solved the problem $95 \%$ - John needed to intervene at the end and reaffirm that I was on the right track and that was the issue. His scaffolding is what led us to the solution and the developers solved the problem within minutes.

What's odd if two developers were present and did not employ the same search strategy that I used with the jira $\mathrm{km}$ tool to find leads. This combined with other developer tools led us there. I used a prior search strategy from my past place of work (searching key related terms and browsing associated cases / tickets) to arrive here.

\section{Figure F14}


Cognitive dimension and trajectory of experiences leading up to Transcendent episode four (T4)

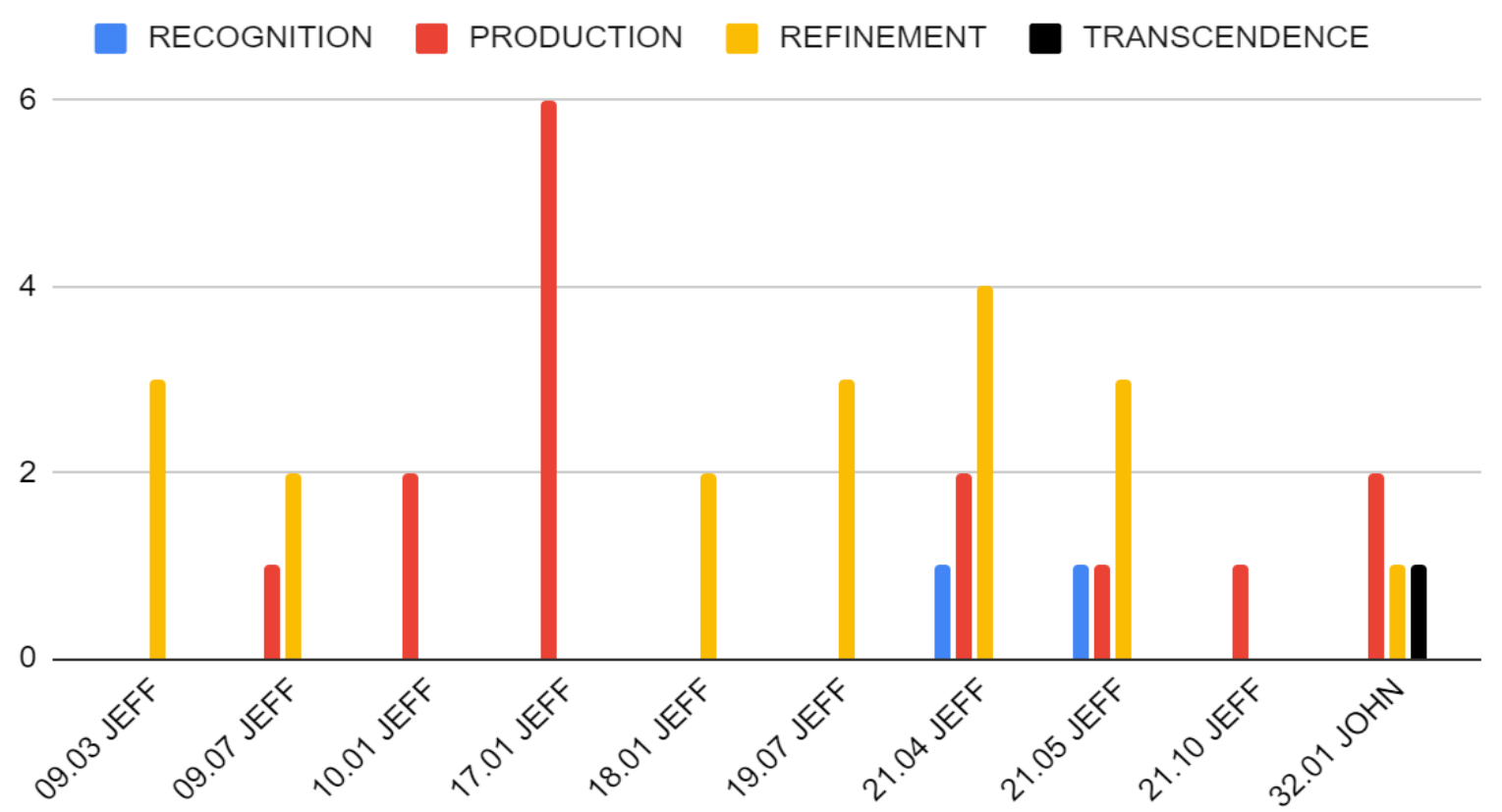




\section{Figure F15}

Knowledge-building dimension and trajectory of experiences leading up to Transcendent episode four (T4)
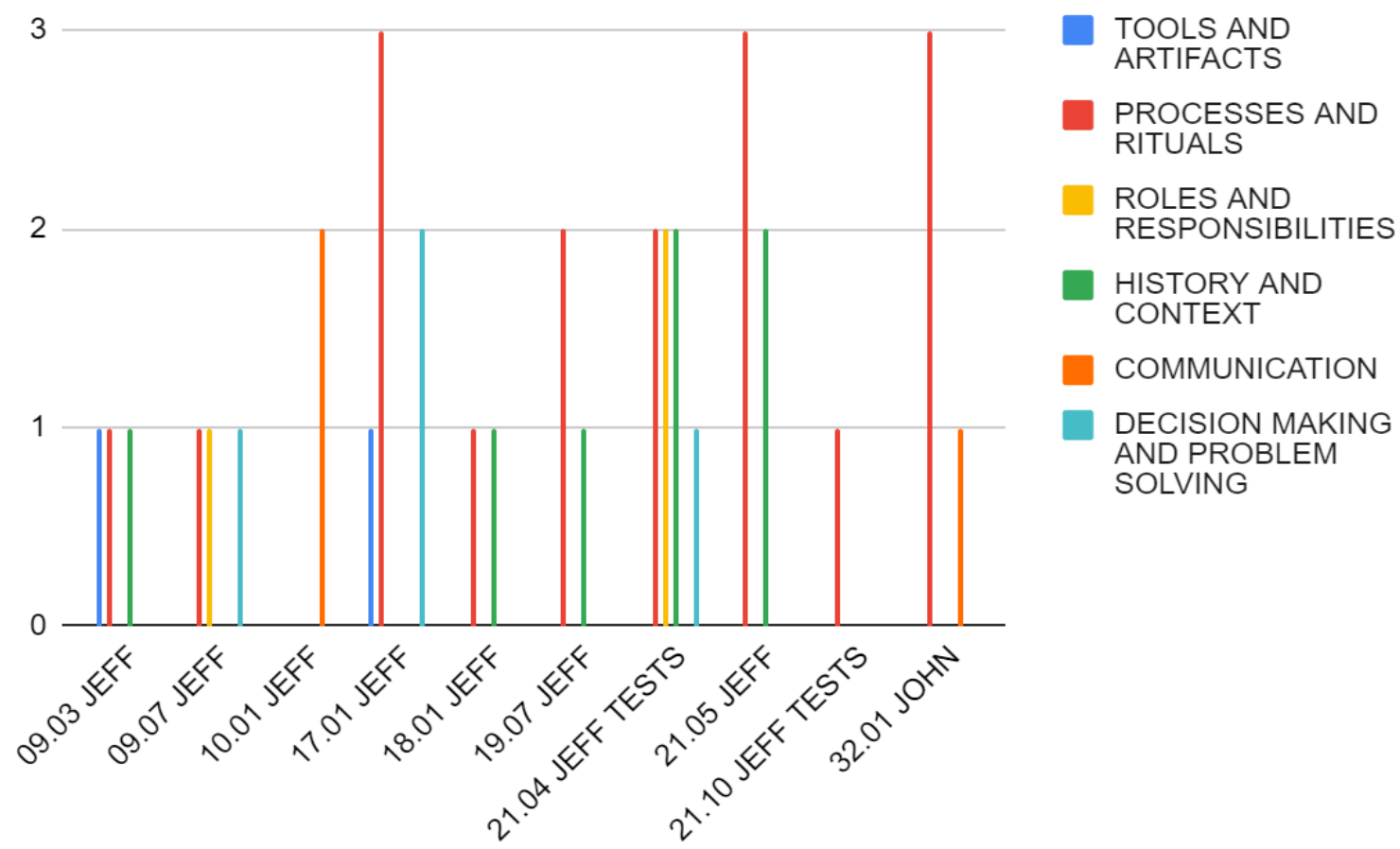


\section{Figure F16}

Situated dimension and trajectory of experiences leading up to Transcendent episode four (T4)

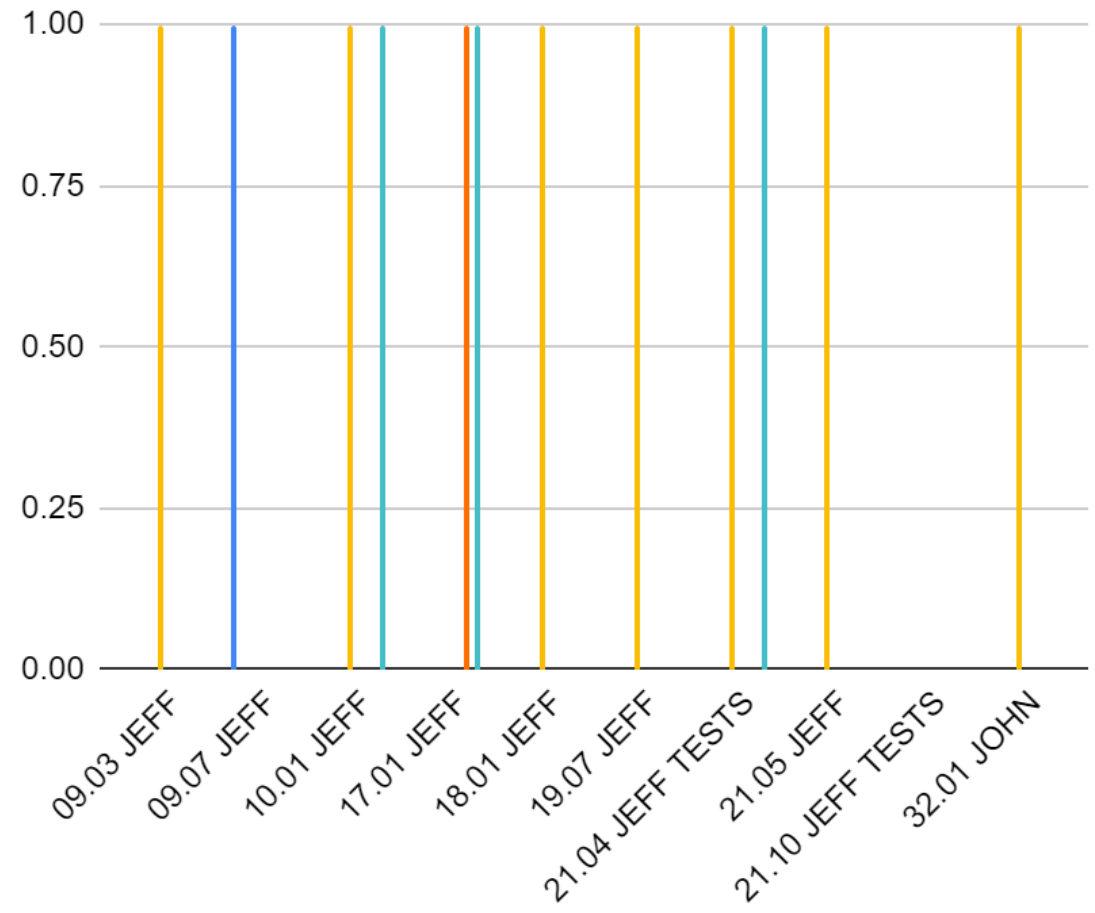

AUTONOMOUS -

REFLECTION

AUTONOMOUS -

PROBLEM SOLVING

COLLABORATIVE EXPLORATION

COLLABORATIVE DISCUSSION

COLLABORATIVE PROBLEM SOLVING

AUTONOMOUS -

EXPLORATION 


\section{T5 - Support Model}

\section{Table F5}

Summary of trajectory of experiences leading up to T5 - Support Model

\begin{tabular}{lll}
\hline Transcendent Episode & Trajectory of Experiences & Description \\
\hline T5 - Support Model & 02.09 & 02.09 \\
& 04.06 & 04.06 \\
& 06.11 & 06.11 \\
& 06.12 & 06.12 \\
13.05 & 13.05 \\
17.02 & 17.02 \\
23.03 & 23.03 \\
23.08 & 23.08 \\
28.07 & 28.07 \\
29.01 & 29.01 \\
& 36.00 & 36.00 \\
38.01 & 38.01 \\
40.10 & 40.10 \\
43.08 & 43.08 \\
44.04 & 44.04 \\
45.07 & 45.07 \\
45.10 & 45.10 \\
46.08 & 46.08 - creating a service and support \\
& & \\
& & model that doesn't exist \\
\hline
\end{tabular}




\section{Figure F17}

Emergence of T4 during experience 46.08

\subsection{JEFF CREATES DOCUMENTS}

I brainstorm and draft a model to implement services and support.

Incident / service requests

Normal incident

Need simple task performed ->*

E.g need an instructor added

Problem with functionality $->*_{-}>*$

E.g issue with class upload

Need a complex task performed $->*_{-}>*$

Need simple training $->*_{-}>*$

Normal service request (lite)

Request for frontend access $->*_{-}>*$

E.g need a client credential

Request for backend/integration access $->*_{-}>$*

Request for reporting services $->*_{-}>*_{-}>*^{*}$

E.g need an advanced report

Need advanced technical training $->*$ _ $*$ 


\section{Figure F18}

Cognitive dimension and trajectory of experiences leading up to Transcendent episode five (T5)

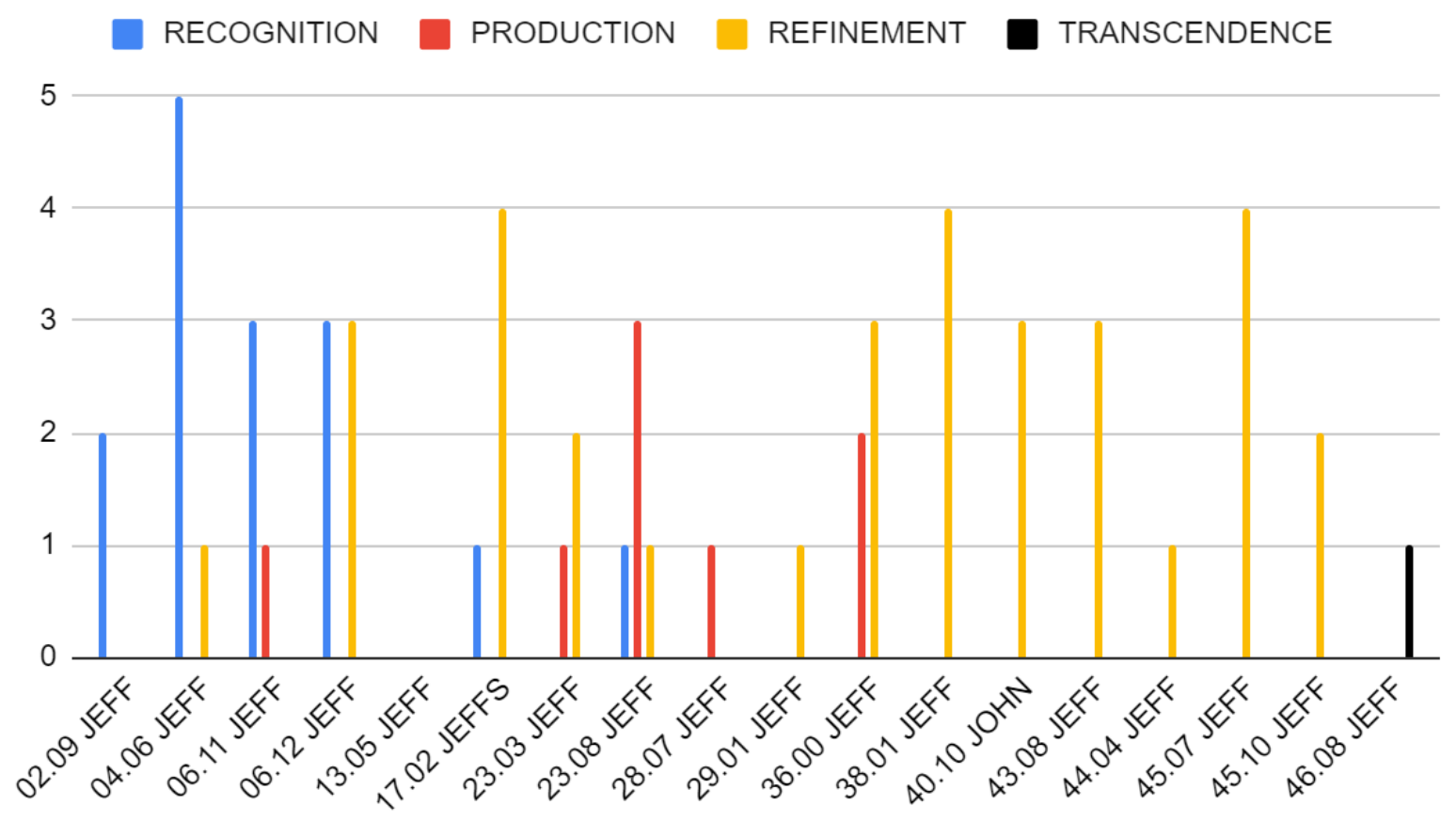




\section{Figure F19}

Knowledge-building dimension and trajectory of experiences leading up to Transcendent episode five (T5)
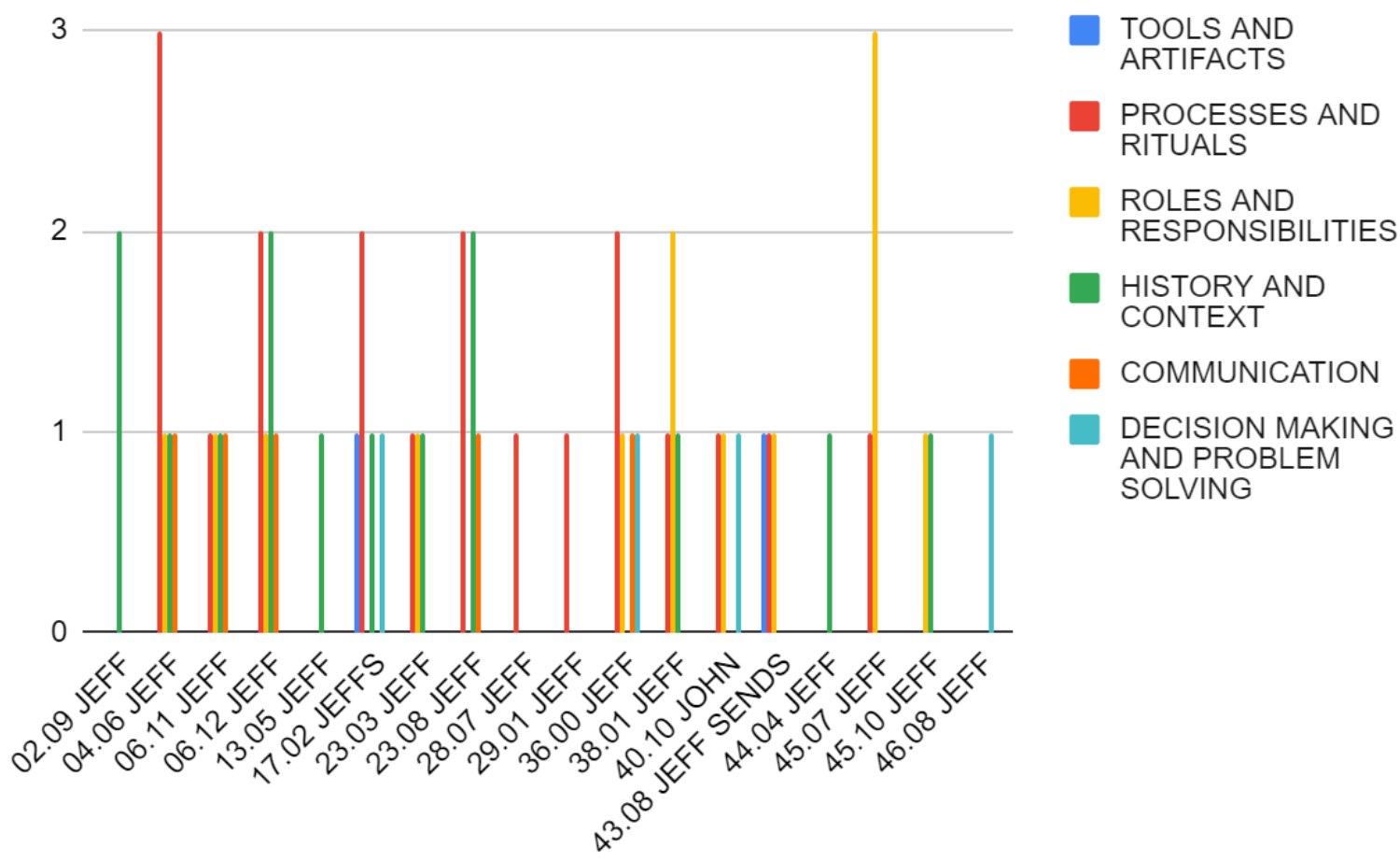


\section{Figure F20}

Situated dimension and trajectory of experiences leading up to Transcendent episode five (T5)

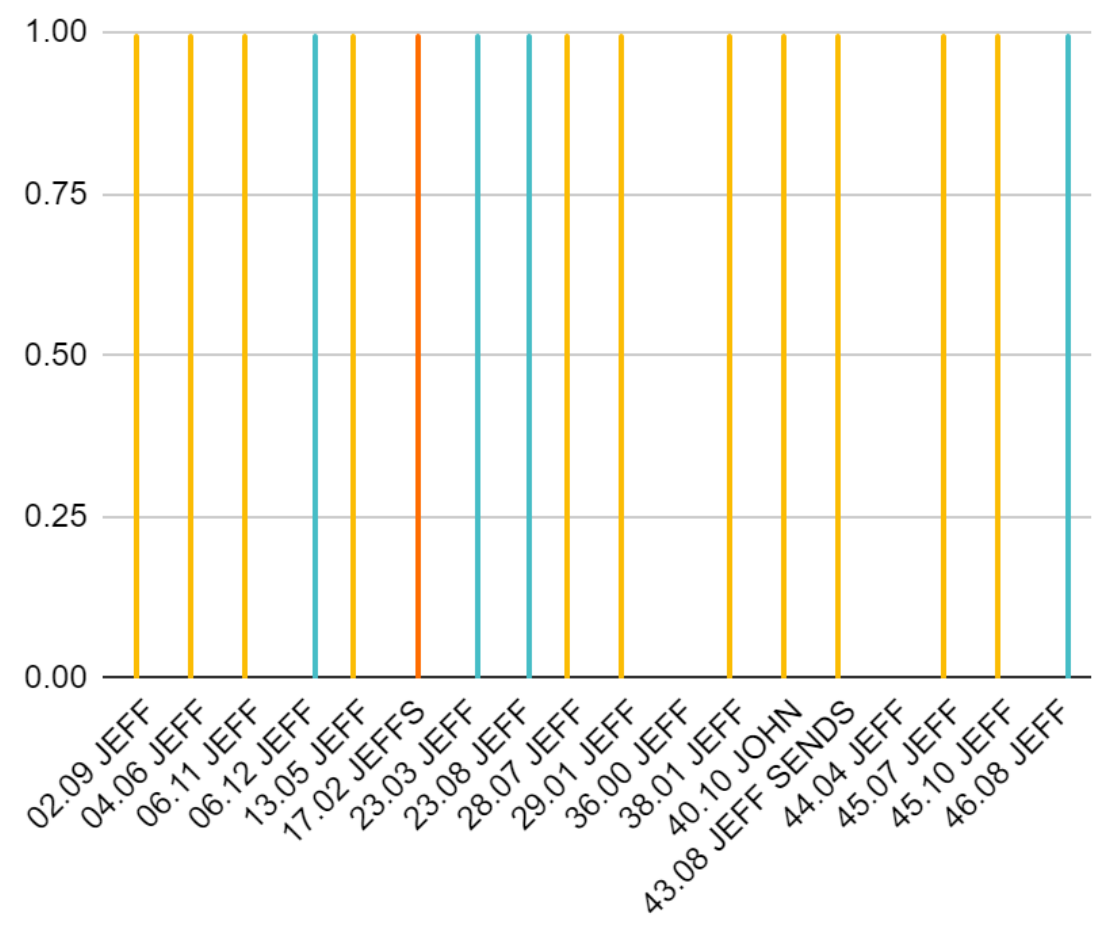

AUTONOMOUS REFLECTION

AUTONOMOUS PROBLEM SOLVING

COLLABORATIVE EXPLORATION

COLLABORATIVE DISCUSSION

COLLABORATIVE PROBLEM SOLVING

AUTONOMOUS EXPLORATION 


\section{T6 - Support Process}

\section{Table F6}

Summary of trajectory of experiences leading up to T6 - Support Process

\begin{tabular}{lll}
\hline Transcendent Episode & Trajectory of Experiences & Description \\
\hline T6 - Support Model & 06.11 & 06.11 \\
& 28.05 & 28.05 \\
& 28.07 & 28.07 \\
& 32.04, & 32.04 \\
& 40.08 & 40.08 \\
& 45.10 & 45.10 \\
& 52.07 & 52.07 \\
& 53.02, & 53.02 \\
& 54.11 & 54.11 - Creating new processes / steps \\
& & and procedures \\
\hline
\end{tabular}

\section{Figure F21}

Emergence of T6 during experience 54.11

\subsection{JEFF ATTENDS MEETINGS}

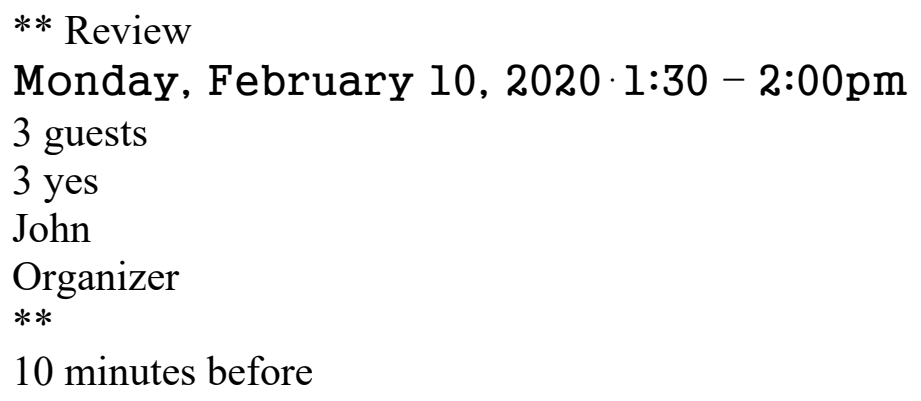

Show ** and John ** work from weekend, demonstrate what is possible ** meeting notes

\section{Figure F22}


Cognitive dimension and trajectory of experiences leading up to Transcendent episode six (T6)

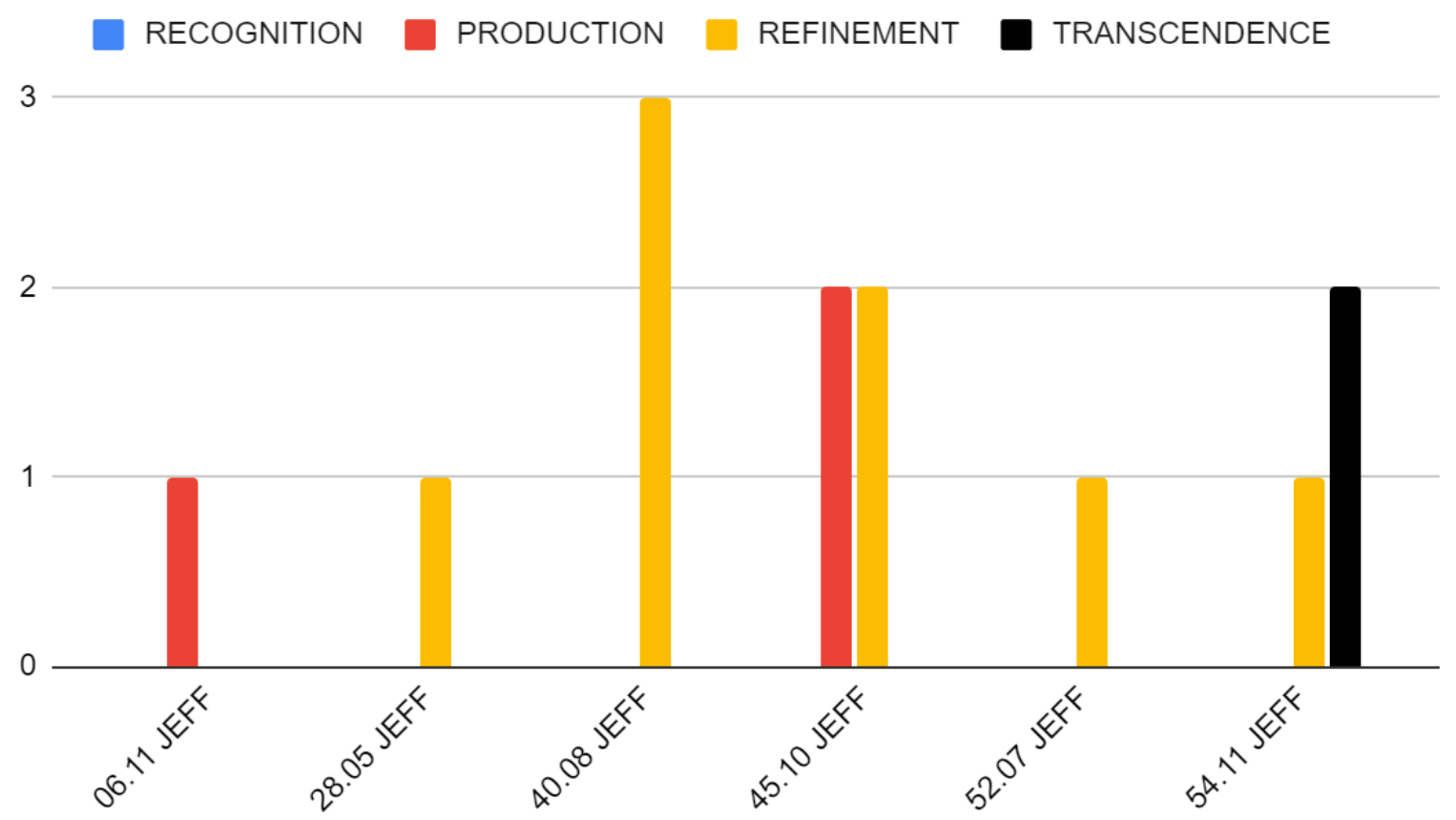




\section{Figure F23}

Knowledge-building dimension and trajectory of experiences leading up to Transcendent episode $6($ T6)

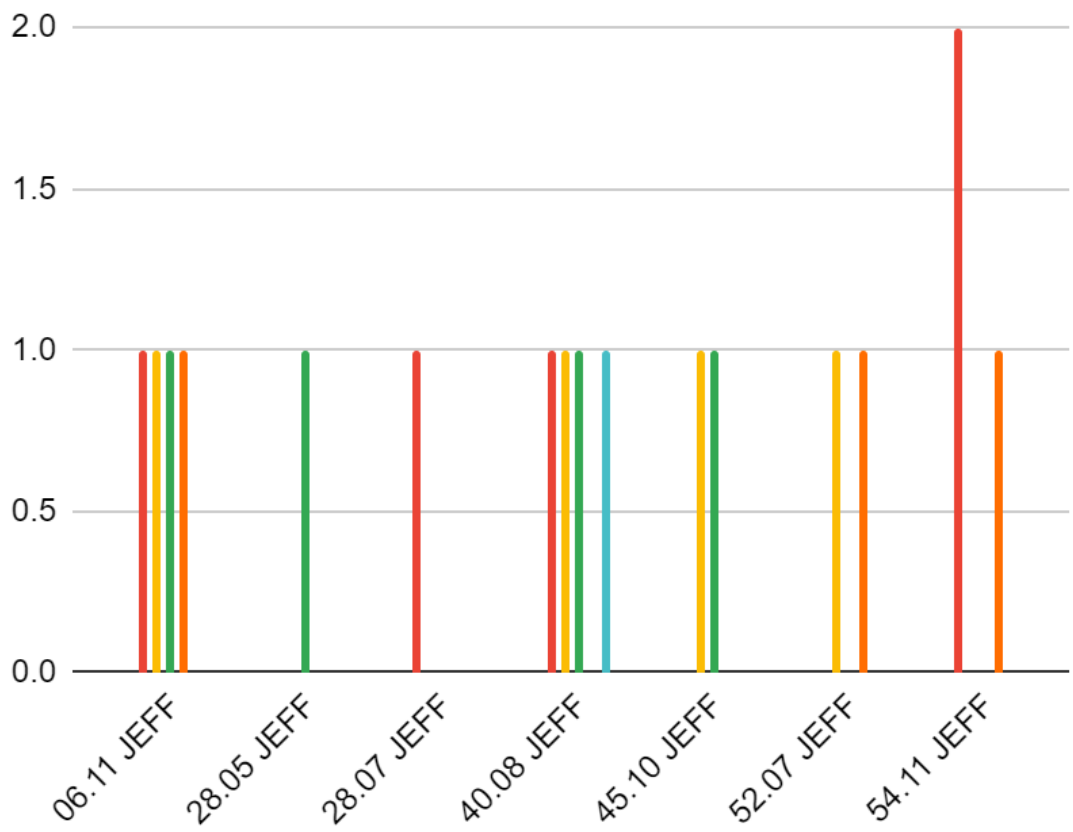

TOOLS AND ARTIFACTS

PROCESSES AND RITUALS

ROLES AND RESPONSIBILITIES

HISTORY AND CONTEXT

COMMUNICATION

DECISION MAKING AND PROBLEM SOLVING 


\section{Figure F24}

Situated dimension and trajectory of experiences leading up to Transcendent episode 1 (T1)

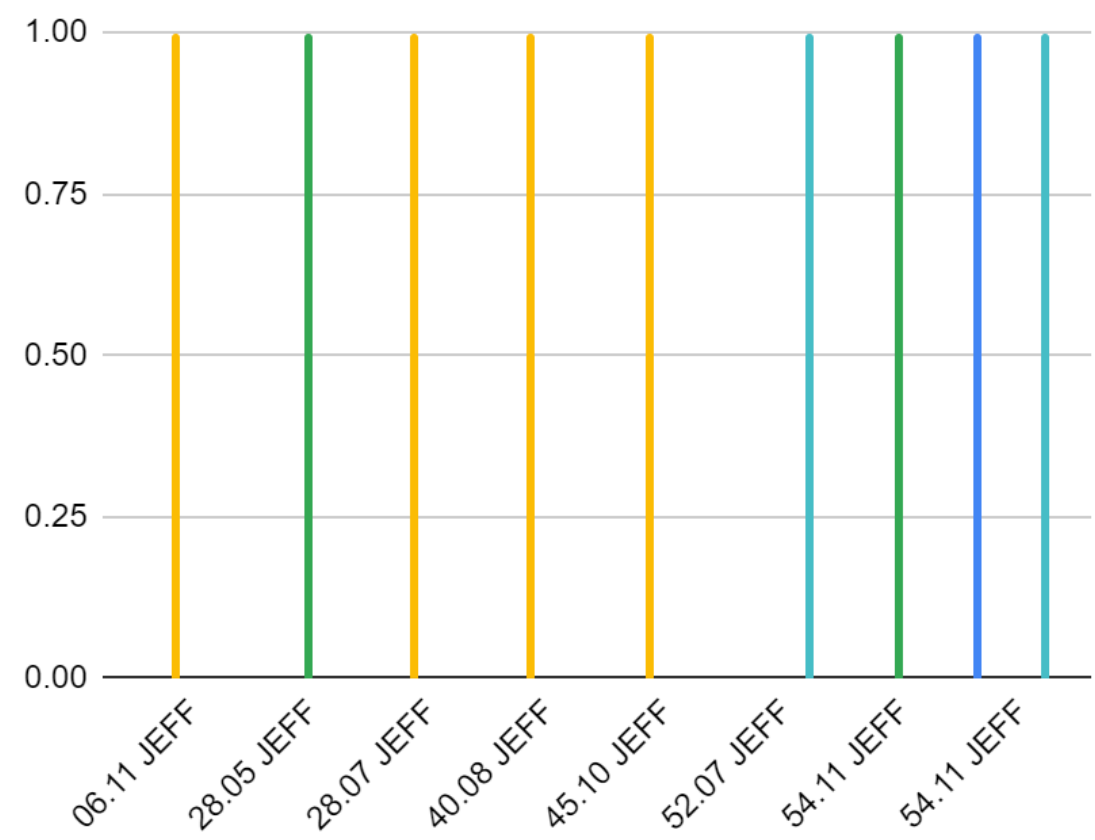

AUTONOMOUS REFLECTION

AUTONOMOUS PROBLEM SOLVING

COLLABORATIVE EXPLORATION

COLLABORATIVE DISCUSSION

COLLABORATIVE PROBLEM SOLVING

AUTONOMOUS EXPLORATION

\section{T7 - Blank Spreadsheet}

\section{Table F7}

Summary of trajectory of experiences leading up to T7 - Support Process

\begin{tabular}{lll}
\hline Transcendent Episode & Trajectory of Experiences & Description \\
\hline T7 - Blank Spreadsheet & 16.00 & 16.00 \\
& 46.03 & 46.03 \\
& 46.04 & 46.04 \\
& 57.03 & 57.03 - Applying spreadsheet used in \\
& & prior work to create new documentation.
\end{tabular}




\section{Figure F25}

Emergence of $T 7$ during experience 57.03

\subsection{JEFF REVIEWS TICKETS \\ ** and subject code}

Used my bulk query spreadsheet w BA!

Chat $\mathrm{w}^{* *}$ and $* *$ about catalog issue, moving forward

\section{Figure F26}

Cognitive dimension and trajectory of experiences leading up to Transcendent episode seven (T7)

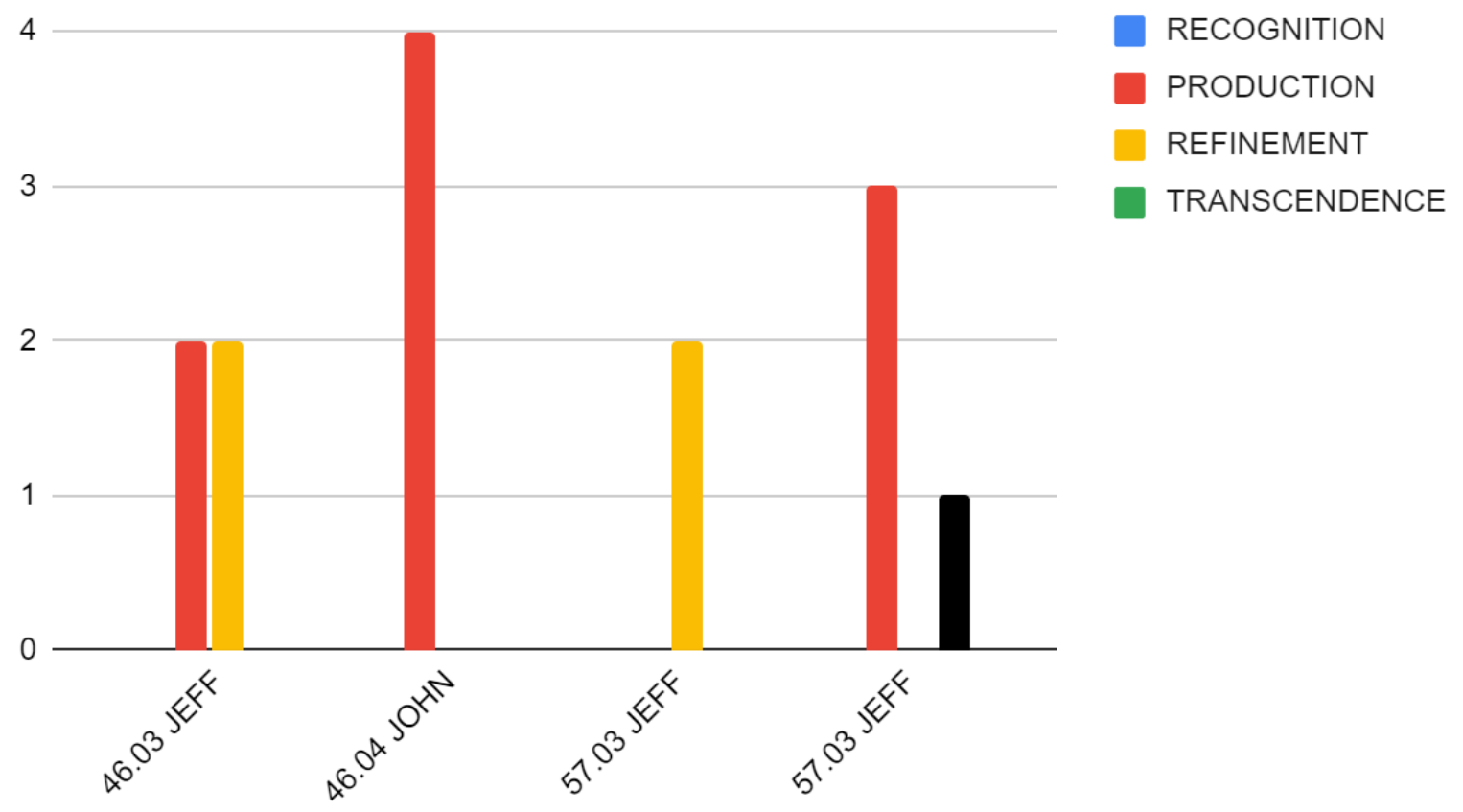




\section{Figure F27}

Knowledge-building dimension and trajectory of experiences leading up to Transcendent episode seven (T7)

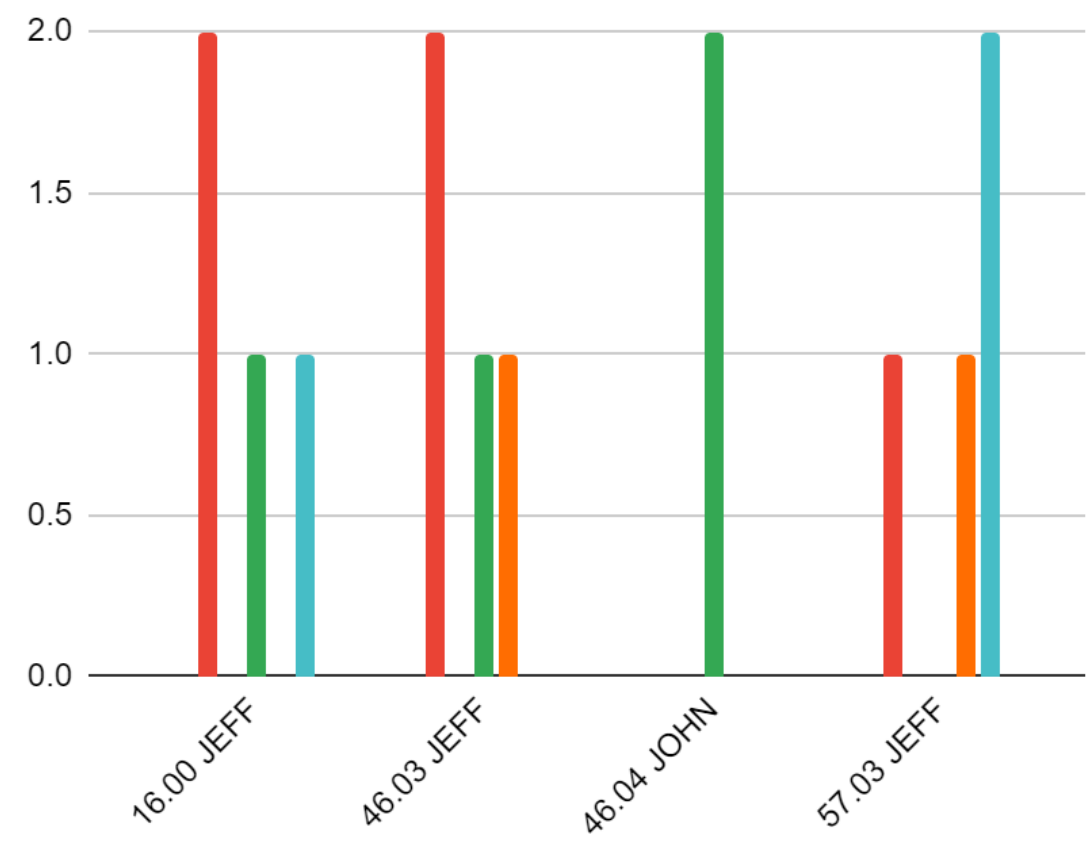

TOOLS AND ARTIFACTS

PROCESSES AND RITUALS

ROLES AND

RESPONSIBILITIES

HISTORY AND CONTEXT

COMMUNICATION

DECISION MAKING AND PROBLEM SOLVING 


\section{Figure F28}

Situated dimension and trajectory of experiences leading up to Transcendent episode seven (T7)

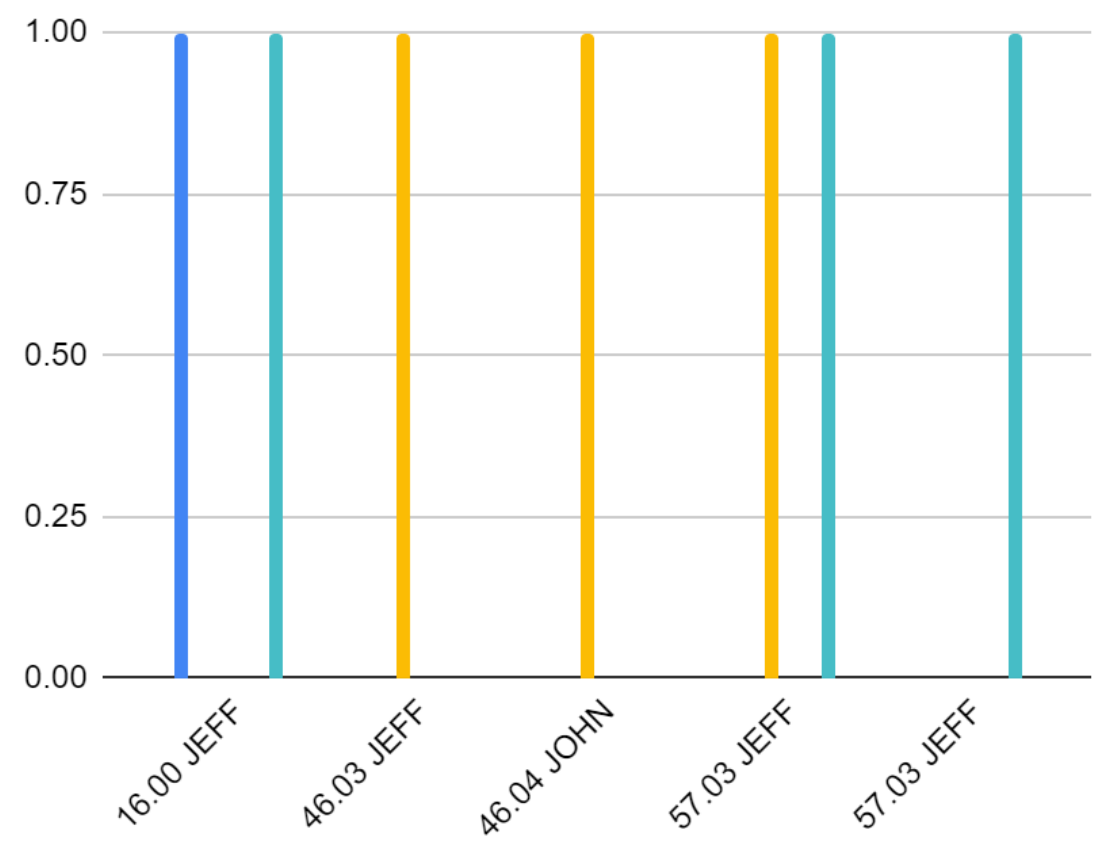

AUTONOMOUS REFLECTION

AUTONOMOUS PROBLEM SOLVING

COLLABORATIVE EXPLORATION

COLLABORATIVE DISCUSSION

COLLABORATIVE PROBLEM SOLVING

AUTONOMOUS EXPLORATION 